Florida International University FIU Digital Commons

$7-5-2013$

\title{
Climate, Land Use and Hydrologic Sensitivities of Stormwater Quantity and Quality in Complex Coastal Urban Watersheds
}

Shams Al-Amin

salam009@fiu.edu

DOI: $10.25148 /$ etd.FI13080704

Follow this and additional works at: https://digitalcommons.fiu.edu/etd

Part of the Civil Engineering Commons, and the Environmental Engineering Commons

\section{Recommended Citation}

Al-Amin, Shams, "Climate, Land Use and Hydrologic Sensitivities of Stormwater Quantity and Quality in Complex Coastal Urban Watersheds" (2013). FIU Electronic Theses and Dissertations. 942.

https://digitalcommons.fiu.edu/etd/942 


\section{FLORIDA INTERNATIONAL UNIVERSITY}

Miami, Florida

\section{CLIMATE, LAND USE AND HYDROLOGIC SENSITIVITIES OF STORMWATER QUANTITY AND QUALITY IN COMPLEX COASTAL URBAN WATERSHEDS}

A thesis submitted in partial fulfillment of the requirements for the degree of MASTER OF SCIENCE

in

ENVIRONMENTAL ENGINEERING

by

Shams Al-Amin 
To: Dean Amir Mirmiran

College of Engineering and Computing

This thesis, written by Shams Al-Amin, and entitled Climate, Land Use and Hydrologic Sensitivities of Stormwater Quantity and Quality in Complex Coastal Urban Watersheds, having been approved in respect to style and intellectual content, is referred to you for judgment.

We have read this thesis and recommend that it be approved.

$\begin{array}{r}\hline \text { Berrin Tansel } \\ \hline \text { Arindam Gan Chowdhury } \\ \hline \text { Omar I. Abdul-Aziz, Major Professor }\end{array}$

Date of Defense: July 05, 2013

The thesis of Shams Al-Amin is approved.

Dean Amir Mirmiran College of Engineering and Computing

Dean Lakshmi N. Reddi University Graduate School

Florida International University, 2013 


\begin{abstract}
OF THE THESIS
CLIMATE, LAND USE AND HYDROLOGIC SENSITIVITIES OF STORMWATER QUANTITY AND QUALITY IN COMPLEX COASTAL URBAN WATERSHEDS
\end{abstract}

by

Shams Al-Amin

Florida International University, 2013

Miami, Florida

Professor Omar I. Abdul-Aziz, Major Professor

The study analyzed hydro-climatic and land use sensitivities of stormwater runoff and quality in the complex coastal urban watershed of Miami River Basin, Florida by developing a Storm Water Management Model (EPA SWMM 5). Regression-based empirical models were also developed to explain stream water quality in relation to internal (land uses and hydrology) and external (upstream contribution, seawater) sources and drivers in six highly urbanized canal basins of Southeast Florida. Stormwater runoff and quality were most sensitive to rainfall, imperviousness, and conversion of open lands/parks to residential, commercial and industrial areas. In-stream dissolved oxygen and total phosphorus in the watersheds were dictated by internal stressors while external stressors were dominant for total nitrogen and specific conductance. The research findings and tools will be useful for proactive monitoring and management of storm runoff and urban stream water quality under the changing climate and environment in South Florida and around the world. 
CHAPTER 1: INTRODUCTION

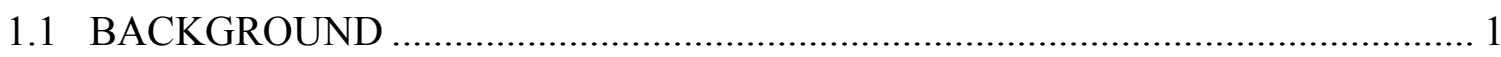

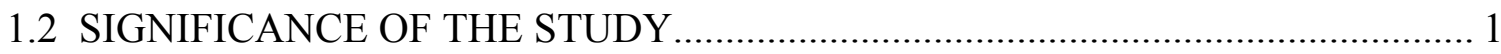

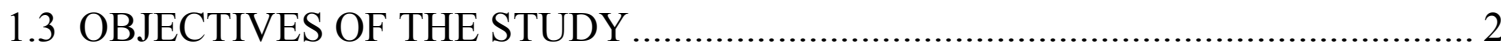

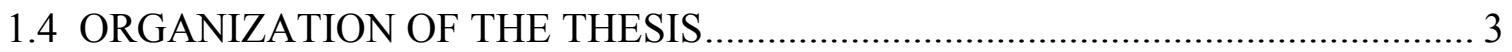

CHAPTER 2: CHALLENGES IN MECHANISTIC AND EMPIRICAL MODELING OF STORMWATER: REVIEW AND PERSPECTIVES

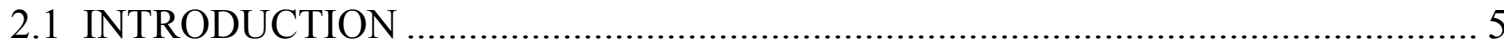

2.2 SCIENTIFIC GAPS IN MECHANISTIC MODELING ........................................... 7

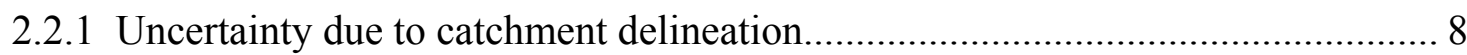

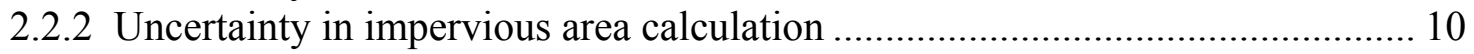

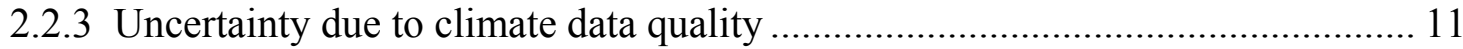

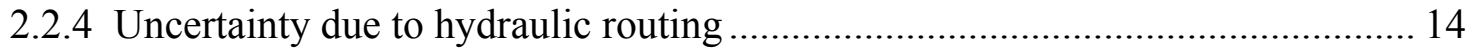

2.2.5 Specific issues in mechanistic quality modeling .............................................. 15

2.3 SCIENTIFIC GAPS IN DATA-DRIVEN EMPIRICAL MODELING ………......... 17

2.3.1 Difficulty in identifying the input variables............................................... 18

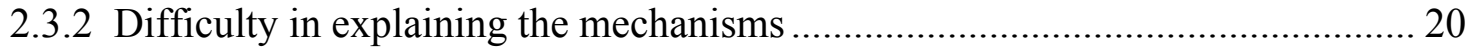

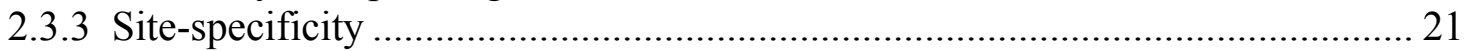

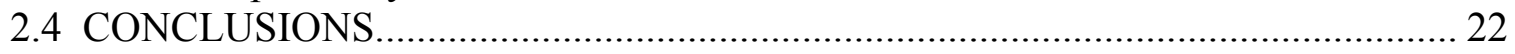

CHAPTER 3: CLIMATE, LAND USE AND HYDROLOGIC SENSITIVITIES OF STORMWATER QUANTITY AND QUALITY IN A COMPLEX COASTAL URBAN WATERSHED

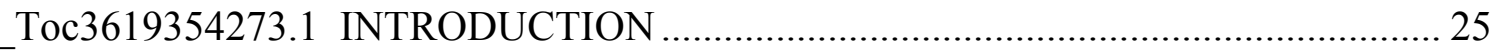

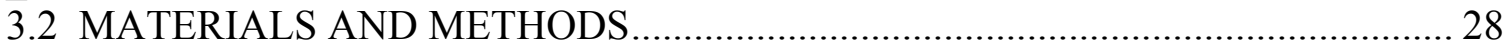

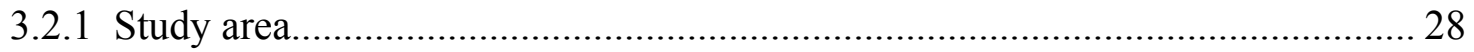

3.2.2 Preparation of datasets .............................................................................. 30

3.2.3 Development of a Storm Water Management Model (EPA SWMM 5)............ 34

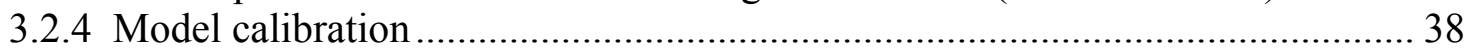

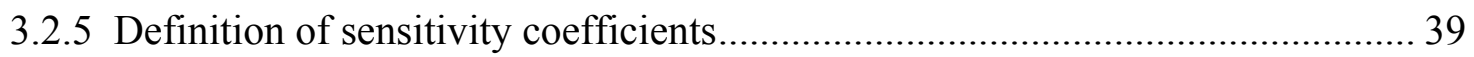

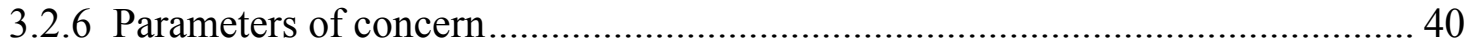

3.3 RESULTS …

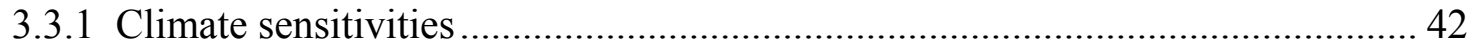

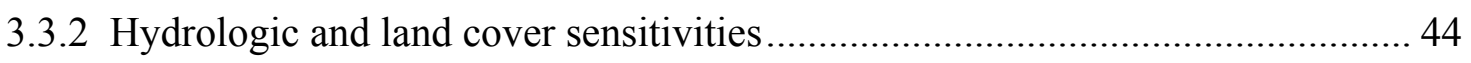

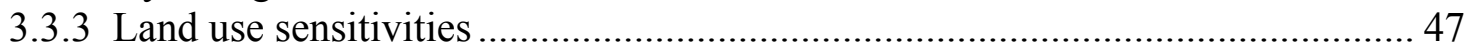

3.3.3.1 Land use sensitivities of runoff............................................................... 47

3.3.3.2 Land use sensitivities of pollutants .......................................................... 48

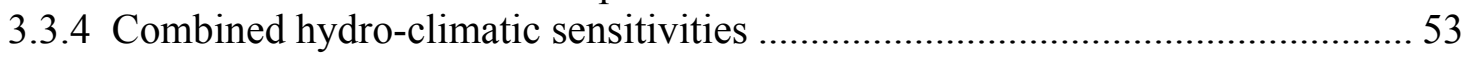

3.3.4.1 Combined sensitivity to rainfall and imperviousness .................................. 53

3.3.4.2 Combined sensitivity to rainfall and roughness........................................... 55

3.3.5 Combined climatic and land use sensitivities .................................................. 56 
CHAPTER 4:_IDENTIFICATION OF DOMINANT ENVIRONMENTAL STRESSORS AND THEIR RELATIVE INFLUENCE ON STREAM WATER QUALITY IN COMPLEX COASTAL URBAN WATERSHEDS

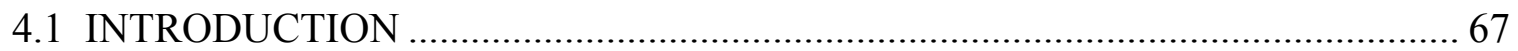

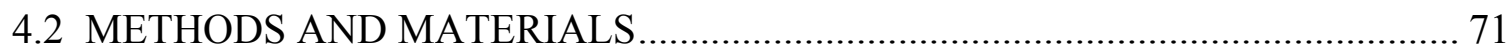

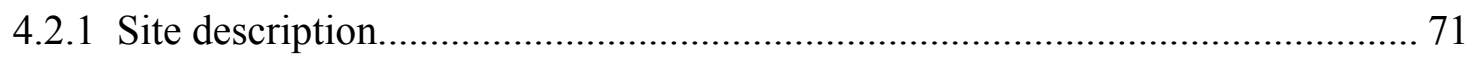

4.2.2 Stream water quality parameters............................................................. 75

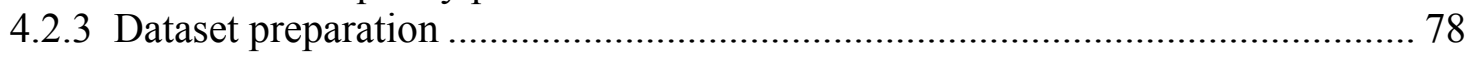

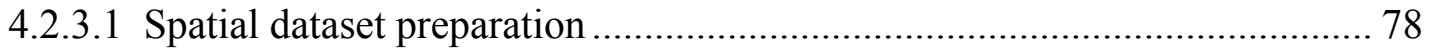

4.2.3.2 Temporal dataset preparation.................................................................. 82

4.2.3.3 Quality assurance/ quality control ........................................................... 84

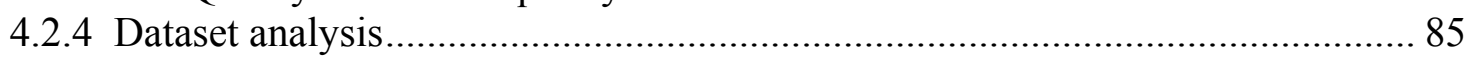

4.2.4.1 Correlation and principal component analysis............................................. 85

4.2.4.2 Multiple regression model development.................................................... 87

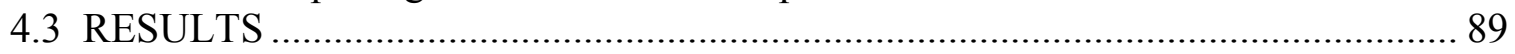

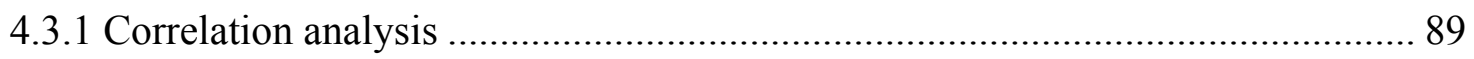

4.3.2 Principal component analysis .................................................................... 94

4.3.3 Multiple regression models for four seasons .................................................. 97

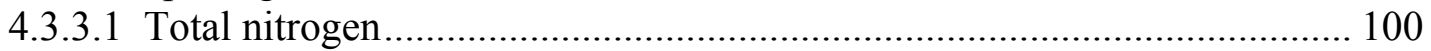

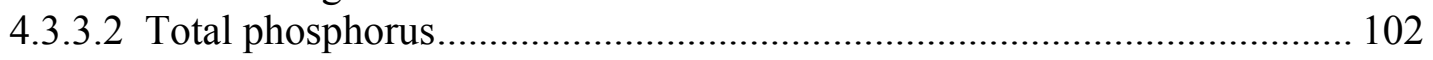

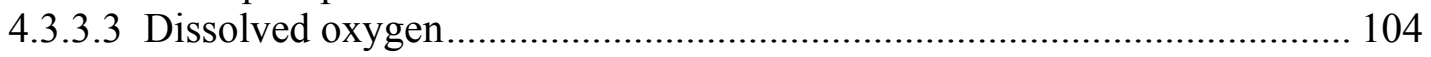

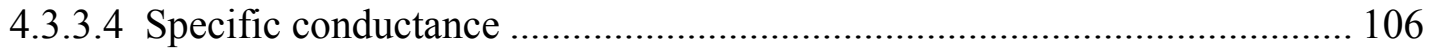

4.3.3.5 Chlorophyll a .................................................................................... 107

4.3.4 Multiple regression models for dry and wet periods ................................... 108

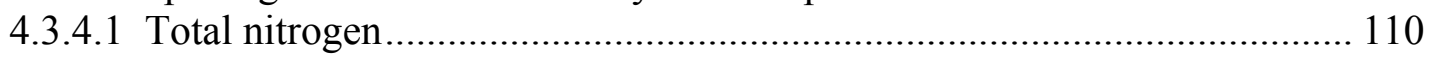

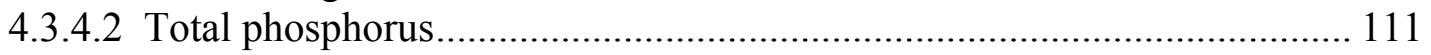

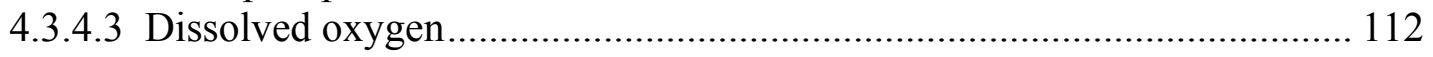

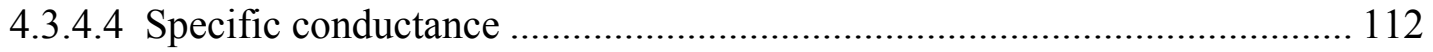

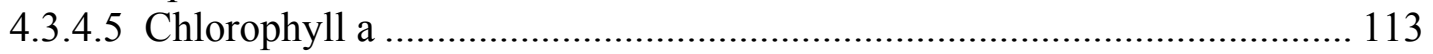

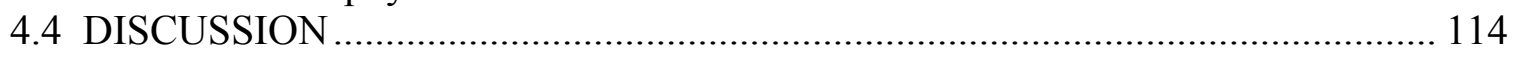

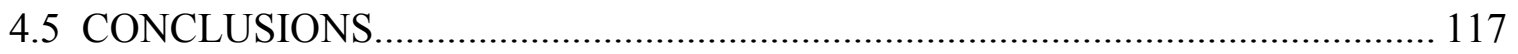

CHAPTER 5: CONCLUSIONS AND RECOMMENDATIONS

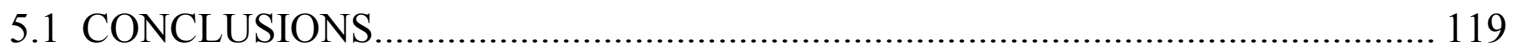

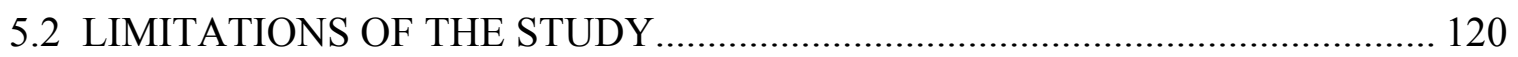

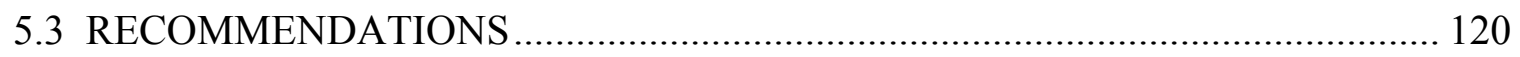

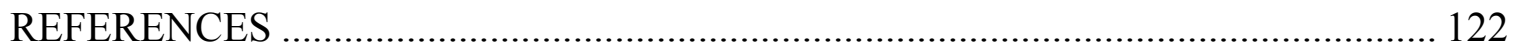

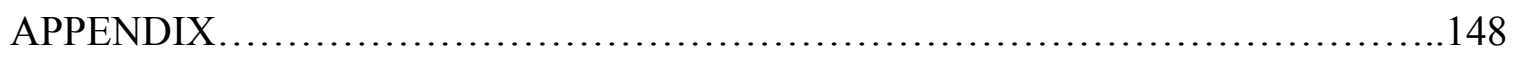




\section{LIST OF TABLES}

TABLE

PAGE

Table 2.1: Variation of input variables for quality study..................... 18

Table 2.2: Examples of data based study on stormwater pollution from roadway... 21

Table 2.3: Land use and climate variables often used in data driven models for stormwater quality....

Table 3.1: Event mean concentrations (EMCs) used for the Miami River Basin...

Table 3.2: Parameters of concern for sensitivity analysis

Table 3.3: Percentage ( $\%$ ) change in parameters due to a $25 \%$ conversion among the land use types of Miami River Basin

Table 3.4: Summary of annual sensitivity coefficients for runoff and quality in Miami Basin.

Table 3.5: Comparison of the combined effects of changes in rainfall and land use on potential pollutant loads in Miami Basin.

Table 4.1: List of parameters and variables considered for empirical analysis of stream water quality

Table 4.2: Summary of in-stream inter-pollutant correlations in the study area....

Table 4.3: Summery of autocorrelation analysis of quality parameters

Table 4.4: Summary of multiple log-linear regression model performances.

Table 4.5: Multiple log-linear regression models description of total nitrogen......

Table 4.6: Multiple log-linear regression models description of total phosphorus..

Table 4.7: Multiple log-linear regression models description of dissolved oxygen..

Table 4.8: Multiple log-linear regression models description of specific conductance. 
Table 4.10: Multiple log-linear regression model performances for dry and wet

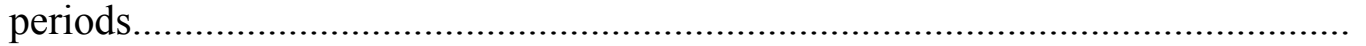

Table 4.11: Multiple log-linear regression models description of total nitrogen.....

Table 4.12: Multiple log-linear regression models description of total phosphorus.

Table 4.13: Multiple log-linear regression models description of dissolved

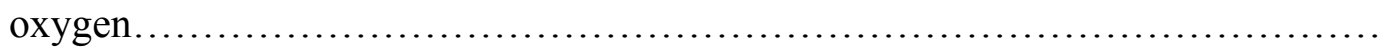

Table 4.14: Multiple log-linear regression models description of specific conductance.

Table 4.15: Multiple log-linear regression models description of chlorophyll a..... 


\section{LIST OF FIGURES}

FIGURE

PAGE

Figure 2.1: Sources of pollution and transport of stormwater.................. 8

Figure 2.2: Comparison of stormwater network boundary and watershed boundary for Wagner Creek, a tributary of the Miami River, Florida......

Figure 2.3: Satellite map (left) and city zoning map (right) for a portion of catchment of Wagner Creek in Miami-Dade County, Florida.....................

Figure 2.4: Division of a subcatchment of Wagner Creek Watershed, Miami for precipitation data interpolations (Inset shows the Miami River Basin....

Figure 2.5: Variation in runoff due to spatial variation of station data in a subcatchment of Wagner Creek Watershed, Miami....

Figure 2.6: Major variables for mechanistic modeling of stormwater

Figure 3.1: Miami River Basin of Florida.

Figure 3.2: Boundary conditions and calibration points for the model.

Figure 3.3: Groundwater observation wells used for the model.

Figure 3.4: Summary of dataset preparation and SWMM model development......

Figure 3.5: Daily calibration for 2010 at S-26(top) and S-25B stations (bottom)

Figure 3.6: Monthly rainfall variation in the Miami River Basin, Florida (top) and Predicted changes in runoff for changes in rainfall in Miami Basin (bottom)......

Figure 3.7: Predicted changes in runoff for increase in imperviousness of the Miami Basin

Figure 3.8: Comparison of the effects of hydrologic and land cover components on runoff in the Miami Basin.

Figure 3.9: Comparison of the effects of land use conversions on runoff in the Miami Basin ...

Figure 3.10: Comparison of the combined effects of changes in rainfall and 
imperviousness on runoff in Miami Basin.

Figure 3.11: Comparison of the combined effects of changes in rainfall and roughness on runoff in Miami Basin....

Figure 3.12: Comparison of the combined effects of changes in rainfall and land use (conversion of parks and open lands) on potential total nitrogen load in Miami Basin.

Figure 4.1: Study area in Southeast Florida, U.S.A. Inset showing the state of Florida is not on the stated scale.

Figure 4.2: Watershed boundaries corresponding to each quality stations. Inset showing the state of Florida is not on the stated scale.

Figure 4.3: Schematic of watershed delineation on the basis of the positions of the monitoring sites.

Figure 4.4: Land use types in the study area. Inset showing the state of Florida is not on the stated scale

Figure 4.5: Change in correlation coefficient with distance for water quality parameters

Figure 4.6: Change in correlation over time for the same quality parameters in study area....

Figure 4.7: Principal component analysis for four seasonal analyses..............

Figure 4.8: Principal component analyses for dry and wet period.

Figure 4.9: Observed vs. predicted values for four seasonal analyses....

Figure 4.10: Observed vs. predicted values for dry and wet period analyses......... 


\section{CHAPTER 1}

\section{INTRODUCTION}

\subsection{BACKGROUND}

The growth and expansion of urban areas have been intervening with the natural drainage of surface water and stressing the surface water quality all over the world. The importance of research in stormwater science, engineering and management, therefore, cannot be overstated. Stormwater runoff is the fourth most extensive cause of water quality impairment of rivers, and the third most extensive source of water quality impairment of lakes in the USA (USEPA, 1990; Novotny, 1991; Novotny \& Olem, 1994; Tsihrintzis \& Hamid, 1996). Research in stormwater science, engineering and management revolves around multidimensional aspects (e.g., climate, land use, hydrology) and a complete understanding of urban runoff is yet to be achieved (Marsalek \& Viklander, 2011). Further research is, therefore, needed to trace the major stressors of stormwater and surface water quality.

\subsection{SIGNIFICANCE OF THE STUDY}

This study first reviewed the major and mostly unresolved challenges in both mechanistic and empirical modeling of stormwater and shed light on the scientific gaps with conventional practices. It offered important perspectives on both the approaches by considering the highly urbanized Miami River Basin of Florida as an example of complex urban-coastal watersheds. The hydro-climatic and land use sensitivities of stormwater 
runoff and quality in the Miami River Basin was then analyzed by developing a dynamic rainfall-runoff model using a Storm Water Management Model (EPA SWMM 5). The research used an innovative approach to resolve stormwater runoff as a component of the total watershed water budget, incorporating all the important processes (i.e., evapotranspiration, surface water, groundwater, sea level, in addition to climatic drivers and land use features). Empirical models were also developed to explain seasonal and annual in-stream water quality in relation to land use, groundwater, seawater and upstream contribution in six major canal basins of Broward County, Florida. Considering these highly urbanized watersheds as pilot studies, the research identified dominant environmental stressors and their relative influence on stream water quality in complex coastal urban watersheds.

\subsection{OBJECTIVES OF THE STUDY}

The overall goal of this study is to determine the climate, land use and hydrologic sensitivities of surface water quantity and quality in complex coastal urban watersheds. The specific objectives are as below.

- To demonstrate the pros and cons of mechanistic and empirical methods of stormwater modeling and their complementary applications for appropriate parameterizations of interactive processes.

- To quantify dominant stressors and their relative, as well as combined, influence on stormwater runoff and six major pollutants (i.e., total suspended solids, total nitrogen, 
total phosphorus, copper, zinc and biochemical oxygen demand) in the complex urban watershed of Miami River.

- To identify dominant sources and stressors (land use, groundwater, seawater and upstream contribution) and their relative influence on in-stream water quality parameters (total nitrogen, total phosphorus, dissolved oxygen, specific conductivity, and chlorophyll a) of six highly urbanized canal basins of Southeast Florida.

- To provide recommendations for more insightful and timely research for robust modeling of stormwater quantity/quality and predictions of in-stream water quality.

\subsection{ORGANIZATION OF THE THESIS}

The thesis is presented in five distinct chapters. The current chapter presents a brief introduction of the study along with the significance, objective and organization of the thesis.

Chapter 2 reviews the literature related to the mechanistic and empirical modeling efforts on stormwater runoff processes. The limitations of both approaches and the scope for improvements are discussed in this chapter.

Chapter 3 describes the sensitivity of stormwater runoff and quality to major climate, land uses, and hydrologic parameters by developing a Storm Water Management Model (EPA SWMM 5) and identifies the dominant stressors in the complex urban watershed of Miami River Basin considering it a pilot study. 
Chapter 4 describes data driven empirical models linking in-stream water quality to the possible stressors of climate, groundwater, seawater, watershed land use and hydrology in six highly urbanized, major canal basins of Broward County, FL.

Chapter 5 summarizes the research outcomes, indicates limitations of the current study and provides recommendations for future research. 


\section{CHAPTER 2}

\section{CHALLENGES IN MECHANISTIC AND EMPIRICAL MODELING OF STORMWATER: REVIEW AND PERSPECTIVES}

\subsection{INTRODUCTION}

As the world becomes increasingly urbanized and cities keep growing, the importance of research in stormwater science, engineering and management cannot be overstated. Stormwater runoff is often blamed for urban flooding and poor water quality in urban streams and rivers around the world. It is the fourth most extensive cause of water quality impairment of rivers, and the third most extensive source of water quality impairment of lakes in the USA (USEPA, 1990; Novotny, 1991; Novotny \& Olem, 1994; Tsihrintzis \& Hamid, 1996).

Much research has focused on the understanding and quantification of urban runoff quantity and quality. Although notable progress was made in the modeling of urban runoff quantity, the progress with stormwater quality-its impacts on receiving waters and the means of mitigating such impacts-has been much slower (Marsalek \& Viklander, 2011). Example of recent research includes identification of significant factors (e.g., land use, percentage imperviousness, conveyance, and watershed controls) affecting stormwater quality using the National Stormwater Quality Database (Maestre \& Pitt, 2006), highway contribution to runoff quantity and pollutant loading (Lau et al., 2009), sampling issues in urban runoff monitoring programs by comparison of composite and 
grab samples (Ma et al., 2009), and groundwater contaminations by stormwater (Pitt et al., 1996; Foulquier, 2010).

Many studies have investigated the correlation between stormwater pollutant generation and urban land use characteristics. Hatt et al. (2004) reported strong influence of urban density and drainage infrastructure on the concentrations and loads of pollutants in small streams. Goonetilleke et al. (2005) developed significant relationships between land use characteristics and pollutant generation by using univariate and multivariate data analysis approaches. Hood (2007) compared stormwater lag times for low impact and traditional residential development. Mahbub et al. (2010) showed significant traffic and climate change impacts on water quality by measuring build-up and wash-off of heavy metals and petroleum hydrocarbons. Mahbub (2012) also predicted wash-off of traffic related semi- and non-volatile organic compounds from urban roads under climate change influenced rainfall characteristics. Simon (2008) developed a predictive model for stormwater runoff on a GIS platform based on the unit area loading method for soil characteristics. Park et al. (2009) analyzed accuracy and precision of the volumeconcentration method for urban stormwater modeling.

The complex interactions among land use and climate variables in the backdrop of highly altered and engineered catchment hydrology are difficult to explain and require data of finest resolutions for proper modeling and quantifications. Generally, two approaches have been pursued to explain and model the underlying biogeochemistry in stormwater processes. Mechanistic models generally include the mathematical representations of relevant physico-chemical processes to generate storm runoff quantity and quality. 
Empirical approaches analyze available data for potential response and predictor variables to trace the interactions of major processes and develop data-driven explanatory and/or predictive relationships.

The potential of climate change increases the dimensions of stormwater challenges and underlines the urgency for more insightful research. The main objective of this chapter is to review and identify the major scientific gaps with conventional mechanistic and empirical modeling of stormwater and offer insights by taking the highly urbanized Miami River Basin of Florida as an example. The chapter demonstrates the pros and cons of mechanistic and empirical methods and their complementary applications for appropriate parameterizations of interactive processes. Recommendations were made for more insightful and timely research for the robust modeling of stormwater quantity and quality.

\subsection{SCIENTIFIC GAPS IN MECHANISTIC MODELING}

The major processes involving stormwater can be divided in two categories: (i) stormwater generation under specific climate conditions and land use features, and (ii) stormwater transport through natural courses (e.g., overland flow, channels) and/or manmade hydraulic networks to a specific outfall. Mechanistic models attempt to parameterize the detailed processes representing runoff generation, transport, and quality (Figure 2.1). A mechanistic stormwater model, therefore, integrates various processes and input variables and generates results mainly based on the principles of physics and chemistry. The sources of major variability and uncertainty of mechanistic modeling of 
stormwater runoff are demonstrated here by taking subcatchments of the highly urbanized Miami River Basin of Florida as examples.

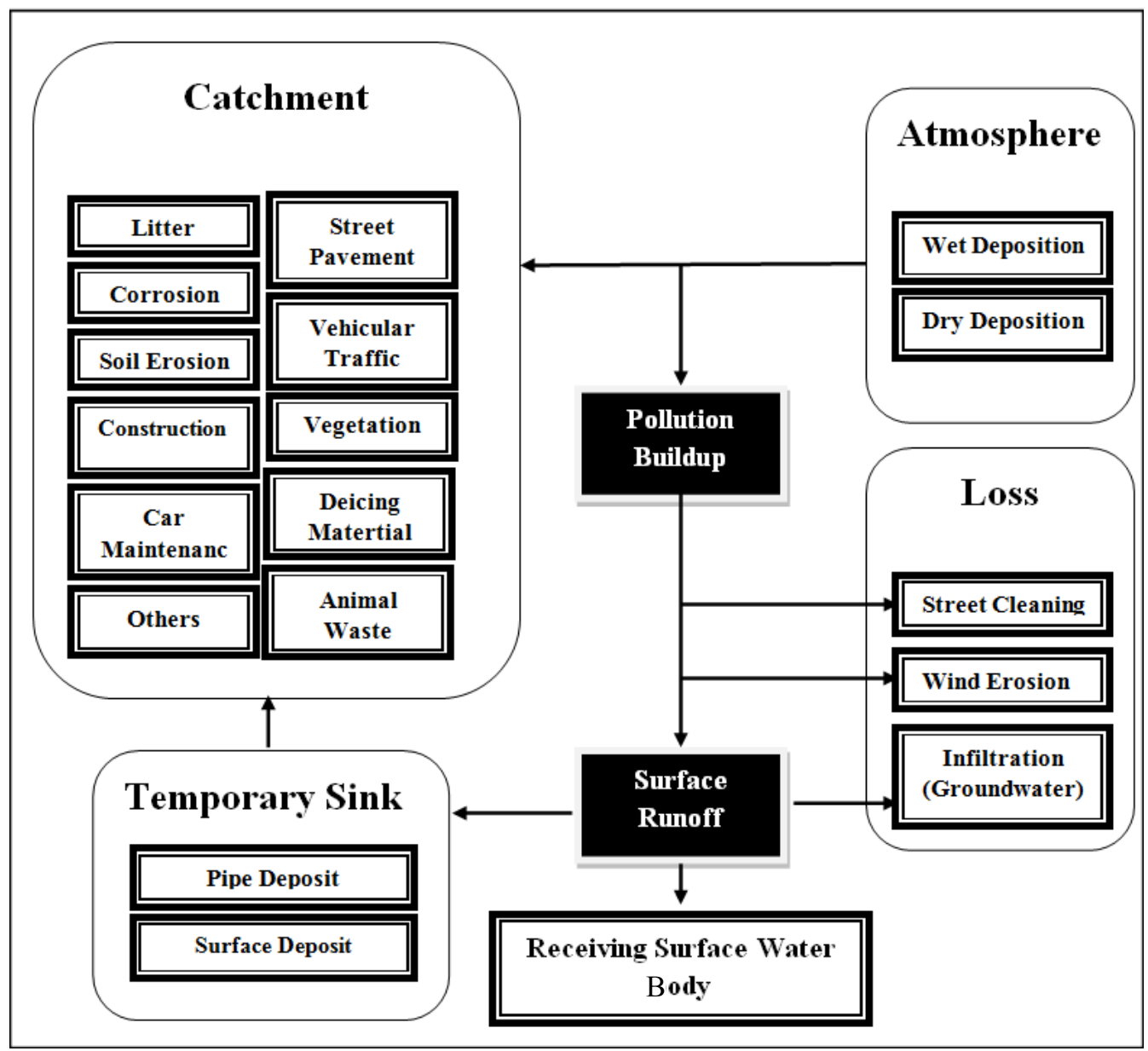

Figure 2.1: Sources of pollution and transport of stormwater.

\subsubsection{Uncertainty due to catchment delineation}

A basic step involved in stormwater modeling is catchment and subcatchment delineation. Traditionally this delineation is based on hydrologic features (Burian et al., 2001). However, the hydrological watershed boundary and the stormwater network boundary vary significantly. To demonstrate this challenge, let us consider the Wagner Creek Watershed, a subcatchment of the Miami River Basin (Figure 2.2). 


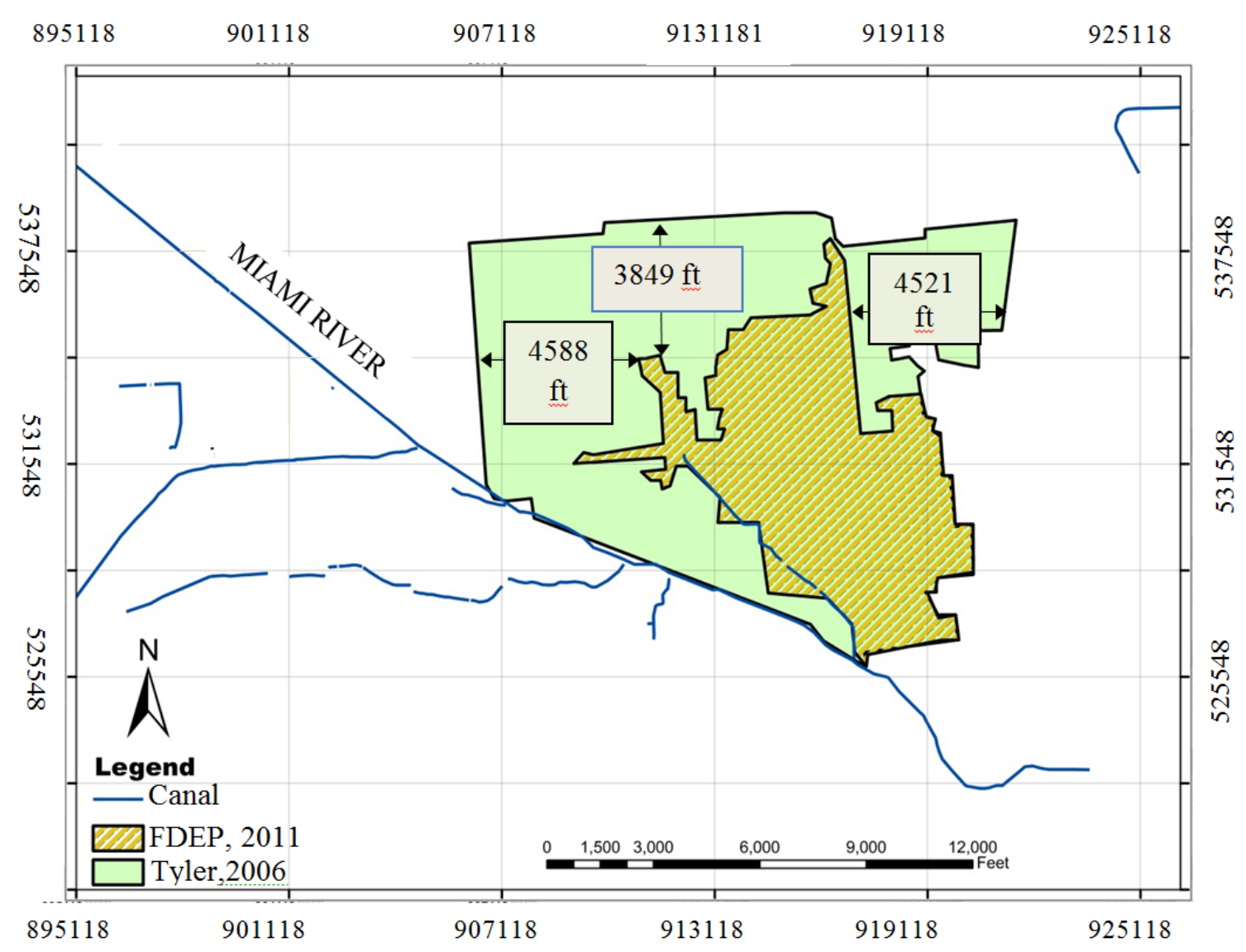

Figure 2.2: Comparison of stormwater network boundary and watershed boundary for Wagner Creek, a tributary of the Miami River, Florida (Shown in the inset).

As shown, the watershed boundary (green shaded area) (Tyler, 2006) and the corresponding stormwater network boundary (yellow shaded area) (FDEP, 2011) for Wagner Creek would contribute a substantially different amount of runoff (and pollutants) through the creek outlet into the Miami River. Although both overland flow and flow through the stormwater network should contribute to stormwater runoff, overland flow from remote locations in the watershed is unlikely to make an effective and a rapid contribution to stormwater runoff into Wagner Creek or its drainage network. The catchment should, therefore, be delineated considering both the relatively slow watershed hydraulics as well as fast conveyance through the stormwater drainage network. Failure 
in keeping an optimum balance between the two approaches would only yield inaccurate and unreliable estimates of the stormwater contributions into the urban streams, rivers, and lakes.

\subsubsection{Uncertainty in impervious area calculation}

Two major parameters used in runoff volume calculation are imperviousness and runoff coefficients. The runoff coefficient is defined as the ratio of runoff to rainfall over a given time period and depends on the percent impervious surfaces, slope, and soil conditions (Chow et al., 1988). Imperviousness of small urban watersheds can be directly measured by field surveys and analysis of aerial photographs (Han \& Burian, 2009); for large watersheds imperviousness can be indirectly determined through analysis of rainfallrunoff data, assigning specific total impervious area (TIA) values to different land use types (Kauffman et al., 2006; Han \& Burian, 2009). A common approach to calculate imperviousness is to use typical values of runoff coefficient following basic literature (UDFCD, 2001) for different land uses and compute the imperviousness as the areaweighted average of the runoff coefficients for all land uses in the subcatchment or study area. Another approach is to use remote sensing technique to extract impervious area from Landsat satellite images, for example (Xian \& Crane, 2005). Significant differences can result with these two approaches subsequently affecting the quantifications of runoff volume and quality. To illustrate further, a portion of the Wagner Creek Watershed was

considered as an example (Figure 2.3). Based on the city zoning map (Miami Dade County, 2010) and UDFCD (2001) coefficients, around $81 \%$ of the shown catchment area is impervious. In contrast, $74 \%$ of the area appeared to be impervious from our analysis 
of satellite image using GIS. Since impervious area is a very important parameter in determining overland flow, uncertainty herein is likely to be crucial in shaping the overall stormwater modeling accuracy and consistency (i.e., precision).

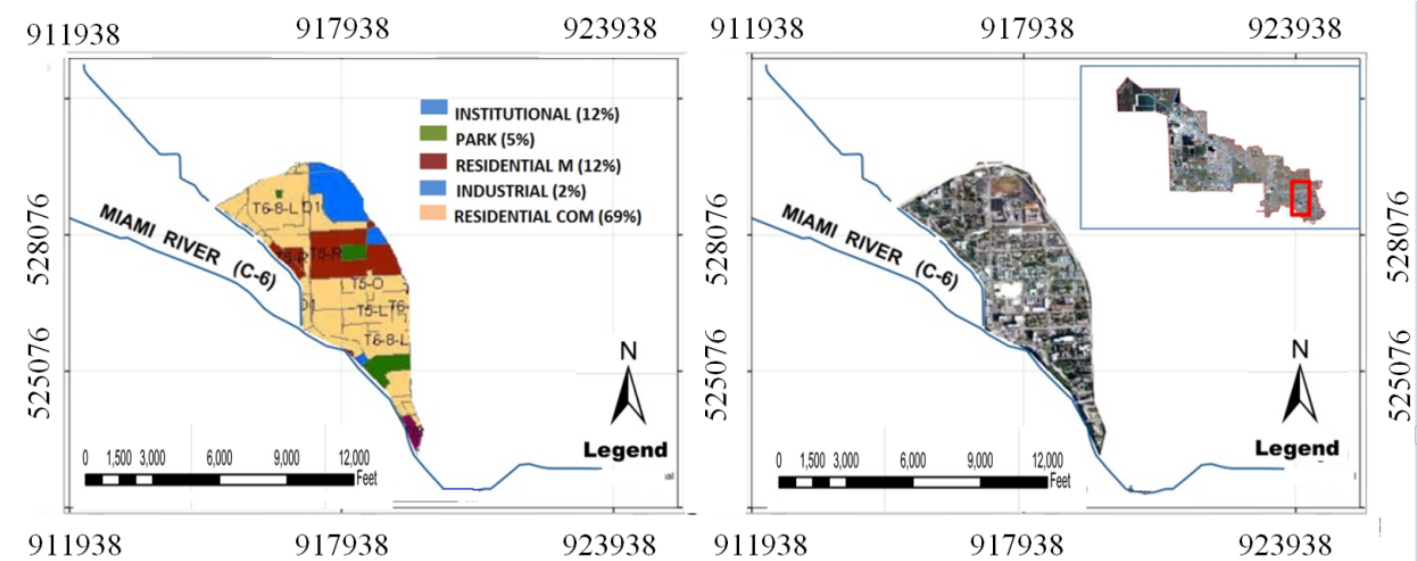

Figure 2.3: Satellite map (left) and city zoning map (right) for a portion of catchment of Wagner Creek in Miami-Dade County, Florida.

\subsubsection{Uncertainty due to climate data quality}

The precision of runoff generation can vary significantly depending on the availability and quality of observed climate data. Rainfall-runoff models are either based on isolated storm events or continuous long term precipitation. Most models often consider an incomplete set of watershed hydrologic processes, including infiltration, overland and channel flow, and possibly interception and detention storage. For a more appropriate evaluation of the contributions of regular (i.e., high frequency, low magnitudes) precipitation impacts on the receiving stream flow or lake during inter-storm periods, continuous simulation models should include additional hydrologic properties such as evapotranspiration, shallow subsurface flow, and groundwater flow. 
Most event models use a constant time interval that typically ranges from minutes to several hours. Continuous simulation models are usually run for a sustained period that includes both rainfall events, as well as inter-storm conditions. The model time-step should be flexible, ranging from sub-hourly to monthly intervals. Modeling time-step is likely to be dictated by the availability of observed input data collection. The frequency of data acts as a frequency of model loading and can affect the runoff generation. The choice of data interval is very important and should be determined based on the study objective and catchment of concern.

Another challenge is that climate data are generally recorded at point stations, which often do not coincide with the study area. Conventional practices in this case include obtaining rainfall data from a nearby recording station or using spatial estimation techniques such as the Thiessen polygon to estimate the areal average rainfall (Subramanya, 1995). The storm runoff volume can substantially vary between the two methods. To demonstrate, we considered two nearby weather stations (S-27_R and Miami 2_R) for a subcatchment of the Wagner Creek Watershed and divided the study area in two rainfall zones (Figure 2.4). 


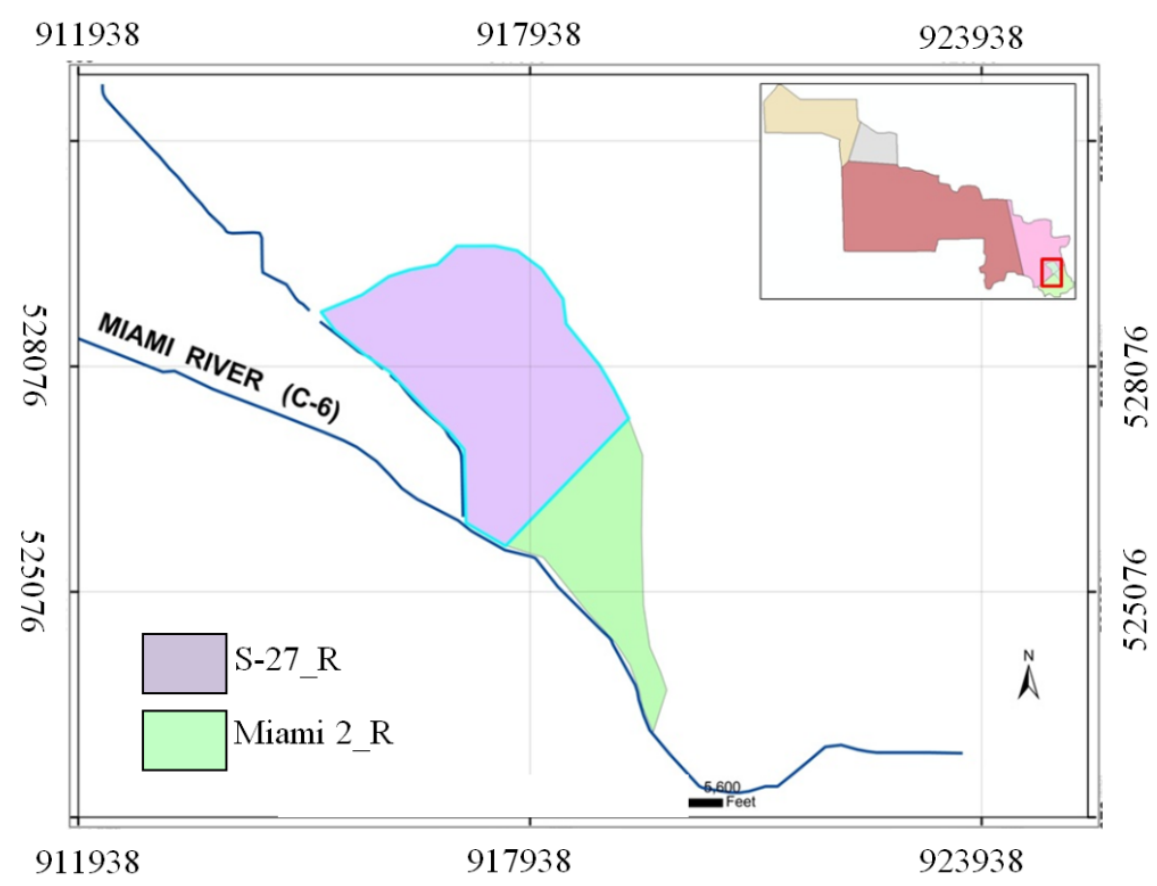

Figure 2.4: Division of a subcatchment of Wagner Creek Watershed, Miami for precipitation data interpolations (Inset shows the Miami River Basin)

The runoff volumes obtained by using rainfall data from any of the stations, as well as from the Thiessen polygon based areal rainfall, for the entire study area were substantially different (Figure 2.5).

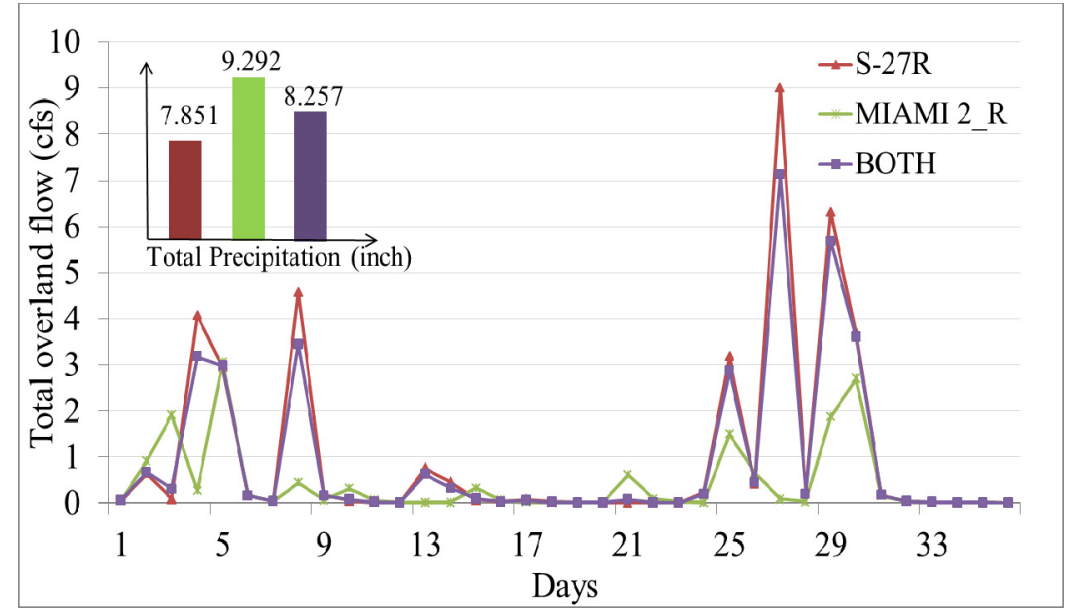

Figure 2.5: Variation in runoff due to spatial variation of station data in a subcatchment of Wagner Creek Watershed, Miami. "Both" refers to the combined spatial distribution of precipitations from station S-27R and Miami 2_R based on a Thiessen polygon method.

Red color refers to S-27R, green to Miami 2_R, and blue refers to the combination. 


\subsubsection{Uncertainty due to hydraulic routing}

Hydraulic routing is a very important feature in stormwater modeling. As overland flow and flow in conveyance network move down-gradient, they are subjected to translation and storage effects. Translation results in movement of the flow without reduction of peak discharge whereas storage effect reduces the peak. The upper limit of flood routing is translation of the peak discharge with no attenuation due to storage and the lower limit corresponds to storage effects acting alone as stormwater moves downstream resulting in maximum attenuation (USDA, 2012).

Compared to channel flow, stormwater routing is more complicated as it constitutes both overland flow and flow through conveyance networks. Although research has investigated the selection criteria of routing methods in natural channels (Moussa, 1996), the choice of the most appropriate hydraulic routing technique for stormwater modeling is not yet completely understood. Following Woolhiser and Liggett (1967), the dynamics of flow tend to be dominated by kinematic waves for a kinematic parameter of $\mathrm{K}$ greater than 10.0. In overland flow, the value of $\mathrm{K}$ usually exceeds this threshold, warranting a kinematic wave approach (Ramirez, 2000). However, in complex urban watersheds where overland flow and networked flow act simultaneously, unsteady and non-uniform flows occur; and the kinematic wave assumptions may not be valid because the significance of inertia and pressure forces compared to the gravitational and frictional forces can increase drastically. 


\subsubsection{Specific issues in mechanistic quality modeling}

Water quality is a challenging part of stormwater modeling. The gaps in water quality modeling can be attributed to the (i) uncertain parameterizations of the relevant physical, chemical, biological, and ecological processes, and (ii) unavailability of water quality data of appropriate spatial and temporal resolutions. The sources of stormwater pollution are numerous. Water quality changes due to physical transport and exchange processes (such as advection and diffusion/dispersion), as well as by biological, chemical, biochemical and physical conversion processes (Rauch, 1998). It is hard to properly quantify all the parameters in terms of mechanistic modeling.

The mechanistic modeling of stormwater quality is conventionally simplified in the two steps of buildup and wash off. The buildup of a pollutant in a catchment is expected to be a function of climate variables, land use parameters and the pollutant characteristics. Subject to the difficulty of parameterizations, buildup is generally associated with land use and expressed as a function of time with coefficients specific to the catchment characteristics. This simplification sometimes overlooks the sensitivity of stormwater pollution to many micro parameters. For example, rainfall is incorporated in models in terms of volume or intensity. Therefore, the role of raindrop size (which is difficult to measure) on pollution cannot be addressed.

A significant portion of pollutants are removed by management practices, which are applied in models in terms of street sweeping. The management practices are run under supervised organization and involve human efforts. To quantify percentage of pollutants removal in street sweeping accurate data are required for sweeping interval and 
operations, which involve diverse parameters and vary both in time and place. Without necessary data, it is hard to quantify the efficiency of street sweeping process. Lack of data of management practices can adversely affect the water quality modeling.

Another important mechanism of pollutant removal is wind erosion. A notable part of gaseous and particulate pollutants can be lost from the catchment area by wind erosion. The materials are suspended in the atmosphere and deposited at another place (Brinkmann, 1985). The effect of wind erosion is not explicitly parameterized in conventional stormwater modeling practices.

A common approach in stormwater quality modeling is the incorporation of Event Mean Concentration (EMC). An EMC is the average pollutant concentration during the storm event and defined as the total pollutant mass divided by total runoff volume (Huber \& Dickinson, 1988). Generally, EMCs are characterized mainly by the land uses in the watershed, because they depend on site characteristics and storm events (Smullen et al., 1999). Pollution estimates are likely to vary with different EMCs for the same land use and pollutants (Park et al., 2009). It is imperative that the EMC method only provide an approximation of actual storm water quality. Subject to data availability, more sophisticated methods (e.g., advection-dispersion-reaction) should be pursued for a more accurate parameterization of the relevant biogeochemical processes to develop dynamic models of storm runoff quality.

Wash off is also correlated with flow and land use variables and parameterized using empirical coefficients. One major improvement in modeling wash off can be the inclusion of impact of individual subcatchment pollutant trapping (Sutherland, 2010). 
Since instantaneous stormwater runoff volume is relatively low most of the time, a significant portion is temporally entrapped in catchments. The common practice of storm water quality routing assuming a continuously stirred tank reactor might overlook the entrapment of pollutant in the catchment.

\subsection{SCIENTIFIC GAPS IN DATA-DRIVEN EMPIRICAL MODELING}

Data-driven models attempt to establish empirical relationships and predict behaviors of different parameters of a system by mathematical equations using concurrent data. Although empirical models do not necessarily describe the pertinent biogeochemical processes of a system, they often provide simple, quite useful impulse-response (rather than causal) type relationships, offering important insights that complement a mechanistic understanding and facilitating engineering applications. Empirical modeling has been extensively explored in water resources engineering, typically involving the rating curves, unit hydrograph method, regression-based statistical models, stochastic methods, linear and dynamic programming, and methods of machine learning (e.g., artificial neural network). Relevant recent examples can include successful applications in hydrology (Govindaraju, 2000; Dibike \& Solomatine, 2001), river water quality

modeling (Mohseni et al., 1998), water system control (Bhattacharya et al., 2003), sediment transport (Bhattacharya et al., 2005), river stage-discharge relationships (Sudheer \& Jain, 2003), streamflow hydrographs (Moradkhani et al., 2004), etc. However, the potential of data-driven empirical modeling in stormwater applications is yet to be fully explored, particularly in the context of a highly complex urban environment. 


\subsubsection{Difficulty in identifying the input variables}

Selection of the appropriate model inputs or decision variables is a major challenge in the developments and applications of data driven empirical models for stormwater quality. To illustrate, we present three relatively recent studies that reported significant correlations between water quality and different climatic, hydro-geomorphic, and biogeochemical variables (Table 2.1).

Table 2.1: Variation of input variables for quality study.

\begin{tabular}{|c|c|c|c|}
\hline $\begin{array}{l}\text { Reference } \\
\text { study }\end{array}$ & \multicolumn{2}{|c|}{ Response variables } & Predictor variables \\
\hline $\begin{array}{l}\text { Brezonik } \\
\text { and } \\
\text { Stadelmann } \\
(2001)\end{array}$ & \multicolumn{2}{|c|}{$\begin{array}{l}\text { Stormwater Loads } \\
\text { (TSS, VSS, TP, DP, } \\
\text { SRP, COD, TKN, NN, } \\
\text { Pb) }\end{array}$} & $\begin{array}{l}\text { Total precipitation, intensity and duration of } \\
\text { precipitation, day since last event (i.e., antecedent dry } \\
\text { days), total drainage area, residential area, commercial } \\
\text { and industrial area, and public and open area. }\end{array}$ \\
\hline $\begin{array}{l}\text { Hatt et al. } \\
(2004)\end{array}$ & \multicolumn{2}{|c|}{$\begin{array}{l}\text { Water quality in } \\
\text { streams (TSS, EC, } \\
\text { total nutrients, } \mathrm{NH}_{4}, \\
\mathrm{NO}_{\mathrm{x}}, \mathrm{FRP}, \mathrm{DOC}, \mathrm{pH}, \\
\text { temperature) }\end{array}$} & $\begin{array}{l}\text { Imperviousness, drainage connection, septic tank } \\
\text { density, unpaved road density, basin area, elevation, and } \\
\text { longitude. }\end{array}$ \\
\hline \multirow{5}{*}{$\begin{array}{l}\text { May and } \\
\text { Sivakumar } \\
(2008)\end{array}$} & \multirow{5}{*}{$\begin{array}{l}\text { Stormwater } \\
\text { loads }\end{array}$} & COD & $\begin{array}{l}\text { Effective impervious area, amount of rainfall during the } \\
\text { preceding } 3 \text { days, peak discharge, total precipitation, } \\
\text { and total storm rainfall depth. }\end{array}$ \\
\hline & & $\mathrm{Pb}$ & $\begin{array}{l}\text { Duration of runoff, impervious area, amount of rainfall } \\
\text { during the preceding } 7 \text { days, residential land-use, peak } \\
\text { discharge, street density, total storm runoff depth, and } \\
\text { sine seasonal variable. }\end{array}$ \\
\hline & & SS & $\begin{array}{l}\text { Duration of rainfall, nonurban land-use, maximum } 5 \\
\text { min rainfall rate, mean annual rainfall, average storm } \\
\text { rainfall intensity, and sine seasonal variable }\end{array}$ \\
\hline & & TKN & $\begin{array}{l}\text { Effective impervious area, ammonium concentration in } \\
\text { rainfall, amount of rainfall during the preceding } 7 \text { days, } \\
\text { peak discharge, and average storm runoff intensity. }\end{array}$ \\
\hline & & TP & $\begin{array}{l}\text { Duration of runoff, effective impervious area, average } \\
\text { soil erodibility, residential land-use, amount of rainfall } \\
\text { during the preceding } 3 \text { days, percent of streets with curb } \\
\text { and gutter drainage, and total precipitation. }\end{array}$ \\
\hline
\end{tabular}

Notes. (1) TSS- total suspended solids, VSS- volatile suspended solid, TP- Total Phosphorus ,DPDissolved Phosphorus , SRP- soluble reactive Phosphorus, COD- chemical oxygen demand, TKN- Total Kjeldahl Nitrogen, NN- Nitrite Nitrogen, Pb- Lead, SS- Suspended Solids, EC- electrical conductivity; NH4- ammonium ,NOx- nitrate/nitrite, FRP- filterable reactive phosphorus, DOC- dissolved organic carbon ; (2) Sine seasonal variable is a variable from Nationwide Urban Runoff Program (NURP) dataset for representing seasonal harmonics. 
As shown, the set of predictor variables differed among the studies. Available literature is commonly used as a source to identify major components and variables in data-driven modeling (Opher et al., 2009). This approach requires prior knowledge of the relevant biogeochemical processes in the watershed. In case of stormwater modeling, the process dynamics are yet to be understood well and predefining the parameters has the possibility of missing major components. Where prior knowledge is not available, an analytical technique such as correlation analysis, is often employed to select potential predictor and response variables (Lee et al., 2003). The major disadvantage with correlation analysis is that it is only able to detect linear dependence between two variables. Therefore, such an analysis is unable to capture any non-linear dependence that may exist between the inputs and the outputs, and can result in the omission of important inputs that are related to the output in a non-linear fashion (Muttil \& Lee, 2005). Some studies used data mining techniques such as the principal component analysis (PCA) and cluster analysis for selecting the significant, statistically independent input variables (Goonetilleke et al., 2004). PCA techniques also suffer from drawbacks as the associated methods are based on linear principles, while the relationships between environmental variables are often non-linear.

Forward selection and backward elimination is another set of useful approaches for datadriven empirical modeling. Forward selection starts by finding the best single input and selecting it for the final model. In each subsequent step, given a set of selected inputs, the input variable that improves the model's performance most is added to the final model. Backward elimination (network trimming) starts with a set of all inputs, and sequentially 
deletes the input that reduces performance the least (Muttil \& Lee, 2005). The main disadvantage of these approaches is that they are based on trial-and-error, and as such, there is no guarantee that they will find the globally best subsets. The forward selection approach may also fail when there is interaction amongst variables, i.e., when a variable that is useless by itself may provide a significant performance improvement when taken in conjunction with the others.

\subsubsection{Difficulty in explaining the mechanisms}

A major criticism of data-driven empirical models is their limitation in explaining the mechanisms of a system. Data driven models are based on correlations between different input variables. They can successfully predict the correlation of variables, their sensitivity and relative significance. But they cannot describe the associated physical-chemical, and biological processes. They can explain 'what' rather than 'why.' We present recent examples of empirical methods that successfully quantified stormwater runoff and quality from roadways (Table 2.2). The studies successfully correlated stormwater quality with different, individual parameters. The role of a certain parameter is explained in depth, however the sensitivity of a parameter with respect to other parameters is seldom investigated. In reality, many parameters act simultaneously and, therefore, to better understand the relative significance of a particular parameter, relevant other parameters should be considered in concert.

The complex interactions between different parameters are difficult to portray through conventional empirical models. Where process-based models can holistically explain the process, the scope of data driven models are confined to available end data rather than the 
governing mechanisms. The application of data driven modeling, has therefore been limited to a section or sub-processes of the overall stormwater generation, transport and interaction with the environment. The study of a whole system through all the components and sub processes in terms of data driven technique is yet to be tested.

Table 2.2: Examples of data based study on stormwater pollution from roadway

\begin{tabular}{|c|c|c|c|}
\hline $\begin{array}{l}\text { Reference } \\
\text { Study }\end{array}$ & $\begin{array}{l}\text { Response } \\
\text { variables }\end{array}$ & Predictor variables & Major findings \\
\hline $\begin{array}{l}\text { Vaze and } \\
\text { Chiew (2002) }\end{array}$ & $\begin{array}{l}\text { Surface } \\
\text { pollutant load }\end{array}$ & $\begin{array}{l}\text { Rainfall regime, } \\
\text { street sweeping }\end{array}$ & $\begin{array}{l}\text { Effect of rain and street } \\
\text { sweeping on surface pollutant } \\
\text { load, and effect of rain and } \\
\text { street sweeping on particle } \\
\text { size distribution of surface } \\
\text { pollutant }\end{array}$ \\
\hline $\begin{array}{l}\text { Gilbert and } \\
\text { Clausen(2006) }\end{array}$ & $\begin{array}{l}\text { Quality and } \\
\text { quantity of } \\
\text { stormwater } \\
\text { runoff }\end{array}$ & $\begin{array}{l}\text { Driveway type } \\
\text { (asphalt, permeable } \\
\text { paver, and crushed- } \\
\text { stone driveways) }\end{array}$ & $\begin{array}{l}\text { Comparison of runoff depth } \\
\text { and concentration of } \\
\text { pollutants among asphalt, } \\
\text { permeable paver, and crushed- } \\
\text { stone driveways }\end{array}$ \\
\hline $\begin{array}{l}\text { Backstorm et } \\
\text { al. (2003) }\end{array}$ & $\begin{array}{l}\text { Heavy metals } \\
\text { in road runoff } \\
\text { and roadside } \\
\text { deposition }\end{array}$ & $\begin{array}{l}\text { Seasonal variation } \\
\text { (summer and winter) } \\
\text {, deicing material }\end{array}$ & $\begin{array}{l}\text { Variation of heavy metals in } \\
\text { summer and winter and the } \\
\text { role of deicing material }\end{array}$ \\
\hline $\begin{array}{l}\text { John and } \\
\text { Horner (1997) }\end{array}$ & $\begin{array}{l}\text { Highway } \\
\text { runoff quality } \\
\text { and quantity }\end{array}$ & Road shoulders & $\begin{array}{l}\text { Quantity and quality of } \\
\text { stormwater from three types } \\
\text { of shoulder materials: } \\
\text { conventional asphalt, gravel, } \\
\text { and porous asphalt. }\end{array}$ \\
\hline $\begin{array}{l}\text { Wheeler and } \\
\text { Rolfe (2003) }\end{array}$ & $\begin{array}{lr}\text { Lead } & \text { in } \\
\text { roadside } & \text { soil } \\
\text { and } & \\
\text { vegetation } & \end{array}$ & $\begin{array}{l}\text { Average daily traffic } \\
\text { volume }\end{array}$ & $\begin{array}{l}\text { The relationship between daily } \\
\text { traffic volume and the } \\
\text { distribution of lead in roadside } \\
\text { soil and vegetation }\end{array}$ \\
\hline
\end{tabular}

\subsubsection{Site-specificity}

The data driven empirical water quality models are generally built on the underlying correlations between the quality variables and those representing climate, hydrologic, 
land use, biogeochemical, and ecological parameters, which can vary significantly from place to place. For example, Mohseni et al. (1998) estimated wide ranges of model parameters after analyzing around 573 different streams across the USA to develop a successful nonlinear regression model of weekly stream and air temperatures. Although some stormwater modeling studies (e.g., Maestre \& Pitt, 2005; Kayhanian et al., 2007) reported relatively small parameter variations across space, application of appropriate scaling can be greatly useful in developing spatio-temporally robust models to predict stormwater runoff quantity and quality.

\subsection{CONCLUSIONS}

Stormwater generation and transport is influenced mainly by the features of climate, land use, and catchment hydrology (Figure 2.6). Proper mechanistic and empirical modeling would require a careful consideration of all these processes. A basic need for stormwater research is, therefore, the availability of data of appropriate spatial and temporal resolutions. Often, unavailability of data leads to the omission or crude approximations of important processes at different scales. For example, lack of precipitation data at finer resolution fails to incorporate local micro-climate and hampers realistic modeling with sufficiently small time intervals (e.g., hour). Reliable stormwater quality data appear to be most scarce. Lack of resources is perhaps the main reason for this undesired scientific gap. The data collection efforts by different agencies and individual researchers should be coordinated in a watershed for the most utilization of available resources. 


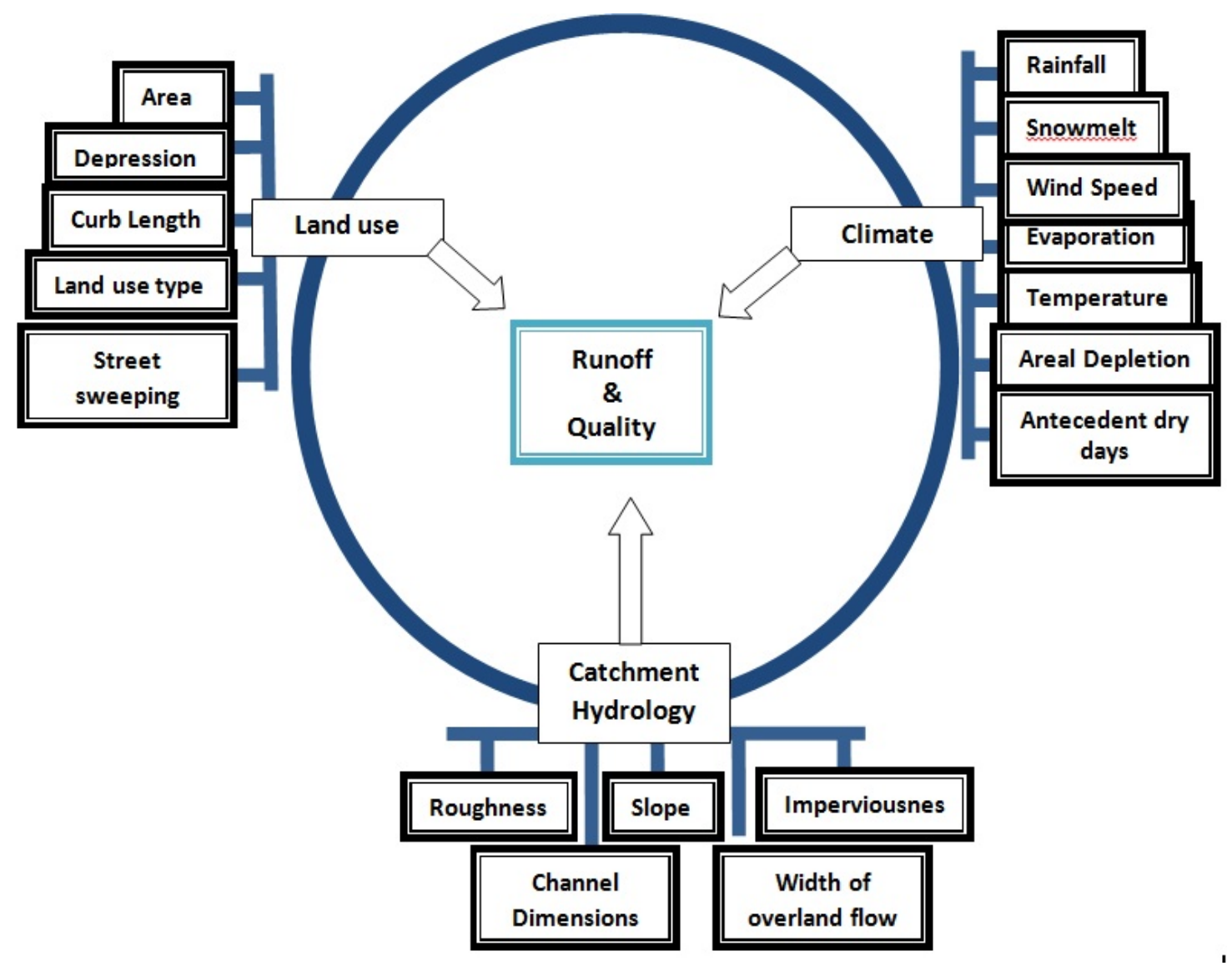

Figure 2.6: Major variables for mechanistic modeling of stormwater.

Most studies look into the stormwater runoff quantity and quality by focusing on either design storms or observed data of a less frequent, high magnitude storm event for a small area. Research into the contributions of high frequency, low magnitude precipitation events incorporating both surface and groundwater components at a watershed scale is lacking. In sum, these typical precipitation events may contribute the most pollution.

Unlike mechanistic modeling, conventional data driven empirical models tend to focus more on some particular aspects of the whole watershed. Given the importance and great utility in engineering applications, data driven models should be developed by incorporating a more complete matrix of potential variables (Table 2.3). The variable list 
is continuously updating, which underlines the need for more detailed study for stormwater research. Further, research into the scaling and similarity patterns of respective biogeochemical variables should be pursued for developing stormwater models that can provide robust predictions in time and space.

Table 2.3: Land use and climate variables often used in data driven models for stormwater quality

\begin{tabular}{ll}
\hline Type & Variables \\
\hline Land use & $\begin{array}{l}\text { Total drainage area, residential area, nonurban land-use , } \\
\text { commercial and industrial area, public and open area, } \\
\text { imperviousness, effective impervious area, drainage connection, } \\
\text { septic tank density, unpaved road density, basin area, elevation, } \\
\text { longitude, average soil erodibility, \% of streets that have curb and } \\
\text { gutter drainage }\end{array}$ \\
& $\begin{array}{l}\text { Precipitation duration, precipitation intensity, day since last event, } \\
\text { amount of rainfall during the preceding 3 days, amount of rainfall } \\
\text { during the preceding 7 days, total precipitation, total storm rainfall } \\
\text { depth, maximum 5 min rainfall rate, mean annual rainfall, average } \\
\text { storm rainfall intensity, sine seasonal variable. }\end{array}$
\end{tabular}

Mechanistic and data driven models can be complementary by accepting and adopting the advancements in respective fields. The empirical models can be a useful means for identifying any missing aspects of mechanistic models. Mechanistic models, on the other hand, can explain the physical, chemical, and biological processes underlying correlations established in data driven models. The respective successes of both approaches indicate their suitability as well as mutual necessity. This aspect should be explored further in future research. 


\section{CHAPTER 3}

\section{CLIMATE, LAND USE AND HYDROLOGIC SENSITIVITIES OF STORMWATER QUANTITY AND QUALITY IN A COMPLEX COASTAL URBAN WATERSHED}

\subsection{INTRODUCTION}

Stormwater is often held responsible for urban flooding and poor water quality in streams and rivers around the world. It is the fourth most extensive cause of water quality impairment of rivers, and the third most extensive source of water quality impairment of lakes in the USA (USEPA, 1990; Novotny, 1991; Novotny \& Olem, 1994; Tsihrintzis \& Hamid, 1996). Therefore, stormwater research integrating land use and climate variables in the backdrop of highly altered and engineered catchment hydrology is important for understanding the science in stormwater generation and runoff to develop appropriate management approaches.

Much research has focused on the understanding and quantification of urban runoff quantity and quality. Example of recent research includes identification of significant factors affecting stormwater quality using the National Stormwater Quality Database (Maestre \& Pitt, 2006), defining the stormwater first flush phenomenon (Bach et al., 2010), identification of hydrologic shortcomings of conventional urban stormwater management and opportunities for reform (Burns et al., 2012), and identification of dominant perspectives and the shape of urban stormwater futures (Winz et al., 2011). Both mechanistic (i.e., process-based) and empirical (i.e., data-driven) techniques have 
been adopted to analyze stormwater runoff and pollutant generation features. Examples of mechanistic model application include estimation of urban imperviousness and its impacts on stormwater systems (Lee \& Heanay, 2003), assessing watershed-scale longterm hydrologic impacts of land-use change using a GIS-NPS model (Bhaduri et al, 2000), and stormwater management implementation through modeling and GIS (Shamsi, 2000). Empirical modeling has also been explored in stormwater modeling,typically involving the rating curves, unit hydrograph method, and regression-based statistical models. Relevant recent examples may include stormwater runoff quality and quantity from asphalt, paved, and crushed stone driveways in Connecticut (Gilbert \& Calusen, 2006), experimental study of pollutant accumulation on an urban road surface (Vaze \& Chiew, 2002), and speciation of heavy metals in road runoff and roadside total deposition (Backstorm et al., 2003).

Studies have reported strong influence of urban density and drainage infrastructure (Hatt et al., 2004), based on land use characteristics (Goonetilleke et al., 2005), on the concentrations and loads of pollutants in small streams. Research linking watershed land uses with primary stormwater pollutants such as sediments (e.g., Nelson \& Booth, 2002) and metals (e.g., Helsel et al., 1979), as well as with secondary stream responses such as aquatic biota (e.g., Lenat \& Crawford, 1994), have demonstrated a significant role of watershed land uses in determining stormwater quality. Furthermore, the entire process of stormwater generation and runoff is believed to be affected by changing climatic conditions and catchment hydrology. Mahbub et al. (2010) reported climate change impacts on water quality by measuring build-up and wash-off of heavy metals and 
petroleum hydrocarbons on urban roads. Shaw et al. (2005) discussed how and why climate change impacts should be incorporated in stormwater design. Ferguson (1990) described the role of the long-term water balance in management of stormwater infiltration. Dean et al. (2005) analyzed the influence of hydrology on rainfall-runoff metal element speciation. Therefore, a simulation simultaneously considering all the important stressors of climate, land use, and catchment hydrologyis necessary for developing a comprehensive understanding of stormwater processes. Mechanistic modeling in a watershed-scale, in particular, can provide important insights for appropriate management of stormwater runoff and quality in complex urban coastal environments around the world.

Considering the Miami River Basin of Florida as an example of complex coastal-urban watersheds, we determined the hydro-climatic and land use sensitivities of stormwater runoff and quality by developing a Storm Water Management Model (EPA SWMM 5.0). The objective of the study was to quantify dominant stressors and their relative, as well as combined, influence on stormwater runoff and potential loads of six major pollutants (i.e., total suspended solids, total nitrogen, total phosphorus, copper, zinc and biochemical oxygen demand) in the Miami River Basin. Unlike traditional studies considering stormwater as a standalone process, we resolved the stormwater runoff as a component of the total watershed water budget, incorporating the important processes of coastal-urban watershed hydrology (i.e., precipitation, evapotranspiration, surface runoff, groundwater, sea level) and land use/cover features (e.g., imperviousness, roughness, slope, drainage networks). In contrast to short-term, event-based applications of SWMM in conventional studies, we have used longer-term, continuous climate and hydrology 
data to calibrate the model and elucidate seasonal, as well as annual, responses of stormwater runoff to changes in climate, land use and hydrologic drivers. Although the research considered the Miami River Basin as a pilot study area, it can provide important insights for appropriate management of stormwater runoff and quality in complex urban coastal environments around the world.

\subsection{MATERIALS AND METHODS}

\subsubsection{Study area}

The study area comprises of the complex urban watershed of Miami River, which is located in Miami-Dade County on the southeast coast of Florida, U.S.A. (Figure 3.1). The juxtaposition of eastern coastal urban developments, including the City of Miami, one of the largest U.S. metropolises and the U.S city most vulnerable to sea level rise, with several surrounding National Parks and natural areas makes the Miami Basin a unique location and living laboratory for analysis of complex socio-ecological interactions. Essential to its historical development as an urban region is the unique and perplexing system of drainage canals that are highly engineered and network throughout the region's relatively flat topography. The Miami River has a length of approximately 15.2 miles from its mouth at Biscayne Bay (Atlantic Ocean) and a drainage area of around 67.5 square miles. Miami Canal (also known as the C-6 Canal) terminates into the Miami River after flowing south-southeast approximately 77 miles from its (Miami Canal) source at the Lake Okeechobee through the Everglade Agricultural Area (EAA) and Water Conservation Area 3 (WCA3). The primary canals of Tamiami, Comfort, and Wagner Creek drain into the Miami River. The secondary canals draining into the Miami 
River or the primary canals include the Russian Colony Canal, NW 58 ST Canal, Melrose Canal, Red Road Canal, and Dressel Dairy Canal, FEC Canal.

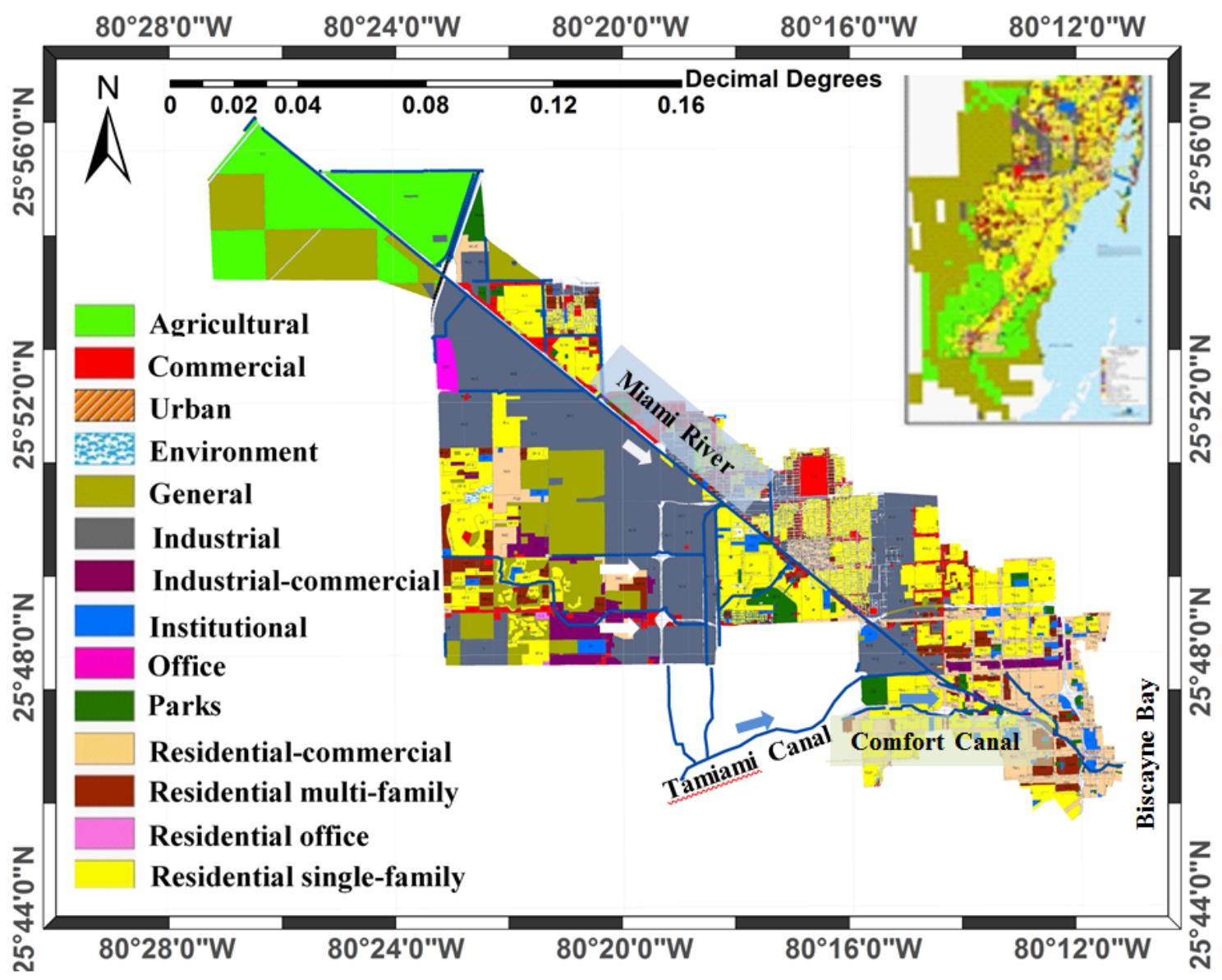

Figure 3.1: Miami River Basin of Florida.

Miami River Basin is highly urbanized and characterized by a variety of land use types, including agricultural lands (in the northwest) and a mixture of park, single/ multi-family residential, commercial and industrial areas. The complex land uses, as well as the inflow from the Miami Canal passing through the EAA and WCA3, cause a variety of pollutant loadings into Miami River. The Basin is characterized by a tropical monsoon climate with hot, humid summers and short, dry winters (Kottek et al., 2006). On 
average, the Basin receives approximately 52 inches of annual rainfall (NCDC). The topography of the study area is almost flat; the elevation varies between 0 to 12 feet (NAVD, 1988) for most of the areas. The agricultural area is the northwest section is relatively lower with elevation varying between 0 to 4 feet. For most of the middle part in the urban basin, the elevation varies between 5 to 8 feet and for southeast urban part between 5 to 12 feet.

\subsubsection{Preparation of datasets}

The Miami River Basin was extracted from the smallest available (12-digit) hydrologic unit codes (HUC ID: 030902061405), as delineated nationally by the US Geological Survey (USGS) (available online at http://water.usgs.gov/GIS/huc.html; last accessed on July 9,2013 .). The study area was further subdivided into 33 subcatchments following the zoning map of Sustainability, Planning and Economic Enhancement Department, Miami Dade County (available online at http://www.miamidade.gov/business/library/maps/zoning.pdf ; last accessed on July 11, 2013). The land use features (i.e., slope, area) were extracted by analyzing the $10 \mathrm{ft}$ FDEM LiDAR Data of the South Florida Water Management District (SFWMD) in an ESRI ARCGIS 9.0 platform. The twelve land use types of the Basin (Figure 3.1) were aggregated into the five land use types of park and open lands (park+agricultural areas), single family residential, multifamily residential, commercial and industrial for each subbasin. Industrial-commercial areas were equally divided in industrial and commercial areas. Similarly, residential-commercial areas were also equally divided into residential and commercial areas. Office and institutional areas were considered as commercial 
areas. The general area was divided following the percentage distribution of other land uses in each subcatchment. The imperviousness of each subcatchment was calculated using an area-weighted average of runoff coefficients for different land uses, as obtained from literature (UDFCD, 2001).

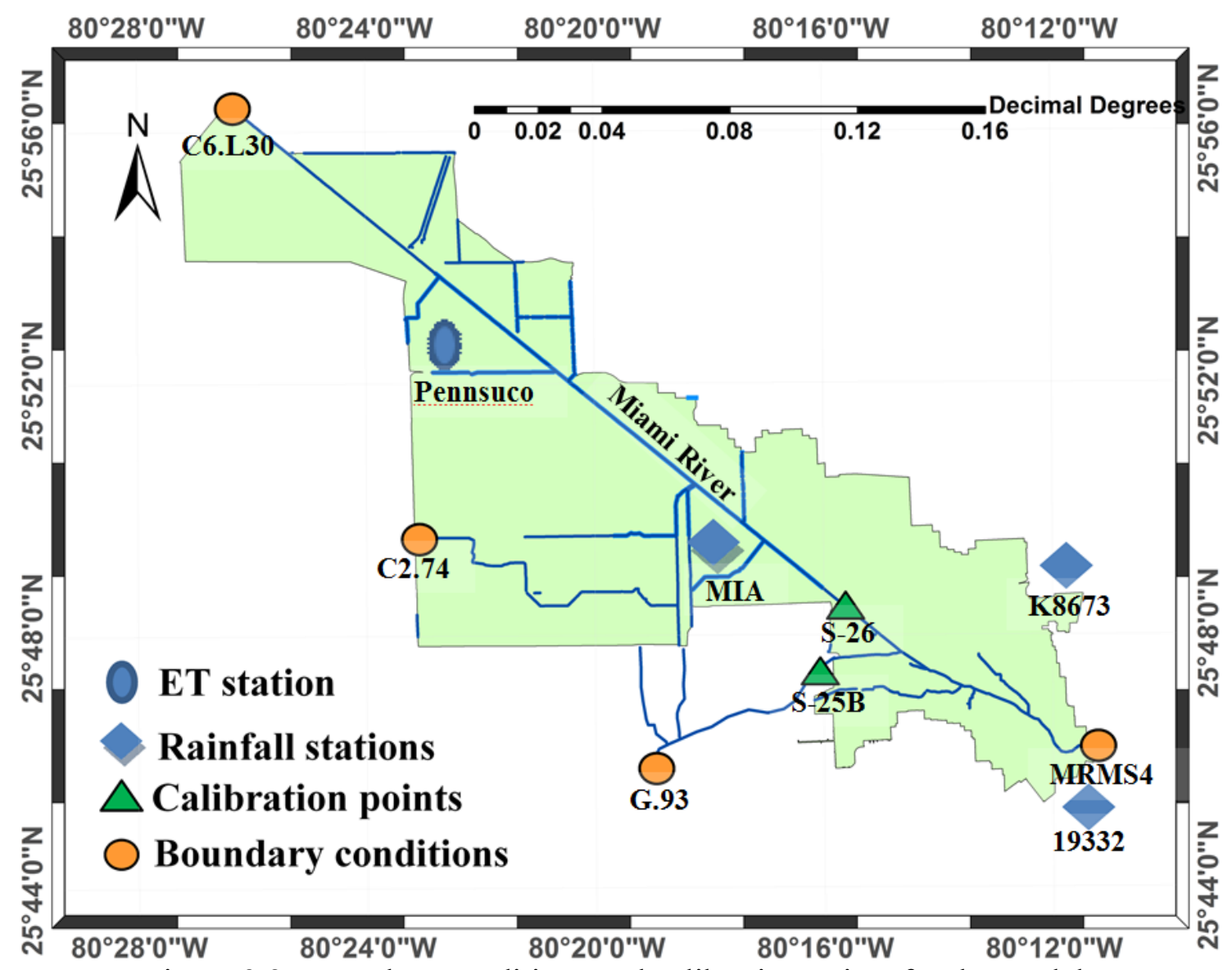

Figure 3.2: Boundary conditions and calibration points for the model.

Flow and stage data for the drainage canals were obtained from the DBHYDRO (Environmental database of SFWMD). Continuous time series data for two upstream inflows, such as Miami Canal east of levee 30 (C6.L30) and Snapper Creek Canal extension at NW74 Street near Hialeah (C2.74) were used as the upstream boundary 
conditions (Figure 3.2). Stage data for two downstream stages, namely the Miami River stage monitoring station (MRMS4) and the Coral Gables Canal (C-3) at Red Road (G.93) were used as the downstream boundary conditions (Figure 3.2).

The bathymetric data (i.e., channel cross section, slope and bed elevations) for canals were extracted from survey data, as collected by SFWMD for the C-4 (Tamiami Canal) Flood Control Operations Modeling Project. The C-4 data were obtained from Dr. Ruben Ortega of SFWMD in 2012 through personal communications. The model domain includes two gated spillway (S-26 and S-25B) and one gated culvert (S-25A). The operational data for the control structures were obtained from DBHYDRO and the C-4 Flood Control Operations Modeling Project Report (Reference this report) and incorporated into the model development.

In order to reflect the spatio-temporal rainfall variability, daily available data for three rainfall stations (with the DBHYDRO station IDs of MIA, K8673 and 19332) within and around the Miami River Basin were used (Figure 3.2). Hourly data were available for only the MIA station. The daily data at other stations were approximately distributed among different hours based on the observed, hourly distribution at the MIA station. Observed daily evaporation data for a US Geological Survey (USGS) station near Pennsuco were used to incorporate evaporation from the basin. 


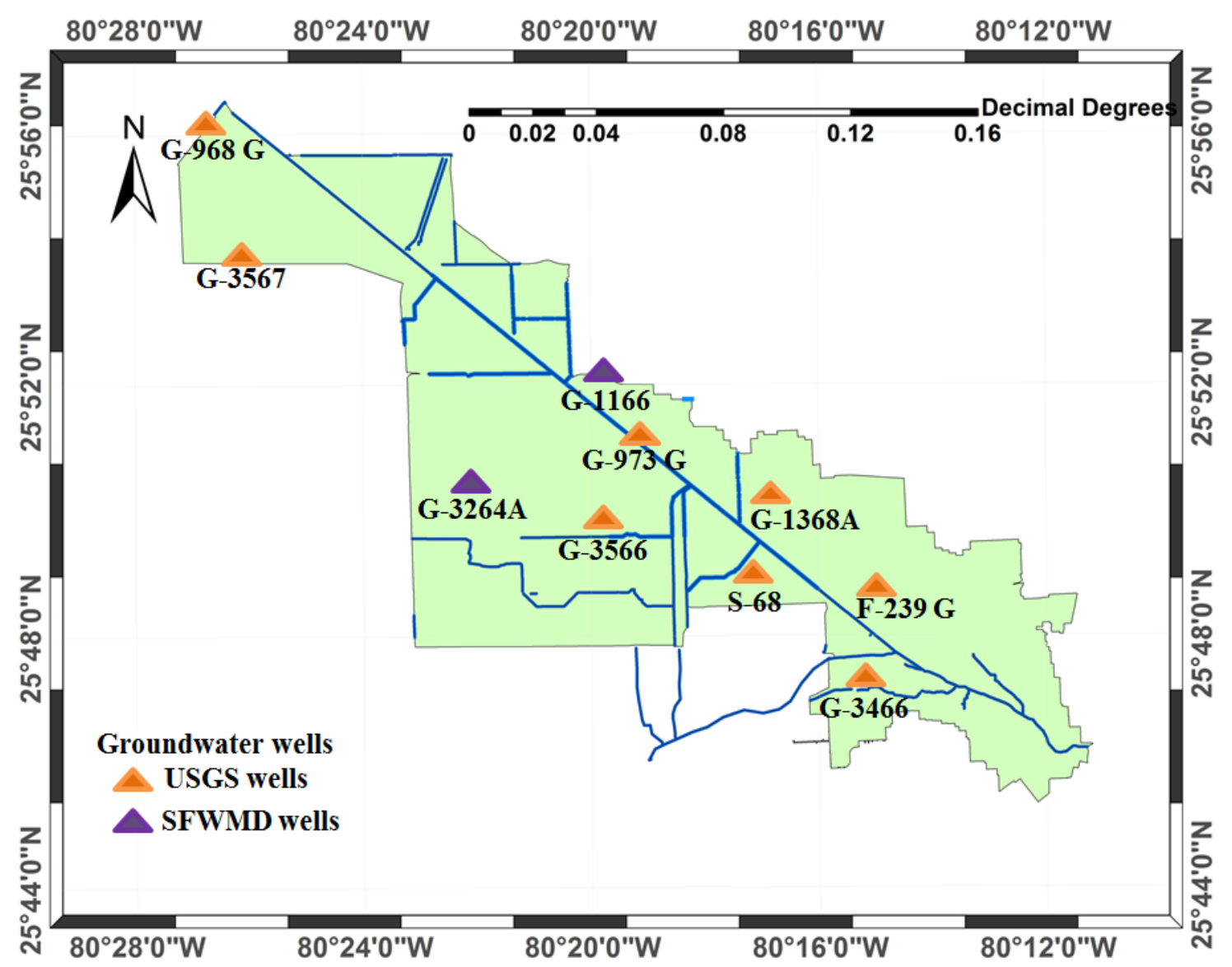

Figure 3.3: Groundwater observation wells used for the model.

The observed groundwater levels (i.e., water table depths) of the Miami Basin were considered to reflect the role of groundwater in stormwater generation. Data from eight USGS observation wells (G-3466, G-3566, G-3567, G-968 G, G-973G, G-1368A G, F239 G, S-68) and two SFWMD observation wells (G-3264A G, G-1166 G) were used (Figure 3.3) as the initial water tables and the model dynamically updated the subsequent groundwater levels. 


\subsubsection{Development of a Storm Water Management Model (EPA SWMM 5)}

The EPA Storm Water Management Model (SWMM 5.0) is a largely mechanistic, onedimensional (longitudinal) dynamic rainfall-runoff model that links climate, land use, and surface and subsurface hydrologic processes (Rossman, 2010). The model primarily computes urban runoff quantity and can estimate quality (potential pollutant loads) based on land use- and pollutant-specific event mean concentrations (EMCs), which represents the average pollutant concentration (i.e., total pollutant mass divided by total runoff volume) during a storm event (USEPA, 1983; Huber \& Dickinson, 1988). Since a comprehensive documentation of SWMM 5.0 developments and application can be found in Rossman (2010) and Gironás et al. (2010), we provide a brief overview here.

SWMM conceptualizes a drainage system as a series of water and material flows between four major environmental compartments of "Atmosphere", "Land surface", "Transportation", and "Groundwater" (Figure 3.4). The atmosphere compartment includes rain gage objects to represent rainfall inputs and evapotranspiration. Spatial variation in rainfall can be represented by assigning different rain gages to different sub catchments. Spatial variation in evapotranspiration (ET) cannot be incorporated in EPA SWMM 5.0 and are assumed to be the same over the model area. Monthly average (inch/day) evapotranspiration data can be incorporated into the model. The model assumes constant daily evapotranspiration for each month and divides the ET according to the time step chosen. The land surface compartment is represented through one or more subcatchment objects that receive precipitation from the atmospheric compartment as rain (and/or snow), allowing infiltration into the groundwater compartment and 
sending surface runoff and pollutant loadings to the transport compartment. Each subcatchment of the land surface compartment is treated as a nonlinear reservoir; inflow can also come from designated upstream subcatchments. Reservoir outflows include infiltration, evapotranspiration, and surface runoff. Reservoir capacity represents the maximum depression storage, which is the ultimate surface storage provided by ponding, surface wetting and interception. Surface runoff occurs only when the depth of water in the reservoir exceeds the maximum depression storage; the outflow is computed by using Manning's equation. The components (e.g., drainage networks) of the transport compartment are modeled as a series of nodes (typically representing large changes in hydraulic head or channel cross section) connected by links (e.g., open channels). The flow in the conduits (i.e., links) is routed using steady flow, kinematic wave or dynamic wave routing. Dynamic Wave routing is the most powerful of the flow routing methods as it solves the complete one-dimensional Saint Venant equations of flow for the entire conveyance network and was chosen for our study. However, each of these routing methods employs the Manning equation to relate flow rate to flow depth and bed (or friction) slope. SWMM models groundwater with aquifer objects using a simple approach (Rossman, 2010). The groundwater compartment receives infiltration from the land surface compartment and dynamically interacts with transport compartment. A threshold groundwater elevation must be reached before any flow occurs. In our model we set the value equal to receiving nodes invert elevation. The groundwater level is dynamically updated by linear transfer due to difference in hydraulic head. This approximation of groundwater flow is reasonable given storm runoff in a highly urbanized area is mainly a surface process, which is rigorously parameterized by SWMM. 


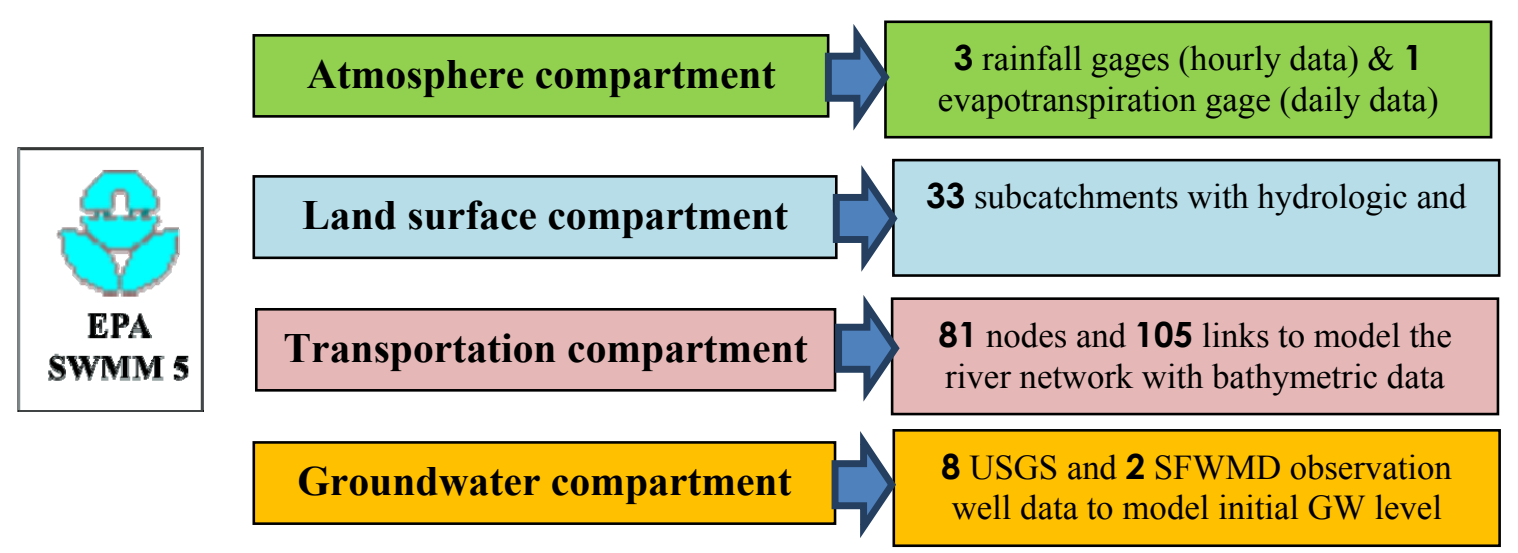

Figure 3.4: Summary of dataset preparation and SWMM model development.

We considered 33 subbasins, 81 nodes, and 105 links to properly represent the land uses, topography, and drainage network of the Miami Basin (Figure 3.4). Land uses in each subbasins were aggregated under five categories: (i) open lands and parks, (ii) single family residential, (iii) multi-family residential, (iv) commercial, and (iv) industrial areas. Since our objective was to determine the basin-scale sensitivity of the total potential stormwater runoff (rather than the actual flooding on the ground), we did not explicitly incorporate management infrastructures such as catch-basins or underground sewers in model development. Instead, we assumed stormwater from the individual subbasins and their temporary retentions (e.g., catch-basin) will eventually flow into the drainage canals, which were represented in the model by a network of nodes and links. Each subbasin was associated with the closest of the three rainfall stations and eight groundwater wells.

The developed SWMM model was constrained by observed time-series of canal discharges at four gauging stations as the boundary conditions (Figure 3.2) and run in an hourly time-step, simulating the surface runoff in each subcatchment and discharges at all 
the nodes on drainage canals. The total stormwater generated for the Miami Basin was computed by summing the runoffs of all subbasins at each time-step. The hourly, basinscale stormwater flow rates (volume per time) were aggregated to compute total monthly and annual stormwater (in volume units), which were later used for determining stormwater sensitivity in the Basin. Hourly simulated discharges (volume per time) were averaged to compute the mean daily discharges at two calibration stations (Figure 3.2). We estimated the potential pollutant load rates (in units of mass per time) from each subbasin by multiplying the simulated hourly runoff with a pollutant-specific event mean concentration (EMC) (Table 3.1), the EMCs for six pollutants (e.g., total suspended solids, total nitrogen, total phosphorus, copper, zinc and biochemical oxygen demand) are obtained from published literature based on existing land uses (Migliaccio \& Castro, 2009) The hourly load rates of all subbasins were aggregated to compute potential monthly and annual pollutant loads (in mass units) for determining load sensitivities to hydro-climatic and land use/cover variations.

Table 3.1: Event mean concentrations (EMCs) used for the Miami River Basin.

\begin{tabular}{llllllll}
\hline \multirow{2}{*}{$\begin{array}{l}\text { Land use } \\
\text { category }\end{array}$} & TN & TP & BOD & TSS & Cu & Pb & Zn \\
\cline { 2 - 8 } $\begin{array}{l}\text { Single family } \\
\text { residential }\end{array}$ & 2.07 & 0.327 & 7.9 & 37.5 & 0.016 & 0.004 & 0.062 \\
\hline $\begin{array}{l}\text { Multi- family } \\
\text { residential }\end{array}$ & 2.32 & 0.520 & 11.3 & 77.8 & 0.009 & 0.006 & 0.086 \\
\hline Commercial & 2.4 & 0.345 & 11.3 & 69.7 & 0.015 & 0.005 & 0.160 \\
\hline Industrial & 1.2 & 0.26 & 7.6 & 60 & 0.003 & 0.002 & 0.057 \\
\hline $\begin{array}{l}\text { Parks and open } \\
\text { lands }\end{array}$ & 3.47 & 0.616 & 5.1 & 94.3 & 0.013 & 0.003 & 0.021 \\
\hline
\end{tabular}




\subsubsection{Model calibration}

The model was calibrated using the mean daily flow data for 2010 at the Miami River (S26) and the Tamiami Canal (S-25B) stations (Figure 3.5). For evaluating calibration performance, the Nash-Sutcliffe Efficiency (NSE) (Nash and Sutcliffe, 1970), RMSEobservations standard deviation ratio (RSR) and correlation coefficient (r) were chosen. The NSE measures the goodness of fit and approaches unity if the simulation is perfectly representing the observation. If the efficiency becomes negative, model predictions are worse than a prediction performed using the average of all observations. The NashSutcliffe model efficiency coefficients for S-26 (Miami River station) and S-25B (Tamiami station) were, respectively, 0.89 and 0.55 , which is satisfactory for calibration with daily observed flow. RSR is calculated as the ratio of the RMSE and standard deviation of measured data. A RSR value of 0 indicates a perfect model with 0 RMSE. Any RSR value in the range of 0 to 0.5 is considered very good. A model with RSR higher than 0.7 is unsatisfactory (Moriasi, 2007). The RSR values for S-26 and S-25B were 0.33 and 0.68 accordingly, which indicates calibration is very good for S-26 and satisfactory for S-25B. The relatively lower value of $\mathrm{S}-25 \mathrm{~B}$ can be attributed to the portion of Tamiami Canal watershed within the model domain for which overland flow was not considered. The correlation coefficient (r) was 0.98 for S-26 and 0.93 for S-25B, which indicates strong linear correspondence between observed and predicted flow rates at both stations. The application of upstream and downstream boundary conditions and calibration with measured data ensured a realistic model response to the hydro-climate, watershed, and land use/cover variables. 


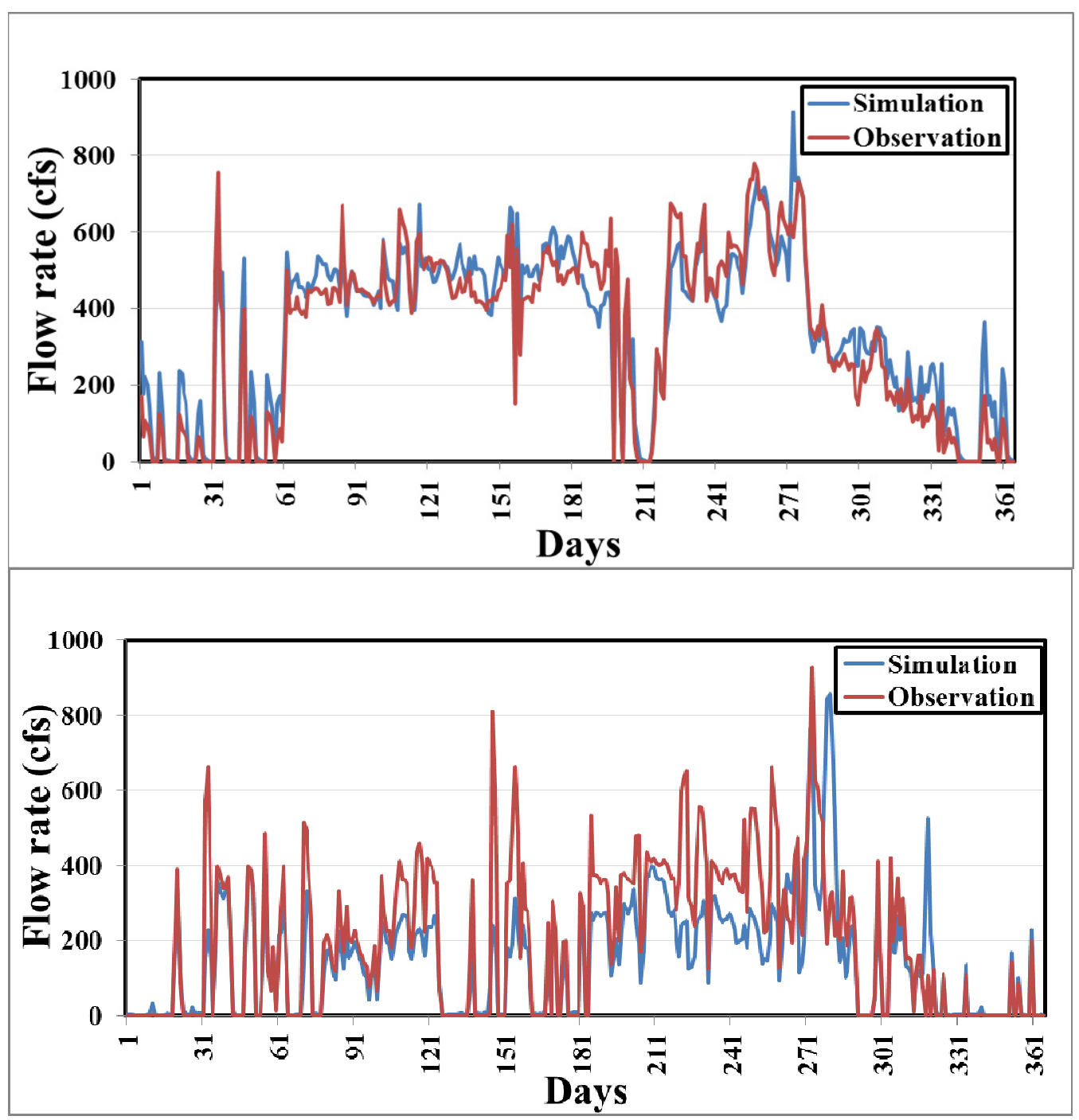

Figure 3.5: Daily calibration for 2010 at S-26(top) and S-25B stations (bottom).

\subsubsection{Definition of sensitivity coefficients}

The changes in predicted stormwater runoff and potential pollutant loads for any changes in model parameters and variables can be determined by defining sensitivity coefficients, which shows both the magnitude and direction (i.e., increase or decrease) of model responses. Following Abdul-Aziz et al. (2010), we defined the dimensionless, relative sensitivity coefficients $\left(S^{*}\right)$ as below. 


$$
S^{*}=\frac{\Delta \mathrm{M} / \mathrm{M}}{\Delta \mathrm{P} / \mathrm{P}}
$$

Where $\Delta \mathrm{P} / \mathrm{P}$ represents the percent change in model parameters (or input variables) and $\Delta \mathrm{M} / \mathrm{M}$ represents the corresponding percent change in model response (i.e., percent changes in predicted runoff or pollutant loads).

Relative sensitivity coefficients of stormwater runoff and potential pollutant loads were computed by changing one parameter at a time for quantifying model responses to variations in hydrologic, climate, and land use parameters and variables. Percent changes in runoff and pollutant loads in each month were calculated for up to $25 \%$ change in each parameter. The $25 \%$ change is considered as a reference for this scenario based analysis so that model responses to different parameters can be compared on a common perturbation basis. The variation of model sensitivity over a year was reflected by the range between maximum and minimum value of sensitivity coefficient for each parameter. Mean annual sensitivity was presented by the annual sensitivity coefficients, which were computed by dividing the percent changes of annual runoff (or pollutant loads) by the specified changes in model parameters/variables.

\subsubsection{Parameters of concern}

We computed relative sensitivity coefficients of stormwater runoff and potential pollutant loads for five hydrologic and two climate parameters/variables and nine land use conversions (Table 3.2). The parameters were selected based on relevance to storm water generations in the Miami Basin (Al-Amin and Abdul-Aziz, 2013) after carefully 
reviewing the parameterization and methodological details in Storm Water Management Model (SWMM 5).

Table 3.2: Parameters of concern for sensitivity analysis.

\begin{tabular}{lll}
\hline Stressor & Parameter & Range \\
\hline & & $0.01-2.32^{\mathrm{a}}$ \\
Climate & Rainfall & $0.00-3.34^{\mathrm{b}}$ \\
& & $0.00-1.57^{\mathrm{c}}$ \\
& Evapotranspiration & $0.37-0.66^{\mathrm{d}}$ \\
\hline \multirow{3}{*}{ Land use } & Single family residential areas & $8-96 \%$ \\
& Multi-family residential areas & $2-100 \%$ \\
& Industrial areas & $4-34 \%$ \\
& Commercial areas & $5-100 \%$ \\
& Open lands and parks & $2-100 \%$ \\
\hline \multirow{3}{*}{ Hydrology } & Slope & $0.0002-0.0054$ \\
and land cover & Imperviousness & $5-85.65 \%$ \\
& Poughness & 0.04 \\
& Percentage routed from impervious to pervious areas \\
& Percentage impervious with zero storage & $25 \%$ \\
\hline
\end{tabular}

${ }^{a}$ Hourly precipitation in station 19332 , ${ }^{b}$ hourly precipitation in station K8673, ${ }^{c}$ hourly precipitation in station MIA, ${ }^{\mathrm{d}}$ monthly evapotranspiration

The hydrologic parameters of percentage of runoff routed from impervious areas to pervious areas before reaching outlet and percentage of impervious areas with zero storage represent management practices. When the runoff from the impervious surface is routed across the pervious surface, the runoff is subjected to infiltration and depression storage in the pervious sub-area. Routing from impervious to pervious areas, therefore, can be used to implicitly model Low Impact Development (LID) controls. Impervious areas with zero storage accounts for immediate runoff that occurs at the beginning of rainfall before depression storage is satisfied. It represents pavement close to the gutters that has no surface storage, pitched rooftops that drain directly to street gutters, new pavement that may not have surface ponding, etc. (Gironás et al., 2010). Nine land use 
conversions among the five land use types were evaluated as follows: open lands and parks to (i) single family residential, (ii) multi-family residential, (iii) industrial, and (iv) commercial areas; single family residential to (v) multi-family residential, (vi) industrial, and (vii) commercial areas; and multi-family residential to (viii) industrial, and (ix) commercial areas.

\subsection{RESULTS}

Using the calibrated SWMM model outputs, we computed the dimensionless, monthly and annual sensitivity coefficients of total potential storm runoff and loads of six pollutants(total suspended solids, total nitrogen, total phosphorus, copper, zinc and biochemical oxygen demand) in response to climate, land uses/cover, and hydrologic variations in the Miami Basin. Although the computed sensitivity coefficients (Eq. 1) can be used to estimate model responses to any changes (increases or decreases) in parameters or variables, we report here the percent changes in runoff and pollutant loads caused by an increase in model parameters and variables as examples.

\subsubsection{Climate sensitivities}

During the model calibration year of 2010, the Miami Basin received lower rainfalls from October to January and higher rainfalls during March to September (Figure 3.5). December and January received the least rainfalls, while September experienced the highest rainfall amounts. The temporal variation of precipitation, in concert with resulting soil saturation, appeared to have caused differential sensitivities of potential stormwater runoff in the basin (Figure3.6). For each month, runoff increased almost linearly with an increase in rainfall. However, percent changes in runoff per changes (\%) in parameter 
(i.e., slope of the sensitivity curves) were much steeper for November and December; Rainfall was increased for the model by increasing rainfall depth (keeping the number of rainfall days unchanged). Therefore, although November and December received very low rainfall, the rainfall events in these months were concentrated in 3-4 days only. A plausible explanation of these higher sensitivities is that soil was already saturated and depression storages were filled due to higher rainfalls in the current or the previous days. Drier months (e.g., January, February) with evenly distributed precipitation showed less change in runoff as initial portion of precipitation was used to saturate the soil and/or fill the depressions first, for each rainfall event.

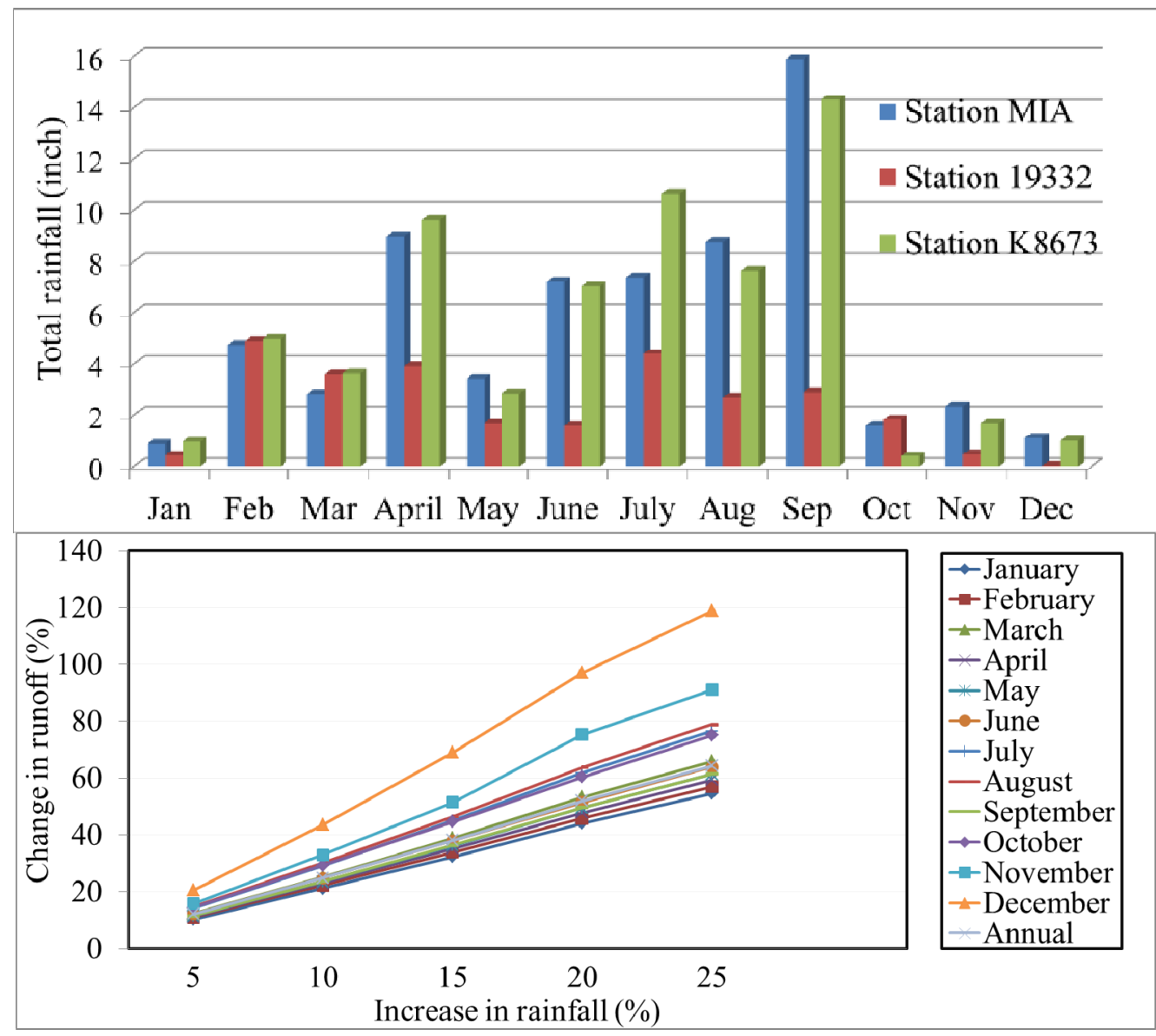

Figure 3.6: Monthly rainfall variation in the Miami River Basin, Florida (top) and Predicted changes in runoff for changes in rainfall in Miami Basin (bottom). 
A comparison of the two major climatic components (i.e., rainfall and evapotranspiration) showed opposite effects on runoff sensitivities. With an increase of $25 \%$ in rainfall and evapotranspiration (ET), annual runoff, respectively, increased by $64 \%$ and decreased by $39 \%$. Rainfall, as expected, was the most dominant driver for runoff. The temporal variation for change in rainfall was also higher compared to that in ET (which is strongly driven by solar radiation and temperature), indicating that temporal variations of stormwater were dictated by rainfall variability rather than by variations in temperature and/or solar radiation. Overall, rainfall had around 50\% stronger leverage than ET on stormwater runoff generation in the basin.

A change in climatic components can lead to varying levels of atmospheric deposition of the pollutants, causing variations in pollutant generation processes. Pollutant transport can also change due to the varied amount of generated runoff. However, the parameterization in SWMM does not include the atmospheric deposition; since we used an EMC based modeling approach, the climate sensitivities of six pollutants (total suspended solids, total nitrogen, total phosphorus, copper, zinc and biochemical oxygen demand) were found to be same as that of storm runoff.

\subsubsection{Hydrologic and land cover sensitivities}

Runoff increased linearly at different, but intriguing monthly sensitivity rates with increasing imperviousness in the Miami Basin (Figure 3.7). For example, increasing imperviousness from $10 \%$ to $25 \%$ led to the highest increases of $5 \%$ to $24 \%$ in October runoff and the lowest increases of $0.5 \%$ to $2 \%$ in December and January runoffs, although these months received similar amounts of rainfall (Figure 3.7). In contrast, 
much higher rainfall months such as September, August, July, and April showed an intermediate level of runoff sensitivities for the same changes in imperviousness. The temporal variation of precipitation, in concert with resulting soil saturation, appeared to have caused differential sensitivities of potential stormwater runoff in this case, as well. But unlike change in precipitation, here the differential sensitivities were influenced by the number of rainfall days in the current or previous months (as rainfall depths were unchanged here). Higher sensitivity was observed for months where an increase in imperviousness caused early soil saturation and filling up of depression storages due to higher rainfalls in the current or the previous months. Overall, the annual runoff increased by around 3 to $10 \%$ for a 5 to $25 \%$ increase in soil imperviousness in the Basin (Figures 3.6).

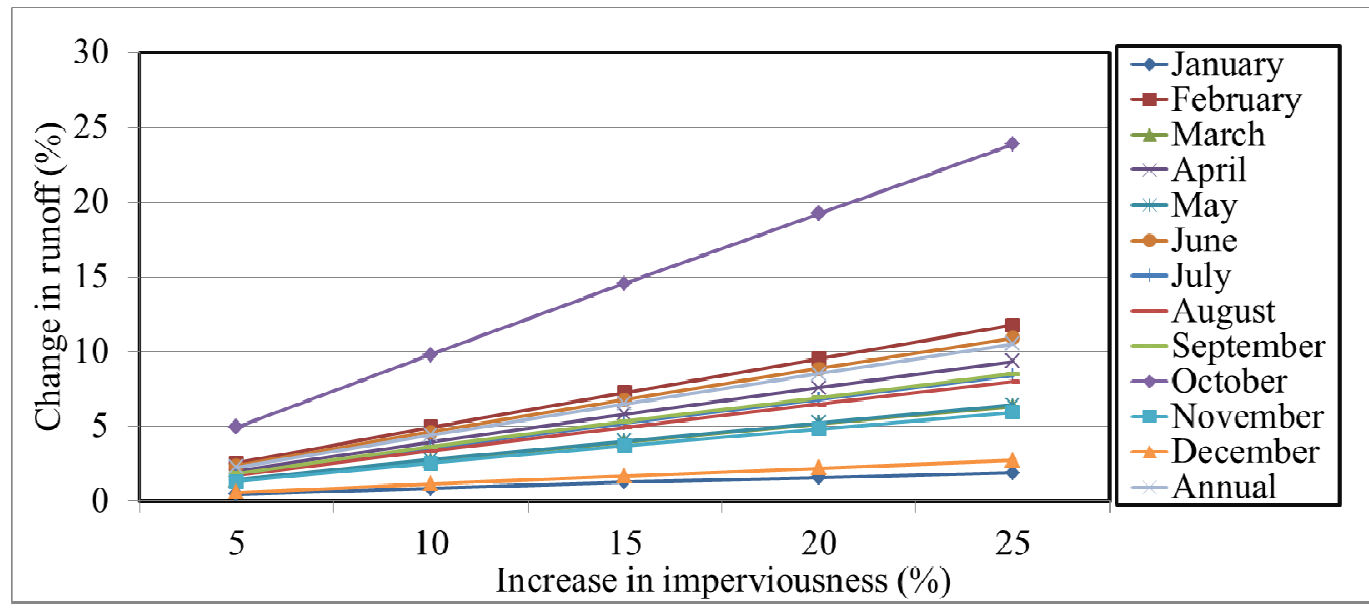

Figure 3.7: Predicted changes in runoff for increase in imperviousness of the Miami Basin.

Among different hydrologic and land cover parameters, watershed imperviousness and slope had positive impacts on runoff generation (Figure 3.8). On average, monthly runoff increased by around $8 \%$ and $10 \%$ for a $25 \%$ increase in imperviousness and slope, 
respectively. The lower runoff changes for slope can be attributed to the relatively flat topography in the Miami Basin. Roughness had a strong negative impact on potential runoff, leading to an average decrease of $13 \%$ in monthly runoff for a $25 \%$ increase in roughness (e.g., greening through plantations and landscaping). Runoff also exhibited high temporal variability to changes in imperviousness and roughness. The parameters of percent impervious area with zero storage (accounts for immediate runoff that occurs at the beginning of rainfall before depression storage is satisfied) and percent runoff routed from impervious to pervious areas before reaching outlet (accounts for higher infiltration and depression storage in the pervious sub-area) can represent conventional management practices on land covers in a watershed. Increasing the percent runoff routed by $25 \%$ decreased the monthly runoff by $25 \%$, while runoff was nearly insensitive to changes in percent imperviousness with zero storage reemphasizing the insignificant presence $(0.08 \%$; see Table 3.1) of this management practice in the Miami Basin. These two parameters contributed no temporal variability in runoff due to their time-invariable representations in the SWMM model. Variations in hydrologic and land cover components can also change the pollutant generation and transport. However, since we modeled the potential pollutant loads using relevant EMCs, which depend on land uses rather than land cover, hydrologic and land cover sensitivities of pollutants were found to be nearly identical to that of runoff. 


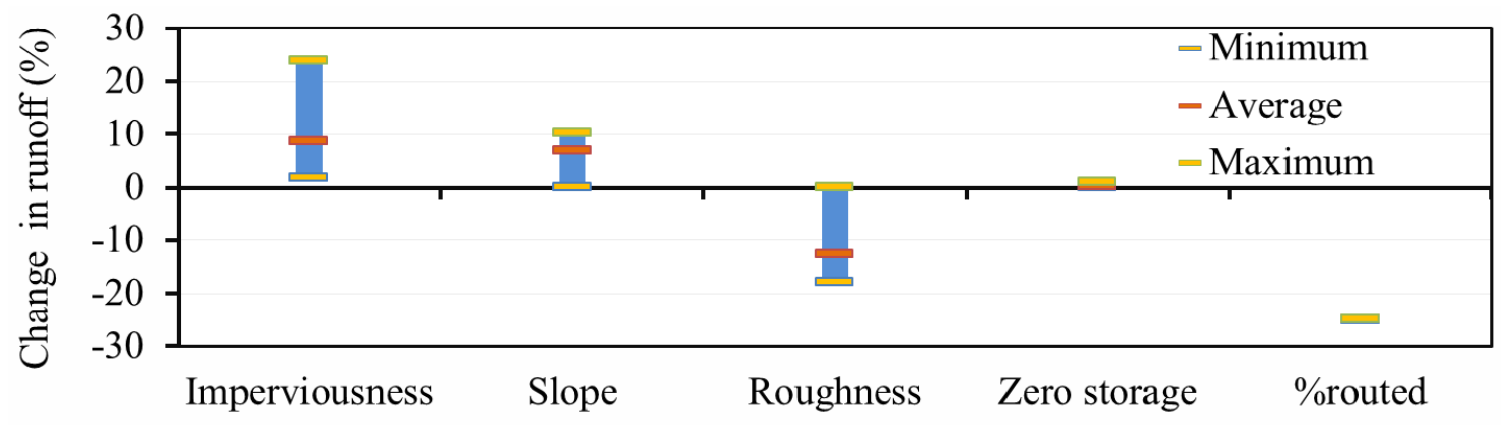

For $25 \%$ increase in parameters

Figure 3.8: Comparison of the effects of hydrologic and land cover components on runoff in the Miami Basin.

\subsubsection{Land use sensitivities}

\subsubsection{Land use sensitivities of runoff}

Land use conversions contributed a change in runoff generation due to the difference in imperviousness associated with each land use type in the Storm Water Management Model (EPA SWMM 5). Percentage change in runoff due to a $25 \%$ conversion of each considered land use was compared (Figure 3.9). Conversion of open lands (25\%) to industrial area caused highest change in runoff (6.5\%) followed by commercial $(6.0 \%)$, residential multi-family (5.5\%) and residential single family areas (5\%).

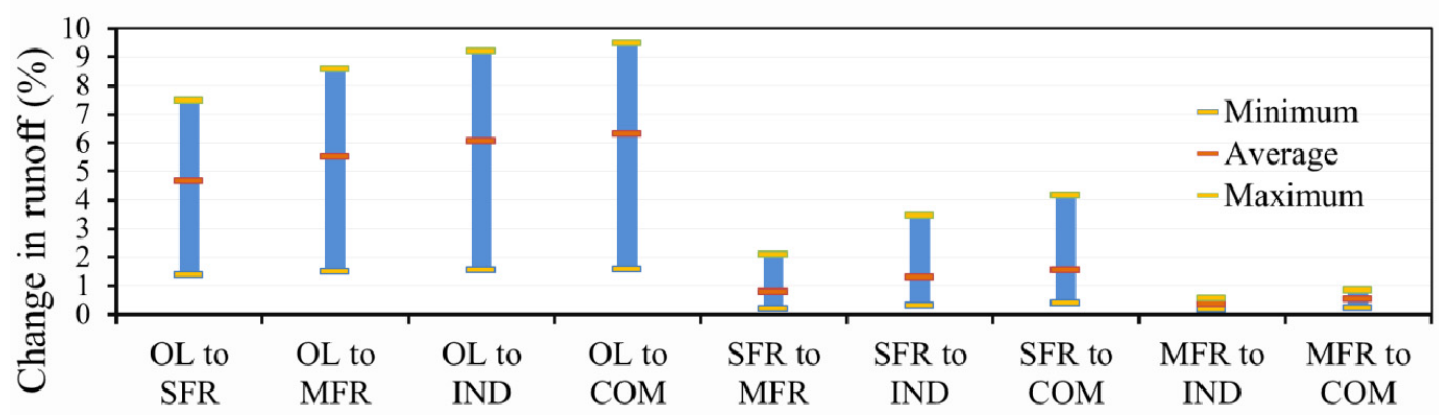

For $25 \%$ increase in parameters

Figure 3.9: Comparison of the effects of land use conversions on runoff in the Miami Basin $(\mathrm{OL}=$ Open lands and parks, $\mathrm{SFR}=$ Single family residential, $\mathrm{MFR}=$ Multi-family residential, $\mathrm{IND}=$ industrial, $\mathrm{COM}=$ commercial areas). 
Conversion of single family residential areas to multi-family residential areas (1\%), commercial areas $(1 \%)$ and industrial areas $(2 \%)$ produced little changes in runoff. The temporal variability for single family residential area conversions was smaller than that of conversions of open lands. Conversion of multi-family residential areas to industrial and commercial areas caused a change in runoff less than $1 \%$. In comparison to climatic and hydrologic parameters, runoff showed less sensitivity to land use parameters. The conversion of open lands to other land use types was found to be most dominant land use conversion for runoff.

\subsubsection{Land use sensitivities of pollutants}

Sensitivities of pollutant loading and runoff were not similar for land use conversions (Table 3.3). Change in runoff due to a change in imperviousness is coupled with the change in Event Mean Concentrations (EMCs) due to land use conversions. The pollutant loading, therefore, varies based on the total runoff generated and the corresponding changes in concentrations.

\section{Total suspended solids (TSS)}

The EMC values are highest for total suspended solids in single family residential areas followed by multi-family residential, commercial and industrial areas. The imperviousness, on the other hand, is higher for industrial areas followed by commercial, multi-family and single family residential areas. Conversion of single residential to multi-family residential, commercial or industrial areas, therefore, produced higher runoff at a lower concentration. So, whether there would be a decrease or increase in terms of TSS loading in runoff, was determined by two factors; change in runoff and change in 
EMC associated with change in land use types. For Miami River Watershed, change in runoff was more dominant and therefore, TSS loading increased in all land use conversions of open lands and single family residential areas (Table 3.3).

\section{Nutrients}

In our study, the nutrients (total nitrogen and total phosphorus) showed highest sensitivity to land use conversions. For total nitrogen, The EMC's were highest for open lands and parks followed by commercial, multi-family residential, single family residential and industrial areas. For total phosphorus, EMC was higher for multi-family residential than commercial. Except for few monthly runoffs for conversion to multi-family residential areas, total nutrient in runoff increased for all the conversion of open lands and parks. Conversion of multi-family residential to industrial areas produced higher runoff with a lower concentration which led to an overall decrease in nutrient loading.

\section{Biochemical oxygen demand (BOD)}

EMC for BOD is highest for multifamily residential and commercial areas followed by single family, industrial and open lands and parks. All the land use conversions increased the BOD generation except conversion of multi-family residential areas to industrial areas. BOD loading in the later was governed by an increase in concentrations whereas for the others BOD loading was dominated by an increase in runoff. 
Table 3.3: Percentage (\%) change in parameters due to a $25 \%$ conversion among the land use types of Miami River Basin.

\begin{tabular}{|c|c|c|c|c|c|c|c|c|c|c|}
\hline 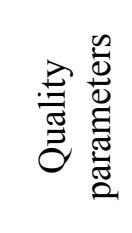 & $\begin{array}{l}\text { Change in } \\
\text { quality } \\
\text { parameters }\end{array}$ & $\begin{array}{l}\text { Open land } \\
\text { to single } \\
\text { family } \\
\text { residential }\end{array}$ & $\begin{array}{l}\text { Open land } \\
\text { to multi- } \\
\text { family } \\
\text { residential }\end{array}$ & $\begin{array}{c}\text { Open } \\
\text { land to } \\
\text { industrial }\end{array}$ & $\begin{array}{c}\text { Open land } \\
\text { to } \\
\text { commercial }\end{array}$ & $\begin{array}{l}\text { Single } \\
\text { family to } \\
\text { multi- } \\
\text { family } \\
\text { residential }\end{array}$ & $\begin{array}{l}\text { Single } \\
\text { family } \\
\text { residential } \\
\text { to } \\
\text { industrial }\end{array}$ & $\begin{array}{c}\text { Single } \\
\text { family } \\
\text { residential } \\
\text { to } \\
\text { commercial }\end{array}$ & $\begin{array}{l}\text { Multi- } \\
\text { family } \\
\text { residential } \\
\text { to } \\
\text { industrial }\end{array}$ & $\begin{array}{c}\text { Multi- } \\
\text { family } \\
\text { residential } \\
\text { to } \\
\text { commercial }\end{array}$ \\
\hline \multirow{3}{*}{ TSS } & Average & 4.2 & 5.7 & 5.8 & 6.4 & 2.9 & 2.4 & 3.2 & -0.9 & 0.3 \\
\hline & Maximum & 7.0 & 9.1 & 9.4 & 9.9 & 3.9 & 4.4 & 5.6 & -0.2 & 0.6 \\
\hline & Minimum & 1.0 & 1.2 & 1.3 & 1.3 & 1.2 & 0.9 & 1.2 & -2.2 & -0.1 \\
\hline \multirow{3}{*}{$\mathrm{TN}$} & Average & 5.4 & 6.5 & 6.6 & 7.5 & 1.2 & 0.1 & 2.1 & -0.8 & 0.6 \\
\hline & Maximum & 8.8 & 10.4 & 10.5 & 11.7 & 2.5 & 2.4 & 4.8 & -0.3 & 1.0 \\
\hline & Minimum & 1.0 & 1.1 & 1.1 & 1.2 & 0.4 & -0.9 & 0.6 & -1.5 & 0.3 \\
\hline \multirow{3}{*}{$\mathrm{TP}$} & Average & 5.2 & 5.3 & 6.5 & 7.2 & 2.3 & 0.3 & 1.9 & -1.4 & -0.4 \\
\hline & Maximum & 8.7 & 8.7 & 10.7 & 11.3 & 3.5 & 2.8 & 4.6 & -0.4 & 0.2 \\
\hline & Minimum & 1.0 & -1.0 & 1.1 & 1.2 & 0.8 & -1.0 & 0.4 & -2.7 & -1.3 \\
\hline \multirow{3}{*}{ BOD } & Average & 4.1 & 5.3 & 5.1 & 6.0 & 2.1 & 1.2 & 3.0 & -1.1 & 0.6 \\
\hline & Maximum & 6.7 & 8.4 & 8.3 & 9.3 & 3.3 & 3.4 & 5.5 & -0.4 & 0.9 \\
\hline & Minimum & 1.1 & 1.2 & 1.2 & 1.3 & 0.9 & 0.2 & 1.1 & -2.2 & 0.3 \\
\hline \multirow{3}{*}{$\mathrm{Cu}$} & Average & 5.4 & 4.6 & 5.3 & 7.3 & -0.7 & -4.4 & 1.7 & 1.1 & 0.5 \\
\hline & Maximum & 8.5 & 7.4 & 8.1 & 11.0 & 1.2 & -1.2 & 4.6 & 2.0 & 0.8 \\
\hline & Minimum & 1.2 & 1.3 & 1.3 & 1.4 & -2.5 & -5.9 & 0.4 & 0.3 & 0.3 \\
\hline \multirow{3}{*}{$\mathrm{Zn}$} & Average & 3.7 & 4.4 & 4.3 & 6.4 & 1.6 & 1.2 & 6.2 & -0.7 & 3.6 \\
\hline & Maximum & 6.2 & 7.2 & 7.1 & 10.0 & 2.8 & 3.5 & 8.1 & -0.2 & 5.6 \\
\hline & Minimum & 1.0 & 1.1 & 1.1 & 1.2 & 0.2 & 0.2 & 3.2 & -1.4 & 1.7 \\
\hline
\end{tabular}




\section{Metals}

For copper $(\mathrm{Cu})$, EMC was highest for commercial areas followed by single family residential, multi-family residential and industrial areas where as for zinc (Zn), EMC was highest for commercial areas followed by multi-family residential, single family residential and industrial areas. As previous, change in $\mathrm{Cu}$ and $\mathrm{Zn}$ was also runoff controlled and $\mathrm{Cu}$ and $\mathrm{Zn}$ generation from the watershed increased for all the open land and park conversions. Conversion of single family residential areas reduced $\mathrm{Cu}$ generation in most of the months. Conversion of multi-family residential areas to industrial areas reduced $\mathrm{Zn}$ generation, too.

The annual sensitivity coefficients are representatives of an average condition for the entire year. Annual sensitivity coefficient for rainfall (2.56) was higher than evapotranspiration (-0.83). The annual sensitivity coefficient for rainfall was 2.56 implies that for $1 \%$ change in rainfall runoff would change by $2.56 \%$ in the Miami River Basin. Although these sensitivity coefficients were obtained for $1 \%$ change in parameters, they can be used to calculate changes in runoff and pollutants for any percentage of change in parameters by applying appropriate multiplying factors. Imperviousness (0.42) and roughness $(-0.47)$ were important hydrologic and land cover sensitivities. Percentage of impervious area with zero storage, which signifies management practices showed very low sensitivity $(0.003)$. Percentage routed from impervious area to pervious area before reaching outlet showed very strong sensitivity $(-1.00)$. 
Table 3.4: Summary of annual sensitivity coefficients for runoff and quality in Miami Basin.

\begin{tabular}{llllllll}
\hline \multirow{2}{*}{ Parameters } & \multicolumn{6}{c}{ Annual sensitivity coefficients for 25\% change in parameters } \\
\cline { 2 - 8 } & Runoff & TSS & TN & TP & BOD & Cu & Zn \\
\hline $\begin{array}{l}\text { Open land to } \\
\text { single family residential }\end{array}$ & 0.22 & 0.2 & 0.26 & 0.25 & 0.24 & 0.26 & 0.17 \\
\hline $\begin{array}{l}\text { Open land to multi-family } \\
\text { residential }\end{array}$ & 0.27 & 0.28 & 0.32 & 0.29 & 0.30 & 0.22 & 0.21 \\
\hline Open land to industrial & 0.29 & 0.28 & 0.32 & 0.32 & 0.29 & 0.25 & 0.21 \\
\hline Open land to commercial & 0.31 & 0.31 & 0.37 & 0.35 & 0.33 & 0.36 & 0.31 \\
\hline $\begin{array}{l}\text { Single family to multi- } \\
\text { family residential }\end{array}$ & 0.04 & 0.12 & 0.05 & 0.10 & 0.14 & -0.02 & 0.08 \\
\hline $\begin{array}{l}\text { Single family residential to } \\
\text { industrial }\end{array}$ & 0.06 & 0.11 & 0.00 & 0.02 & 0.10 & -0.18 & 0.06 \\
\hline $\begin{array}{l}\text { Single family residential to } \\
\text { commercial }\end{array}$ & 0.07 & 0.15 & 0.10 & 0.09 & 0.18 & 0.08 & 0.27 \\
\hline $\begin{array}{l}\text { Multi-family residential to } \\
\text { industrial }\end{array}$ & 0.02 & -0.03 & -0.03 & -0.04 & 0.01 & 0.04 & -0.02 \\
\hline $\begin{array}{l}\text { Multi-family residential to } \\
\text { commercial }\end{array}$ & 0.02 & 0.01 & 0.03 & -0.01 & 0.07 & 0.02 & 0.12 \\
\hline
\end{tabular}

Conversion of open lands and parks to residential, commercial or industrial areas showed highest sensitivity which reemphasizes the need for up-gradation of management strategies and drainage infrastructure to counteract the increased runoff and pollutant generation corresponding to these conversions. Although the land use conversions among single family and multifamily residential areas to commercial or industrial areas did not show much sensitivity, these conversions might be crucial from individual pollutants perspective. For example, conversion of residential areas to commercial or industrial areas might increase $\mathrm{Zn}$ loading to surface water bodies and have detrimental effects on aquatic lives in a watershed. The sensitivities of pollutants, therefore, need careful consideration from watershed perspectives. 


\subsubsection{Combined hydro-climatic sensitivities}

The relative sensitivity analysis showed that imperviousness and roughness are the most important hydrologic parameters. Increased imperviousness is a consequence of urbanization and causes shorter lag time and high runoff (Shuster et al., 2005). Increased roughness, on the other hand, increases lag time and decreases runoff (Darboux \& Huang, 2005). We analyzed the effects of increasing imperviousness and roughness under an increasing rainfall to examine watershed responses under combined hydro-climatic changes. Unlike the relative sensitivity analysis, the combined sensitivity analysis was undertaken by changing both the climate (rainfall) and hydrologic parameters (imperviousness and roughness) simultaneously. Change in runoff was analyzed for 5\% increment in both climate and hydrologic parameters. For ease of visualization, change in runoff for a change of parameters up to $20 \%$ is presented.

\subsubsection{Combined sensitivity to rainfall and imperviousness}

As previous, runoff increased linearly with an increase in rainfall and with an increase in imperviousness (Figure 3.10). However, increase in runoff due to increase in rainfall was much higher than for increase in imperviousness. 


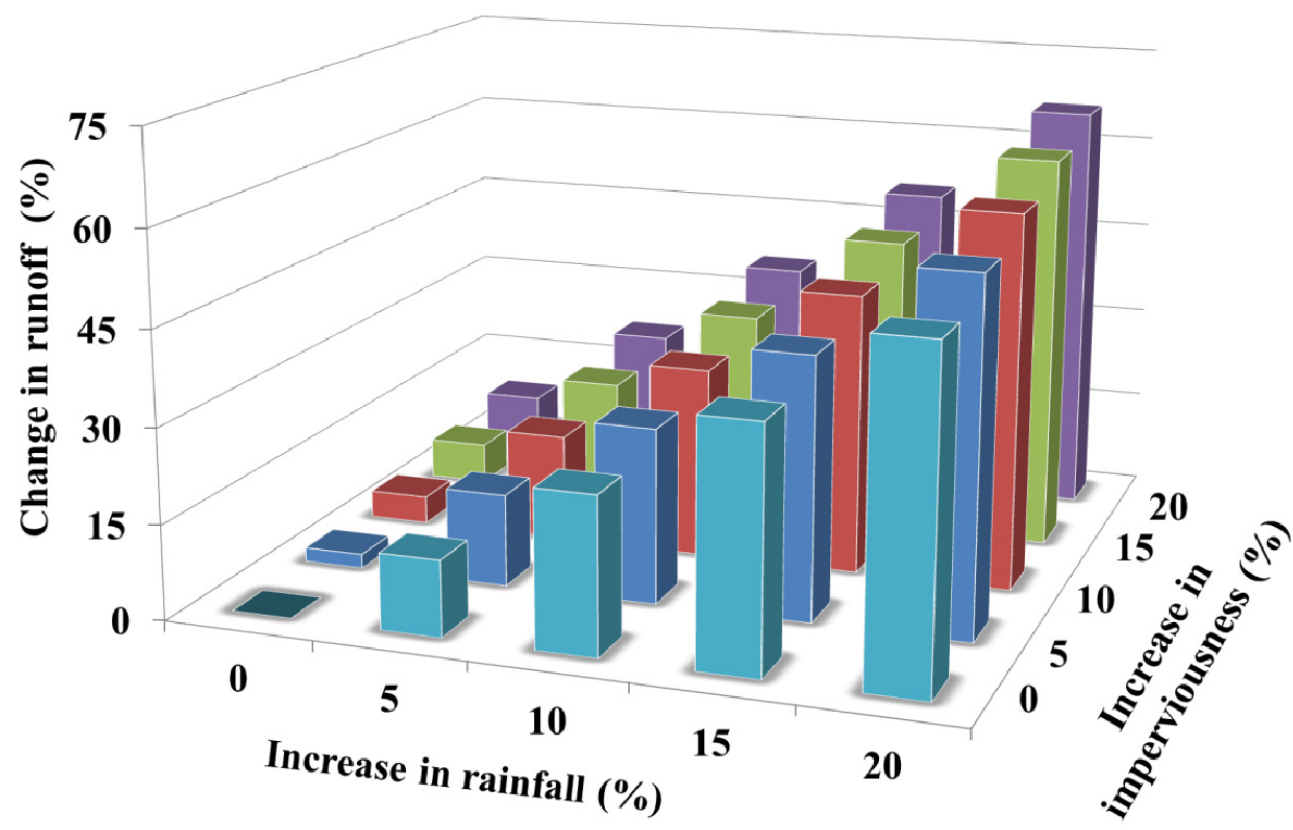

Figure 3.10: Comparison of the combined effects of changes in rainfall and imperviousness on runoff in Miami Basin.

The change in runoff under combined hydro-climatic changes was not entirely linear. For a $20 \%$ increase in rainfall, runoff increased by $52 \%$. For $20 \%$ increase in imperviousness, runoff increased by $8.5 \%$. But, when both rainfall and runoff were increased by $20 \%$, runoff increased by $66 \%$, which is higher than sum of their individual contributions $(60 \%)$. The synergic effect of simultaneous increase in rainfall and imperviousness, therefore, can be significantly different than the projected standalone impacts of changing climate or growing urbanization. The management strategies developed without due consideration of this effect poses risk of overlooking a considerable margin (10\%) which may led to an insufficient or ineffective arrangement to counteract stormwater runoff and quality. 


\subsubsection{Combined sensitivity to rainfall and roughness}

An increase in surface roughness increases lag time and possibility of infiltration due to higher residence time. An increase in roughness, therefore, decreases surface runoff (Figure 3.11). When roughness was increases by $20 \%$ in the model, runoff decreased by $10 \%$. On the other hand, when rainfall was increased by $20 \%$, runoff increased by $52 \%$. But when both rainfall and roughness were increased by $20 \%$, runoff increased by $39 \%$. The change in runoff is also different than their individual linear contributions (42\%).

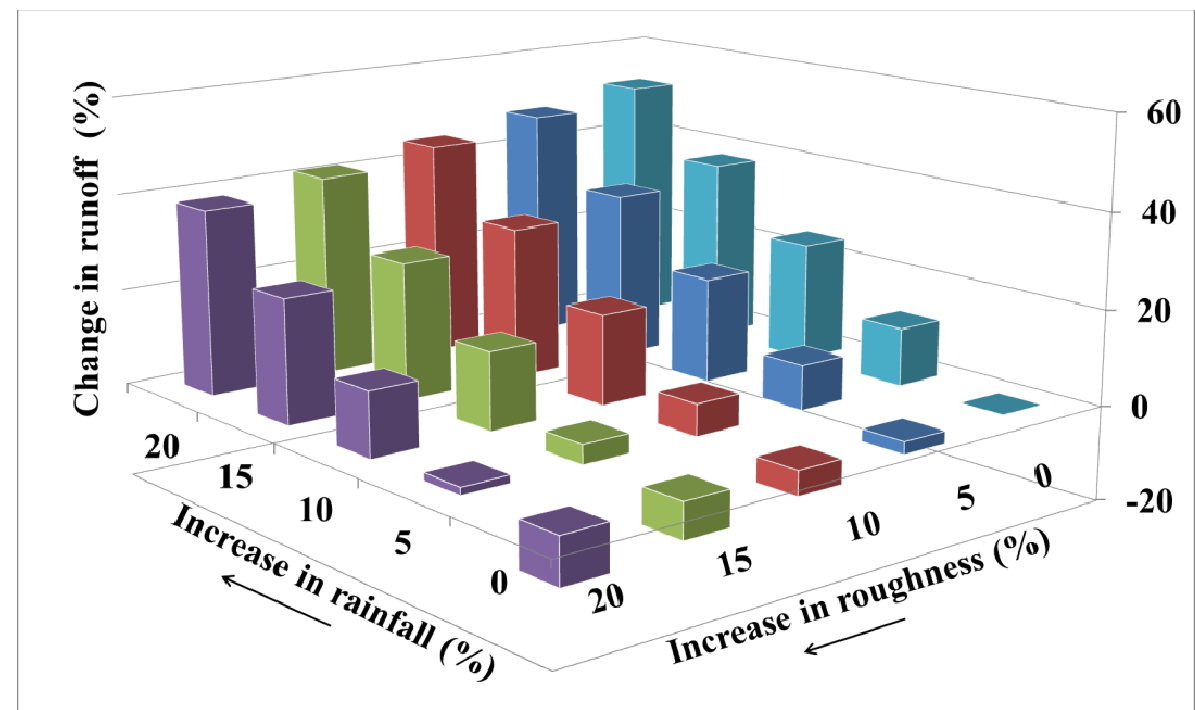

Figure 3.11: Comparison of the combined effects of changes in rainfall and roughness on runoff in Miami Basin.

The results are in line with our previous findings for imperviousness. The surface roughness showed higher utility in minimizing runoff and effectively brought down the runoff by almost $8 \%$ under the combined effect of climate. The non-linear response of stormwater runoff under combined hydro-climatic changes emphasizes needs for further research and due consideration in scenario based stormwater management approaches. 


\subsubsection{Combined climatic and land use sensitivities}

In the relative sensitivity analysis, it was observed that conversion of open lands and parks to residential, commercial and industrial areas were most dominant land use changes for stormwater runoff and pollutant generation. Since conversion to industrial and commercial areas showed close sensitivities, we analyzed the combined climatic and land use sensitivities for conversion of open lands and parks to residential and commercial areas only. Analyses of changes in pollutants were also minimized to four pollutants (i.e., TSS, TN, CU and DO) to address the four major categories of pollutants observed in relative sensitivity analyses. Changes in runoff were not included as the changes would take place due to the varying amount of impervious areas, which was discussed in a previous section. Climate was dominant over land use conversions in the combined analysis also (Fig 3.12 and Table 3.5). For a 20\% increase in rainfall, TSS increased by $52.8 \%$. The increases in $\mathrm{TN}(52 \%), \mathrm{Cu}(52 \%)$ and DO (53\%) were similar. On the other hand, for a $20 \%$ conversions of open lands and parks to residential areas, the increase in pollutants were very small (TSS (5\%), TN (6\%), $\mathrm{Cu}(4 \%)$ and DO (5\%)).

Interestingly, when rainfall was increased by $20 \%$ and $20 \%$ of open lands and parks were converted to residential areas simultaneously, changes in TSS $(60 \%), \mathrm{TN}(61.5 \%), \mathrm{Cu}$ (59\%), DO $(60 \%)$ were higher than the summation of their individual contributions (TSS (58\%), TN (58\%), $\mathrm{Cu}(56.5 \%)$, DO (57\%)). 

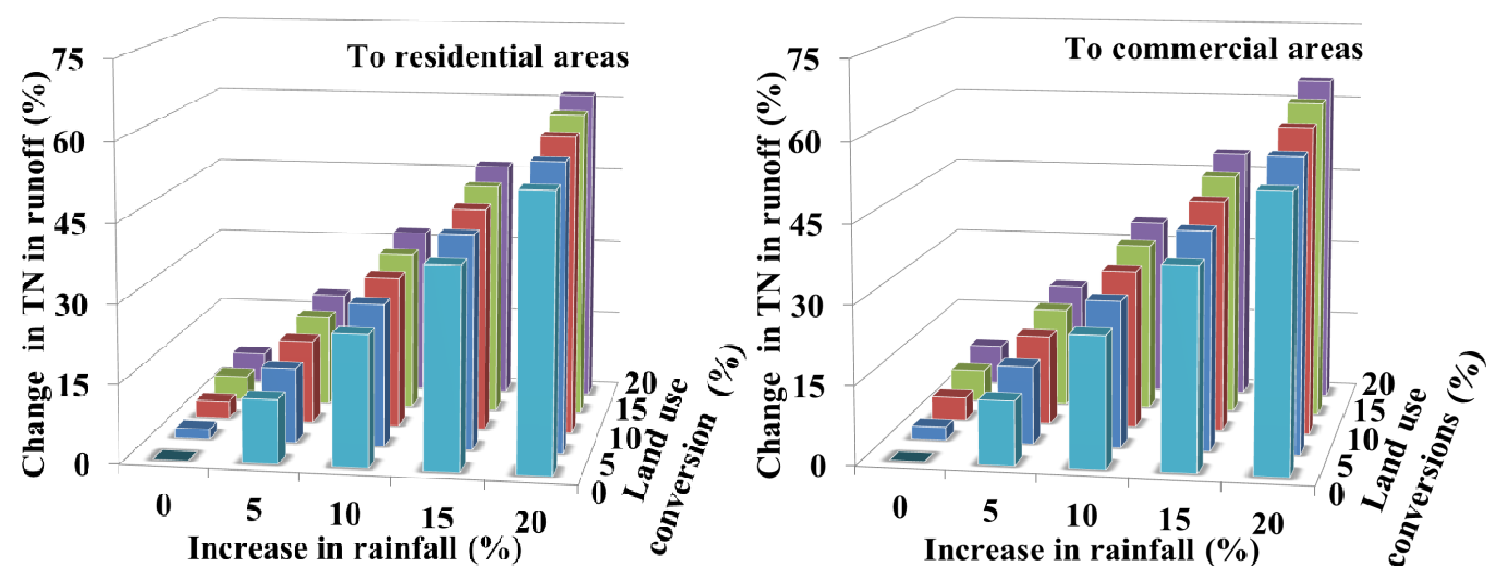

Figure 3.12: Comparison of the combined effects of changes in rainfall and land use (conversion of parks and open lands) on potential total nitrogen load in Miami Basin.

Similar results were also found for conversion of open lands and parks to commercial areas. When rainfall was increased by $20 \%$ and simultaneously $20 \%$ of open lands and parks were converted to commercial areas, changes in TSS (63\%), TN (64\%), $\mathrm{Cu}(64 \%)$, DO $(62 \%)$ were higher than the summation of their ( rainfall and conversion of land use) individual contributions (TSS (59\%), TN (60\%), Cu (60\%), DO (59\%)). In general, Total Nitrogen (nutrients) was most sensitive to combined climate and land use changes. Conversion of open lands and parks to commercial areas produced more pollutants than conversion to residential areas. The results are in line with the relative sensitive analysis. The difference of pollutant generations under combined climate and land use changes require more in details research. 
Table 3.5: Comparison of the combined effects of changes in rainfall and land use on potential pollutant loads in Miami Basin.

\begin{tabular}{|c|c|c|c|c|c|c|c|c|c|c|c|c|c|c|c|c|c|c|c|c|}
\hline \multirow{3}{*}{$\begin{array}{c}\text { Increase } \\
\text { in } \\
\text { rainfall }\end{array}$} & \multicolumn{19}{|c|}{ Conversion of open lands and parks to residential areas } & \\
\hline & \multicolumn{4}{|c|}{$\mathbf{0 \%}$} & \multicolumn{4}{|c|}{$5 \%$} & \multicolumn{4}{|c|}{$10 \%$} & \multicolumn{4}{|c|}{$15 \%$} & \multicolumn{4}{|c|}{$20 \%$} \\
\hline & $\Delta \mathrm{TSS}$ & $\Delta \mathrm{TN}$ & $\Delta \mathrm{Cu}$ & $\Delta \mathrm{DC}$ & $\Delta \mathrm{TSS}$ & $\Delta \mathrm{TN}$ & $\Delta \mathrm{Cu}$ & $\Delta \mathrm{DO}$ & $\Delta \mathrm{TSS}$ & $\Delta \mathrm{TN}$ & $\Delta \mathrm{Cu}$ & $\Delta \mathrm{DO}$ & $\Delta \mathrm{TSS}$ & $\Delta \mathrm{TN}$ & $\Delta \mathrm{Cu}$ & $\Delta \mathrm{DO}$ & $\Delta \mathrm{TSS}$ & $\Delta \mathrm{TN}$ & $\Delta \mathrm{Cu}$ & $\Delta \mathrm{DO}$ \\
\hline $0 \%$ & 0.0 & 0.0 & 0.0 & 0.0 & 1.5 & 1.9 & 0.8 & 1.3 & 2.7 & 3.4 & 2.0 & 2.5 & 3.9 & 4.7 & 3.1 & 3.6 & 4.9 & 5.9 & 4.1 & 4.6 \\
\hline $5 \%$ & 12.3 & 12.2 & 12.2 & 12.3 & 13.9 & 14.3 & 13.1 & 13.7 & 15.4 & 16.1 & 14.1 & 15.1 & 16.6 & 17.5 & 15.7 & 16.3 & 17.8 & 18.8 & 16.8 & 17.4 \\
\hline $10 \%$ & 25.2 & 25.0 & 25.1 & 25.2 & 27.0 & 27.3 & 26.0 & 26.8 & 28.6 & 29.3 & 27.6 & 28.3 & 31.0 & 30.9 & 28.9 & 29.6 & 31.3 & 32.4 & 30.2 & 31.0 \\
\hline $15 \%$ & 38.7 & 38.4 & 38.5 & 38.7 & 40.7 & 41.0 & 39.6 & 40.5 & 42.4 & 43.1 & 41.3 & 42.1 & 44.0 & 45.0 & 42.8 & 43.7 & 45.5 & 46.7 & 44.2 & 45.1 \\
\hline $20 \%$ & 52.8 & 52.4 & 52.4 & 52.8 & 54.9 & 55.2 & 53.6 & 54.8 & 56.9 & 57.6 & 55.5 & 56.6 & 58.6 & 59.7 & 57.2 & 58.2 & 60.2 & 61.5 & 58.7 & 59.8 \\
\hline \multirow{3}{*}{$\begin{array}{c}\text { Increase } \\
\text { in } \\
\text { rainfall }\end{array}$} & \multicolumn{19}{|c|}{ Conversion of open lands and parks to commercial areas } & \\
\hline & \multicolumn{4}{|c|}{$0 \%$} & \multicolumn{4}{|c|}{$5 \%$} & \multicolumn{4}{|c|}{$10 \%$} & \multicolumn{4}{|c|}{$15 \%$} & \multicolumn{4}{|c|}{$20 \%$} \\
\hline & $\Delta \mathrm{TSS}$ & $\Delta \mathrm{TN}$ & $\Delta \mathrm{Cu}$ & $\Delta \mathrm{DC}$ & $\Delta \mathrm{TSS}$ & $\Delta \mathrm{TN}$ & $\Delta \mathrm{Cu}$ & $\Delta \mathrm{DO}$ & $\Delta \mathrm{TSS}$ & $\Delta \mathrm{TN}$ & $\Delta \mathrm{Cu}$ & $\Delta \mathrm{DO}$ & $\Delta \mathrm{TSS}$ & $\Delta \mathrm{TN}$ & $\Delta \mathrm{Cu}$ & $\Delta \mathrm{DO}$ & $\Delta \mathrm{TSS}$ & $\Delta \mathrm{TN}$ & $\Delta \mathrm{Cu}$ & $\Delta \mathrm{DO}$ \\
\hline $0 \%$ & 0.0 & 0.0 & 0.0 & 0.0 & 1.9 & 2.5 & 2.3 & 1.7 & 3.6 & 4.5 & 4.3 & 3.3 & 5.1 & 6.2 & 6.0 & 4.6 & 6.4 & 7.7 & 7.4 & 5.9 \\
\hline $5 \%$ & 12.3 & 12.2 & 12.2 & 12.3 & 14.4 & 15.0 & 14.8 & 14.2 & 16.3 & 17.2 & 17.0 & 15.9 & 18.0 & 19.2 & 18.9 & 17.5 & 19.4 & 20.8 & 20.6 & 19.0 \\
\hline $10 \%$ & 25.2 & 25.0 & 25.1 & 25.2 & 27.6 & 28.1 & 27.9 & 27.4 & 29.7 & 30.7 & 30.4 & 29.3 & 31.5 & 32.8 & 32.5 & 31.0 & 33.2 & 34.7 & 34.4 & 32.7 \\
\hline $15 \%$ & 38.7 & 38.4 & 38.5 & 38.7 & 41.3 & 41.8 & 41.7 & 41.1 & 43.7 & 44.7 & 44.4 & 43.2 & 47.1 & 47.1 & 46.8 & 45.1 & 47.6 & 49.2 & 48.9 & 47.0 \\
\hline $20 \%$ & 52.8 & 52.4 & 52.4 & 52.8 & 55.7 & 56.1 & 55.9 & 55.4 & 58.2 & 59.2 & 58.9 & 57.8 & 61.9 & 61.9 & 61.5 & 59.9 & 62.6 & 64.3 & 63.9 & 62.0 \\
\hline
\end{tabular}




\subsection{DISCUSSION}

Limited availability of data is a major constraint in the development of stormwater models. Generally, Stormwater models are, therefore, developed for small catchments and single storm events. In contrast, we have used long-term, continuous climate, hydrologic, and sea level data to elucidate seasonal, as well as annual, responses of stormwater runoff to changes in climate and hydrologic drivers. Since the model explored the stormwater responses in a watershed scale, the results might not be accurate enough in smaller sub catchment scales, but water balance of the total watershed is preserved, and the objective of evaluating stormwater runoff and quality sensitivity in watershed scale is well served.

The selection of the calibration parameter for Storm Water management model (EPA SWMM 5.0) depends on the objectives of the study and the data availability (Tsihrintzis \& Hamid, 1998). Selection of parameters for calibration, therefore, varied in literature. For example, Bedient and Huber (1988) estimated the catchment area, imperviousness, slope, Manning's n, pervious and impervious depression storage and Green-Ampt parameters. Jewell et al. (1978) used the percentage imperviousness as the main calibration parameter for volume and Manning's $\mathrm{n}$, and the characteristic width for peak adjustment. Warwick and Tadepalli (1991) concluded that detail in model representation was not significant in calibration, and percentage imperviousness as the single calibration parameter was more useful than pervious depression storage. However, recent developments in impervious area calculations (Han \& Burian, 2008) have facilitated accurate prediction of impervious areas in watersheds. For our study, therefore, 
impervious area is a set parameter and the calibration was based on roughness (Manning's n) and groundwater parameters. The Nash-Sutcliffe model efficiency coefficients (NSE) for calibration against daily observed flow at S-26 and S-25B were 0.89 and 0.55 . The RMSE- standard deviation ratio (RSR) for the two stations were 0.33 (very good) and 0.68 (satisfactory), as well. The application of upstream and downstream boundary conditions and calibration with measured data ensured a realistic model response to the hydro-climate, watershed, and land use/cover variables. In a previous study (Dotto et al., 2010), the NSE varied between -0.04 to 0.46 for TSS and between -0.38 to 0.36 for TN . Due to unavailability of quality data at appropriate boundaries and time scale, we could not incorporate observed water quality data in our model. Instead, Event Mean Concentrations (EMCs) from published literature based on existing land uses, (Migliaccio \& Castro, 2009) were incorporated. Site-specific data for water quality, measured at the boundaries and calibration points, would have improved the model performance.

Land use conversions and associated landscape modification significantly affects the watershed hydrogeology. According to literature, runoff was most sensitive to the imperviousness (Jewell et al., 1978) among hydrologic parameters. Roughness (Manning's $\mathrm{n}$ ) and the characteristic width influences the shapes and peaks of the predicted hydrographs. In another study (Tsihrintzis \& Hamid, 1998), the impervious depression storage (IDS) was the most sensitive parameter, followed by the roughness (Manning's n), the Green-Ampt infiltration parameters and the pervious depression storage (PDS). In our study too, runoff showed profound sensitivity to imperviousness 
and percentage routed from pervious to impervious areas, followed by roughness. One novel contribution of our study is that we have not only evaluated the individual sensitivity of each parameters but also identified the range over which the sensitivity varied in different months. The study this way took care of the seasonal variation of the sensitivity coefficients in a watershed scale.

The synthesis of precipitation (rainfall depth and duration) with catchment properties (e.g., topology, land cover and soil condition) controlled the runoff characteristics in the watershed. According to literature, changes in rainfall were always amplified in runoff, the amplification being greater in drier catchments (Chiew et al., 1995). Nearing et al, (2005) reported that relative change in runoff (sensitivity) was higher for small storms while absolute change (total runoff) was higher for larger storms. In a different context, we also found highest sensitivity of runoff in drier months (Figure 3.6) when the precipitation was concentrated in smaller durations. The sensitivity was lowest for drier months when precipitation was distributed. For wet periods, precipitation was evenly distributed and sensitivity was moderate. This emphasizes the need for separate management strategies based on rainfall intensity and duration. Controlled urban landscaping (e.g., grass lawns in residential areas and grass strips along the pavements, topologic modification to guide runoff in block scale) can be effective for counteracting the short duration high intensity dry period precipitations that produces sudden increase in runoff. Developments of catch basins and drainage infrastructure should be aimed at the long duration wet period precipitation events which produces larger volume of runoff. 
The model predictions were compared to field observations of stormwater quality data. Maestre and Pitt (2006) analyzed significant factors ( e.g., The EPA rain zone, percentage of imperviousness, land use, type of conveyance, controls in the watershed, sample analysis method, and type of sampling procedures) affecting stormwater quality using the National Stormwater Quality Database. It was observed that TSS, TP and $\mathrm{Cu}$ concentration in stormwater runoff was higher in summer and fall than in winter and spring. In our study too, the model predicted higher pollutant generation in wet period that receives most of the precipitations (April to September). The model prediction of a decrease in pollutant generation with an increase of imperviousness was also verified against the observations in this study. The development and application of mechanistic model for stormwater quality is restrained by the availability of data of appropriate frequency in a watershed scale. However, the model provides useful information for stormwater quality and its sensitivity to hydro-climatic parameters and land use conversions in complex urban watershed.

Runoff was most sensitive to climate under combined climate-land use changes in a previous study (Legesse et al., 2003). A 10\% decrease in the daily rainfall amount yearround caused an average annual decrease in runoff at the outlet of about $30 \%$ in the tropical Africa. In our study, analyzing a different land use and hydrologic regime, we found a change of $24 \%$ in runoff corresponding to a $10 \%$ increase in rainfall. The study (Legesse et al., 2003) also considered a scenario based land use change of forest to short crops (50\% of the total catchment area) and observed an increase in evapotranspiration of about $2.5 \%$ and a decrease in the mean annual river flow of about $8 \%$ with respect to the 
actually simulated value. In our study, we found less sensitivity to changes of open lands and parks to residential (5\%) and commercial (6.5\%) areas. This was expected as Miami River Basin is highly urbanized and the base percentage of open lands and parks are relatively lower. In another study (Tu, 2009), the change in stream flow under both climate and land use change scenarios was found consistent to that under only climate change scenario. In our study also, we found smaller differences (compared to combined hydro-climate affect) between response of runoff to simultaneous climate and land use changes to the arithmetic summation of their individual changes. However, the responses of runoff under combined hydro-climatic changes were significantly different than arithmetic summation of their individual contributions. Urbanization (increasing imperviousness) caused higher increase in runoff (from its standalone impact by $10 \%$ ) whereas roughness caused higher decrease in runoff (from its standalone impact by $8 \%$ ) under the synergic effect of climate (rainfall). The non-linear response of stormwater runoff under combined hydro-climatic changes emphasizes needs for further research and due consideration in scenario based stormwater management approaches.

Although we differentiated land use parameters from hydrologic and land cover parameters, a change in either of these two, will simultaneously change the others. For example, changing open lands and parks to residential or commercial areas will automatically change the landscapes and will change the slope, imperviousness and roughness of a watershed. Since, conclusive correlations are yet to be made between land uses and land cover parameters, the parameterizations in most commonly used models do not take care of their mutual dependency. Therefore, we differentiated land use 
parameters from land cover parameters to identify their relative roles. The changes in land uses thus should be interpreted in terms of changes in imperviousness and pollutant generation only. All the analyses in this study were also undertaken under the assumption of constant drainage density. With changes in climate and land use, the drainage density is expected to be revised and upgraded. However, this study analyzed runoff and pollutant generations from the source perspective. The objective was to compare the runoff and pollutant generation and need for drainage infrastructures and density upgradation. The assumption of constant drainage density is, therefore, satisfactory.

The EMC based stormwater quality modeling approach in this study revealed small differences in sensitivity for different pollutants. According to literature, the dominant factors that control pollutant generation in a watershed are different. Hence, the sensitivity analyses for stormwater quality need further research. Empirical relationships based on the data driven models of a particular hydro-climatic regime can be fit into this models to analyze sensitivities more coherently to their contributing stressors. Although all the stormwater models are based on existing knowledge of the pollutant generation and runoff processes, their parameterization varies significantly. The results, thus, should be carefully considered keeping the parameterization of SWMM in mind. An uncertainty analysis can be helpful to accommodate the variability of the sensitivities of stormwater runoff and pollutants.

\subsection{CONCLUSIONS}

We quantified sensitivities of stormwater runoff and quality to hydro-climatic and land use parameters in complex urban-coastal watersheds. The temporal variation of 
precipitation, in concert with resulting soil saturation, appeared to have caused differential sensitivities of runoff in different months in the watershed. Stormwater runoff in the complex urban basin showed the greatest sensitivity to rainfall (stronger responses in the drier winter months). Among the hydrologic parameters, imperviousness and roughness showed relatively stronger influence than slope. Higher increase in runoff and pollutants resulted from conversion of open lands/agricultural to residential, commercial or industrial areas. Conversion among residential, commercial, and industrial land uses showed much less changes. The combined sensitivity analyses showed that the change in runoff and pollutants under simultaneous hydro-climatic or climate-land use changes were significantly different than the arithmetic summation of their individual contributions.

The quantified climate and land use sensitivity is useful for appropriate management of stormwater quantity and quality in complex urban watersheds under changing climate, sea level, hydrology, and land use/cover. Although the research considered the Miami River Basin as a pilot study area, it can provide important insights for appropriate management of stormwater runoff and quality in complex urban coastal environments around the world. For example, the results reemphasize that decreasing imperviousness, as well as increasing roughness and percentage routed from impervious to pervious areas can be effective ways of stormwater runoff management, echoing the call for a greener urban planning. In particular, inclusion of grass lawns in residential, commercial and industrial areas, as well as adding grass strips alongside the pavements can be relatively low-impact means for stormwater runoff and pollution control in the Miami Basin. 
Watershed slope can be adjusted at the local scale (e.g., subbasin or block level) through landscaping, leading stormwater to flow and infiltrate in lawns and grass covers. The temporal variation in sensitivities can provide a guideline for seasonal management strategy developments for efficient utilization of time and money. The model is not limited to short-term, event-based applications; rather we used long-term, continuous climate, hydrologic, and sea level data to elucidate seasonal, as well as annual, responses of stormwater runoff and quality to changes in climate and hydrologic drivers.

A comparison with similar watershed scale models developed in some of the other parts of the world with similar climate and land use features will be helpful for comparing the robustness of the model prediction. Similar watershed scale models can be developed for different hydro-climatic regimes to assess stormwater sensitivity and assist stormwater management. It will also be interesting to see the model response in connection with some of the regional climate models (RCM) for assessing future stormwater runoff and quality under changing climate and land use scenarios (Rehfeldt et al., 2012; Terando et al., 2012). Considering the availability of quality data, development of empirical models with similar approaches including hydro-climatic and land use parameters, might be useful for understanding major drivers in stormwater runoff and quality. 


\section{CHAPTER 4}

\section{IDENTIFICATION OF DOMINANT ENVIRONMENTAL STRESSORS AND THEIR RELATIVE INFLUENCE ON STREAM WATER QUALITY IN COMPLEX COASTAL URBAN WATERSHEDS}

\subsection{INTRODUCTION}

Human and ecological use of in-stream water depends on ambient water quality. Human alterations of the landscape has an extensive influence on watershed hydrology (Claessens et al., 2006; Chang, 2007), pollutant loadings (Kang, 2010), and heat budget (Oke, 1987) that subsequently increases in-stream water temperature (Nelson \& Palmer, 2007). The surface water-groundwater interactions (Jolly, 2008) and seawater intrusion (Rahman, 2010) can also affect the hydrology and pollutant loadings, particularly in coastal streams. All these factors can modify in-stream biogeochemical processes that drive dissolved oxygen, nutrient, sediment cycling, and ultimately the stream food webs (Baker, 2003; Abdul-Aziz, 2008; Abdul-Aziz et al., 2010). Therefore, identifying spatial and temporal changes in water quality (Chang, 2008), as well as linking stream water quality to land use patterns (Kang, 2010) in river basins, have been a major research focus for decades.

Much research has been undertaken to quantify the role of anthropogenic activities and natural contributions to pollutant generations in stream water. Noteworthy research includes that on the Frome River in U.K. (Hanrahan et al., 2003), the Struma River in Bulgaria (Astel et al., 2007) and northern Greece (Simeonov et al., 2003), the Lake Tahoe 
Basin in U.S.A. (Stubblefield et al., 2007), the Han River in South Korea (Chang, 2008), the Amu Darya River in Central Asia (Crosa et al., 2006), the Bagmati River in Nepal (Kannel et al., 2007), the Stream Zerede in Brazil (Alves et al., 2009), and the Florida Gulf Coast streams (Chelsea Nagy et al., 2012). Results from these studies revealed the multi-dimensional aspects (e.g., influence of drainage density, snow and glacier melt, irrigation, river discharge, biological activity etc.; classification in stream pollution zones; seasonal and temporal variability) of stream water quality deterioration.

Watershed land uses, as proxies of anthropogenic activities, can a play pivotal role to shape stream water quality. Using multiple linear regression and constraint least squares regression techniques, Kang et al. (2010) reported strong links of land use types with metal and coliform concentration in rivers. Tran et al. (2010) used proximity analysis to measure relative role of near land use and far land use in stream water quality. They concluded that at the watershed zone of influence, water quality indicators did not correlate significantly with land cover type. Dissolved oxygen values within the 200-m buffer zone varied inversely with the percentage of urban-land cover. Raogsta et al. (2010) reported strong associations between riparian canopy cover, presence or absence of cattle, rainfall, solar radiation, month of year, dissolved oxygen, turbidity, salinity, and enterococcus concentrations in riparian surface soils. Butler et al. (2011) demonstrated synergies between water quality regulations (community, tourists, tour operators and fishermen) and floodplain recreational and commercial fisheries (fishermen), identifying trade-offs and thresholds between services and associated stakeholders. 
Surface water-groundwater interaction is also believed to be a mean of trade off of pollutants between these two sources. Cardenas (2008) proposed a mechanistic foundation and explanation for temporal fractal stream chemistry through surface watergroundwater exchange across bed forms, bars and bends, and basins characteristics. Stedmon et al. (2011) developed a potential approach for monitoring drinking water quality from groundwater systems using organic matter fluorescence as an early warning for contamination events using parallel factor analysis (PARAFAC). Rozemeijer (2011) proposed a method of direct measurements of the tile drain and groundwater contributions to surface water contamination by using field-scale concentration patterns in groundwater and catchment-scale surface water quality. Reay et al. (1992) analyzed groundwater discharge and associated nitrate concentration in coastal environments, reporting higher groundwater contributions near shore at low tide periods and markedly decreasing contributions with increasing distance offshore (towards the coast).

More recent research focused on the complex interactions of surface water, groundwater, and seawater intrusion. Viezzoli et al. (2011) developed a quasi-3D interpretation of the airborne electromagnetics outcome by a spatially constrained inversion method, distinguishing different hydrogeological features down to a depth of about $200 \mathrm{~m}$. Akbar et al. (2011) applied multivariate statistical techniques for assessing surface water quality at the Mid-Black Sea Coast of Turkey and quantified dissolved salts from soil leaching and runoff process. Groundwater was to be endangered by salt water encroachment due to lateral intrusion of present sea water and up-coning of connate salt water trapped in paleodeltaic sediments (Barrocu \& Dahab, 2011). Developing a coupled groundwater- 
surface water model, Sonnenborg et al. (2012) reported significant climate Although much research (e.g., Varol \& Sen, 2009; Singh et al., 2004) investigated the combined effect of different stressors on stream water pollutions, the relative influence of watershed land uses, surface hydrology, groundwater, seawater carriage of pollutants, and upstream pollutant inflow (i.e., contributions from boundary inputs) on stream water quality is yet to be understood well. Particularly in heavily urbanized, complex coastal environments (e.g., South Florida, U.S.A.), a mechanistic model building to achieve comprehensive insights into stream water quality is challenged by the perplexing complexity in system representation, over parameterizations without much gain in predictive power, and lack of pertinent observational data. In contrast, successful applications of data-driven approaches in hydrology (Govindaraju, 2000; Dibike \& Solomatine, 2001), river temperature modeling (Mohseni et al., 1998), sediment transport (Bhattacharya \& Buraimo, 2003), river stage-discharge relationships (Sudheer \& Jain, 2003), etc. encourage empirical modeling as a viable alternative tool for understanding and predicting stream water quality dynamics in complex urban watersheds. Application of advance statistical techniques such as principal component analysis and partial least squares regression analysis (;were especially useful for constructing empirical models that can describe different pollutant sources (Mahbub et al., 2011) and predict stream water quality using satellite observations (Singh et al., 2013).

The objective of this study is to develop an understanding of relative influence of land uses, surface hydrology, groundwater, seawater, and upstream contributions on the stream and river water quality of six highly urbanized, complex urban watersheds of 
Southeast Florida. We employed correlation analysis to understand the correlations among quality parameters and the change in quality parameters with distance and time. Principle component analysis was also conducted to analyze the mutual correlations of the spatial parameters, as well as, to the quality parameters. Empirical models were developed to explain seasonal stream water quality using multiple land uses, surface hydrologic parameters, groundwater, seawater, and upstream contributions simultaneously. Our findings provide important insights on the dominant environmental stressors and their relative influence in shaping seasonal stream water quality of complex coastal urban watersheds.

\subsection{METHODS AND MATERIALS}

\subsubsection{Site description}

The study basins are mostly located in Broward County of Southeast Florida, U.S.A. (Figure 4.1). It has the Everglades to the west and the Atlantic Ocean to the east. More than 266 miles of primary natural and dredged canals connect these two large aquatic systems and traverse the county's urban corridor. The primary drainage system for Broward County consists of nine major canals and their corresponding drainage basins, as identified by Florida Department of Environmental Protection (FDEP)'s Water Body Identification Number (WBID): Hillsboro Canal (3264), C-14 Canal (WBID 3270), Pompano Canal (WBID 3271), C-13 Canal (Middle River, WBID 3273), C-12 Canal (Plantation, WBID 3276), North New River Canal (WBID 3277), C-11 Canal (South New River, WBIDs 3279 and 3281), C-9 Canal (Snake Creek, WBIDs 3283 and 3284), and the C-10 Canal (Hollywood Canal, WBID 3282) (Cooper \& Lane, 1987). 
The Hillsboro canal drains an area of approximately 102 square miles of which 40 square miles are located in northeastern Broward County and the remaining within the boundaries of southeastern Palm Beach County. The canal's headwaters are in Palm Beach County (Cooper \& Lane, 1987). Four water quality measuring sites were considered for this study from this canal. Site 4 primarily represents water quality discharged to the parts of Hillsboro Canals in Broward County. Site 3 is the central most site. Site 2 represents the final discharge point into the brackish regions of the canal and Site 1 is in the brackish part of the canal.

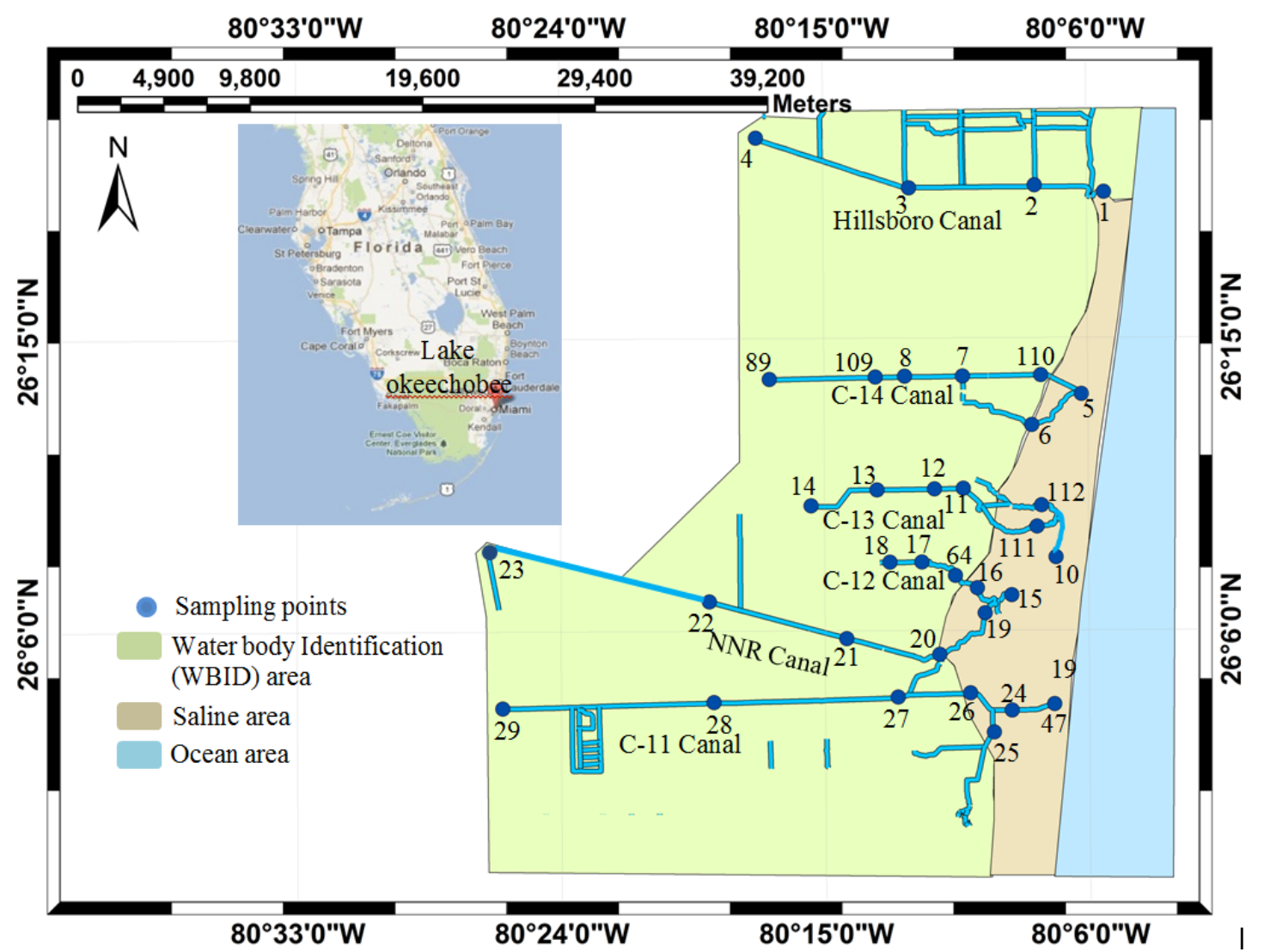

Figure 4.1: Study area in Southeast Florida, U.S.A. Inset showing the state of Florida is not on the stated scale. 
The C-14 Canal (Pompano Canal) Basin is located in northern Broward County and is one of the larger basins with an area of 59 square miles (Cooper \& Lane 1987). Data for seven water quality measuring sites were considered from this canal. Sites 6 and 7 are in the same segment of the waterway continued from C-14, also called the Cypress Creek Canal (Figure 4.1). Site 6 and site 110 are the two easternmost sites and represent water quality that is discharged to the brackish regions. Site 5 is in the brackish region. The C14 Canal has three more sites in the upstream. Site 89 is the furthest upstream quality measuring point that represents quality of water that enters in Broward County through C-14 from its upper part in Everglades. Site 8 and 109 are in the same section of C-14 Canal hydrologically but are physically in separate drainage areas of the overall C-14 Basin.

The C-13 Canal (Middle River Canal) Basin is a medium-sized basin located in northcentral Broward County with an area of 39 square miles (Cooper \& Lane, 1987). Six water quality sites were considered for this study from this canal. Site 14, 13 and 12 are freshwater sites and site 11 represents entrance into the brackish region. Site 111, site 112 and site 10 are in the brackish region. Site 111 is in the segment of waterway also called South Fork Middle River.

The C-12 Basin has a relatively small drainage area of 19 square miles and is located in east-central Broward County (Cooper \& Lane, 1987). The C-12 Basin is unique among the major basins because no temporary or permanent flow originates from the upstream Water Conservation Area (WCA) seepage and water supply to the basin is limited to rainfall (Cooper \& Lane 1987). Overall flow in the canal is basically limited to major 
storm events. A recent study (BCDPEP, 1999) compiled the SFWMD flow estimations for fourteen months and showed that no flow occurred $85 \%$ of the time at Station 33 (not shown in Figure 4.1). From the C-12 Canal, 5 water quality measuring sites were considered for the study. Three of these sites (site 18, site 17 and site 64) are in freshwater and two sites (site 16 and site 15) represent brackish water.

The North New River Canal (NNRC) Basin is a medium-sized drainage area of approximately 30 square miles (Cooper \& Lane, 1987). The North New River Canal was the first in Broward County to connect to Lake Okeechobee (in upstream; see the inset in Figure 4.1) through a series of levees and water control structures. The NNRC connects to the $\mathrm{C}-12$ and the South Fork Middle River as it reaches the estuary. Site 23 represents water quality that enters NNRC in Broward County from its upper portion. Site 22 and 21 are intermediate freshwater sites. Site 20 and 19 are in the brackish region.

The C-11 Canal (South New River Canal) Basin is the largest basin located entirely within the county. It has an area of 100 square miles (Cooper \& Lane, 1987). The C-11 Canal receives flow from the Hollywood Canal as it reaches the estuary (Figure 4.1). Data for seven water quality measuring sites on this canal were available for this study. Site 29 is the most upstream station within Broward County. Site 28 and site 27 are intermediate freshwater sites. Site 26, 24 and 47 are brackish sites with site 47 being the furthest downstream station. Site 25 represents water quality of the incoming flow from the Hollywood Canal. 


\subsubsection{Stream water quality parameters}

The upstream flow from Everglades and wildlife management areas brings a considerable amount of pollutants to the canals in Broward County. The six major canals, along with secondary and tertiary canals, eventually drain eastward to the estuarine areas (e.g., Intracoastal Waterway) at the Atlantic coast. Seawater from the Atlantic Ocean and the underlying Biscayne Aquifer is believed to affect the in-stream geochemical processes (Broward County Environmental Protection Department, 2007). Six water quality parameters (i.e., total nitrogen, total phosphorus, dissolved oxygen, chlorophyll a, salinity, and specific conductivity) were measured by the Broward County Environmental Lab in 44 water quality sites quarterly each year; the data were made available online through the Natural Resources Planning and Management Division (http://www.broward.org/NaturalResources/Lab/Pages/canalwaterquality.aspx; last accessed on 6-16-2013) of Broward County.

Total nitrogen $(\mathrm{TN})$ is the sum of nitrate-nitrogen (NO3-N), nitrite-nitrogen (NO2-N), ammonia-nitrogen (NH3-N) and organically bonded nitrogen. Sources of nitrogen include fertilizer, organic substances (e.g., grass clippings, seeds, flowers, and leaf litters, pruning wastes and tree trimmings from lawns and gardens), nitrogenous compounds released from the soil and plants through volatilization and decomposition processes, pet waste and septic tank, laundry detergents (car washing), vehicle exhaust fumes, etc. In the five canals except C-12 Canal, TN decreased as the canals approached towards the coast. Maximum five year (2006-10) annual average of TN was observed in site 4 (1.71 $\mathrm{mg} / \mathrm{L})$ for Hillsboro Canal, site $89(1.33 \mathrm{mg} / \mathrm{L})$ for C-14 Canal, site $14(1.45 \mathrm{mg} / \mathrm{L})$ for C- 
13 Canal, site $22(1.67 \mathrm{mg} / \mathrm{L})$ in North New River Canal and site $29(1.64 \mathrm{mg} / \mathrm{L})$ in C-11 Canal. In C-12 Canal maximum TN was observed in site $16(1.29 \mathrm{mg} / \mathrm{L})$ which is closest to the coast. In most of the freshwater quality sites TN was highest in spring or winter. However in sites in brackish region (i.e., Site 1, 10, 19, 15) TN was often highest in fall.

Phosphorus may be found in dissolved form (orthophosphate), inorganic form (reactive plus condensed or acid hydrolysable phosphate) and organically bound forms. Total phosphorus (TP) is the sum of reactive, condensed and organic phosphorous. Sources of phosphorus include particles of soil and rock, living and dead organisms, volatile compounds released from plants, natural fires, and the burning of fossil fuels, recently fertilized land surfaces, pet waste and septic tank, laundry detergent (car washing), etc. Unlike TN, total phosphorus generally increased as the canal approached the coast in the six study basins. Maximum five year annual average for TP was observed in site 110 $(0.0769 \mathrm{mg} / \mathrm{L})$ for C-14 Canal, in site $112(0.0579 \mathrm{mg} / \mathrm{L})$ for C-13 Canal, in site 19 for North New River Canal and site $25(0.05 \mathrm{mg} / \mathrm{L})$ for C-11 Canal. For Hillsboro (site 3) and C-12 Canal (site 64) maximum TP was found in intermediate sites. No specific seasonal trend was observed in the sites and concentration in different seasons at the same station was close.

Dissolved oxygen (DO) is a measure of in-stream oxygen demanding substances, which include organic materials, low-boiling hydrocarbon fractions of oils and greases resulting from transportation and industrial sources, benzene from gasoline, synthetic detergents, pesticides, herbicides, wood preservatives, and a wide range of synthetic organic industrial chemicals. For DO, maximum five year annual average was found in 
intermediate sites. Maximum DO was observed in site $2(6.14 \mathrm{mg} / \mathrm{L})$ for Hillsboro Canal, in site $7(6.45 \mathrm{mg} / \mathrm{L})$ for C-14 Canal, in site $12(6.25 \mathrm{mg} / \mathrm{L})$ for C-13 Canal, in site 17 $(6.11 \mathrm{mg} / \mathrm{L})$ for C-12 Canal, in site 19 for NNRC $(5.64 \mathrm{mg} / \mathrm{L})$ and in site $15(5.56 \mathrm{mg} / \mathrm{L})$ for C-11 Canal. Higher DO concentrations were observed in all the sites in spring followed by summer, winter and fall.

Chlorophyll a is a specific form of chlorophyll used in oxygenic photosynthesis. The concentration of chlorophyll a is a measurement of the health of streams. Chlorophyll is also an important link between the nutrient levels in water and the plant growth. When there is a large amount of algae in a lake or reservoir the organisms change the chemical composition of the water by absorbing oxygen. If too much dissolved oxygen is absorbed by the algae, the health of all other organisms in the water decreases. Maximum five year annual average of chlorophyll a was observed in site $3(20.98 \mu \mathrm{g} / \mathrm{L})$ for Hillsboro Canal, in site $110(14.54 \mu \mathrm{g} / \mathrm{L})$ for C-14 Canal, in site $111(10.40 \mu \mathrm{g} / \mathrm{L})$ for C-13 Canal, in site $64(30.62 \mu \mathrm{g} / \mathrm{L})$ for C-12 Canal, in site $20(8.35 \mu \mathrm{g} / \mathrm{L})$ for NNRC and in site $27(6.35$ $\mu \mathrm{g} / \mathrm{L}$ ) for C-11 Canal. Except for C-12 Canal, higher chlorophyll a concentrations were observed in summer and fall in all the five canals. For C-12 canals higher concentrations were observed in winter.

Specific conductance is a measure of the ability of water to conduct an electrical current. It is highly dependent on the amount of dissolved solids (such as salt) in the water. The specific conductance is thus a measure of salinity in stream water. For all the sites in brackish region specific conductance were very high, as expected. Maximum five year 
annual average for conductance was observed in site 11 (35147 umhos/cm) on C-11 Canal followed by site 10 (33390 umhos/cm at $\left.25^{\circ} \mathrm{C}\right)$ on C-13 Canal and site 5 (32390 umhos/cm) on C-14 Canal. Neither freshwater nor brackish water sites show any seasonal trend.

\subsubsection{Dataset preparation}

To assess the correlations of stream water quality to land use, surface hydrology, groundwater, seawater, and upstream contributions, a comprehensive set of parameters and their spatio-temporal variations were analyzed(Table 4.1).

Table 4.1: List of parameters and variables considered for empirical analysis of stream water quality

Water quality Total nitrogen, total phosphorus, dissolved oxygen, specific parameters conductance, chlorophyll a.

Total area, imperviousness, characteristics length, slope, single Spatial parameters family residential area, multifamily residential area, commercial (Land uses/cover and area, Industrial area, parks and open lands area, forests, distance surface hydrology) from coast.

Temporal parameters Groundwater, upstream concentration.

\subsubsection{Spatial dataset preparation}

The watersheds for which each of the water quality monitoring sites work as an outlet were delineated (Figure 4.2). The watersheds were delineated considering the 12-digit Hydrologic Unit Code (HUC) (HUC 030902061100 for Hillsboro Canal, HUC 030902061201 for C-14 Canal, HUC 030902061202 for C-12 Canal, HUC 030902061203 for NNR Canal, HUC 030902061204 for C-11 Canal upper segment, 
HUC 030902061205 for C-11 Canal lower segment) maps (available online at http://water.usgs.gov/GIS/huc.html; last accessed on July 9, 2013.) developed by US Geological Survey (USGS) as primary (national or global) reference. Then Water Body Identification Number (WBID) delineation by Florida Department of Environmental Protection (FDEP) and independent watersheds generated by taking into account the canal network and topology of the region using Arch Hydro tool in an Arc GIS platform (ESRI ARCGIS 9.0) were used to delineate subbasins for individual quality monitoring stations.

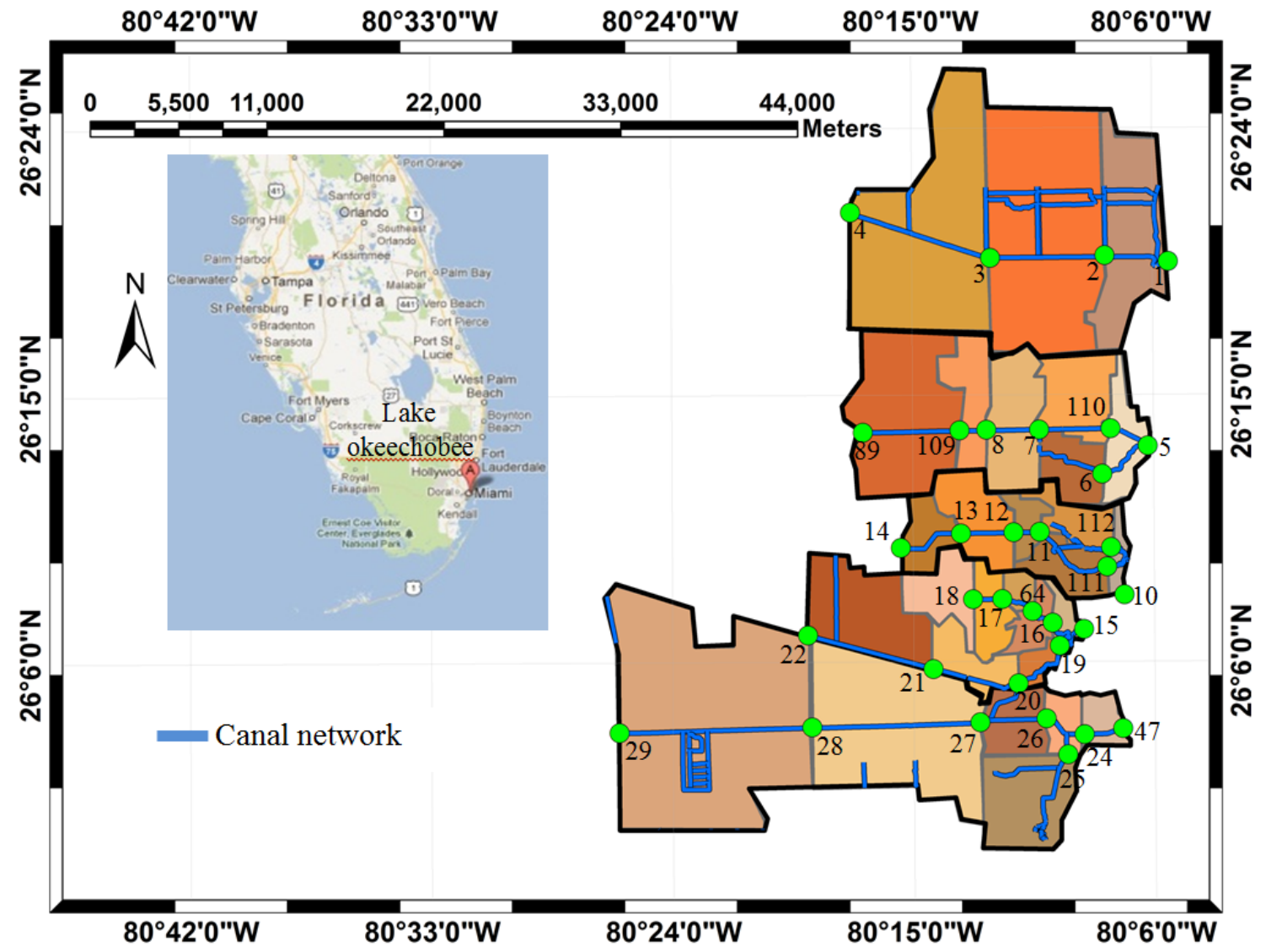

Figure 4.2: Watershed boundaries corresponding to each quality stations. Inset showing the state of Florida is not on the stated scale. 
Although sub-basins for individual quality stations were delineated (Figure 4.2), water quality contributing area for a particular station on the canal were computed using a cumulative approach, which means watershed delineated for a lower stream site encompasses the watershed corresponding to any upper stream site (Figure 4.3). As such, the impacts of watershed characteristics (e.g., land-use, slope, imperviousness, area, and characteristic length) on the water quality at a monitoring station can be evaluated independently without relying on the observations of adjacent monitoring sites (Kang et al., 2010).

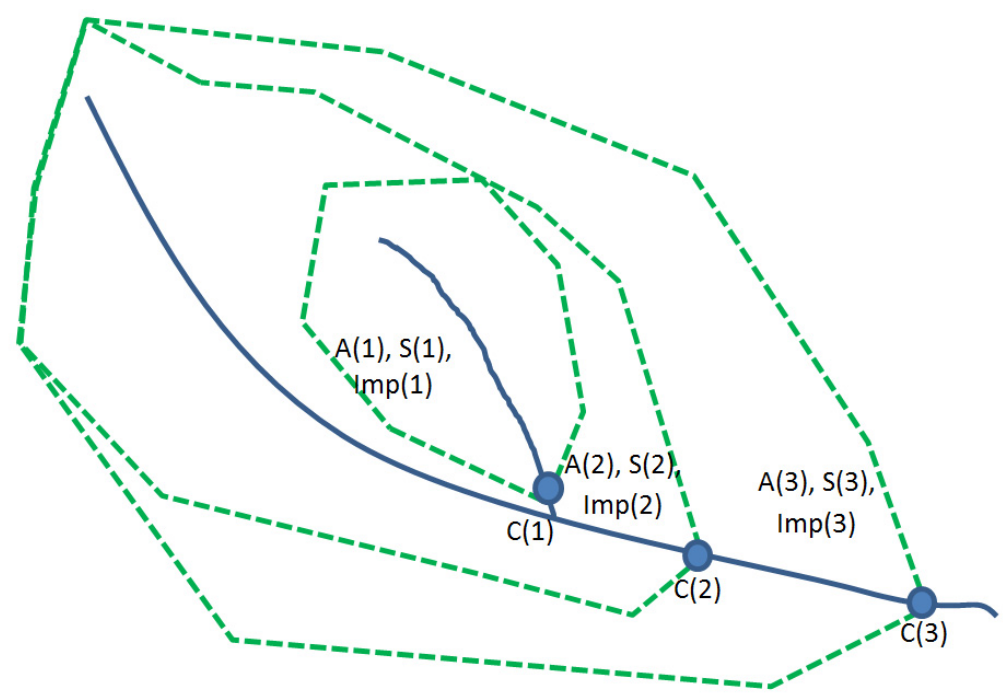

Figure 4.3: Schematic of watershed delineation on the basis of the positions of the monitoring sites. $A(j), S(j)$, and $\operatorname{Imp}(j)$ are respectively the area, the average slope, and the imperviousness of watershed $\mathrm{j}, \mathrm{C}(\mathrm{j})$ is the quality reading at the site on the outlet point of watershed $j$

Area and slope of each watershed were calculated using ESRI ARCGIS 9.0. Slope was calculated by analyzing the $10 \mathrm{ft}$ LiDAR data available through DBHYDRO, South Florida Water Management District's corporate environmental database (available online at http://my.sfwmd.gov/gisapps/sfwmdxwebdc/dataview.asp?; last accessed on July 18, 
2013). Land use, and imperviousness of each watershed was estimated using land use maps of Broward County available through DBHYDRO (available online at http://my.sfwmd.gov/gisapps/sfwmdxwebdc/dataview.asp?; last accessed on July 18, 2013). The imperviousness of each watershed was calculated using area-weighted average of runoff coefficients from literature (UDFCD, 2001) for different land uses. The land uses were categorized in the six categories of single family residential area, multifamily residential area, commercial area, industrial area, parks and open lands area, and forests (Figure 4.4).

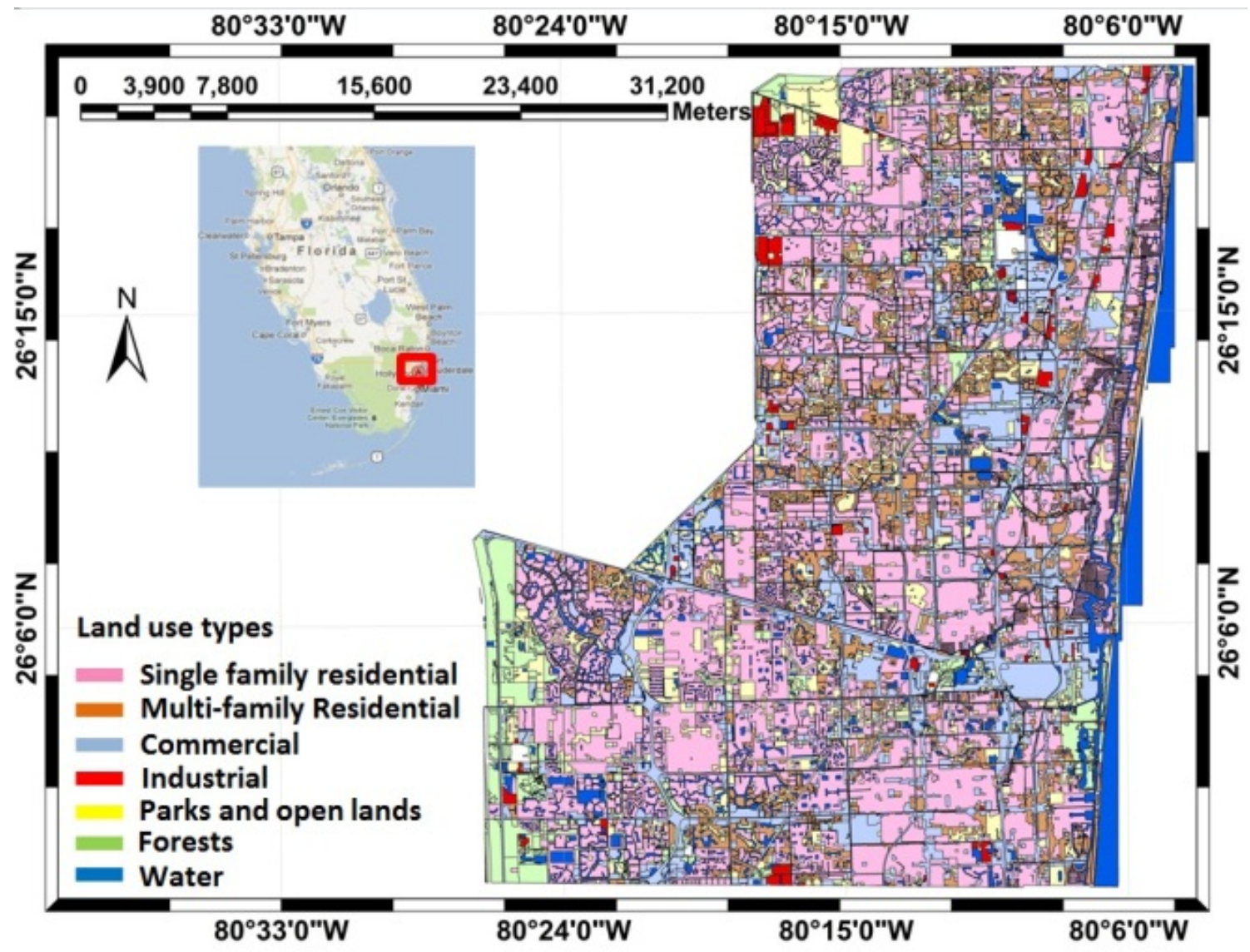

Figure 4.4: Land use types in the study area. Inset showing the state of Florida is not on the stated scale. 
The parks and open lands are representation of golf course, recreational places, race tracks, parks and zoos, disturbed land, borrow areas, and spoil areas. Examples of the forested areas include mixed rangeland, pine flatwoods, upland coniferous forests, upland hardwood forests, live oak, upland mixed conifers, tree plantations, hardwood and coniferous plantations, forest regeneration, mixed wetland hardwood, mixed shrubs, cypress, pine savannah, saltwater marsh, and wet prairies.

\subsubsection{Temporal dataset preparation}

The temporal dataset for the analysis include water quality and groundwater measurements at the inlets and outlets of different subbasins, each representing a quality monitoring station. . Six water quality parameters (i.e., total nitrogen, total phosphorus, dissolved oxygen, chlorophyll a, salinity and specific conductivity) were gathered from the Natural Resources Planning and Management Division of Broward County for 44 water quality sites quarterly each year during 1999-2000. . Salinity was not considered in this study as specific conductance is a surrogate for salinity and offers more analytical flexibility due to no occurrences of zero values. The sites include both freshwater and brackish water sampling sites. The sites along the coast line were not included in our analysis, because for these stations a watershed that correlates to the water quality in the stream could not be defined. As such, water quality data for 12 years (1999-2010) for 29 sites were considered for correlation analysis. For multiple regression analysis, data for 19 stations for 5 years (2006-2010) were considered. Sites on the C-12 Basin were not considered for multiple regression analysis as this basin is unique among the basins with no temporary or permanent flow originating from the upstream Water Conservation Area 
(WCA) and seepage and water supply to the basin being limited to rainfall (Cooper \& Lane 1987). The most upstream site in each canal was considered as representation of upstream contribution and was not considered for multiple regression analysis, as well. The water quality data at each site were collected in four seasons. Since our objective was to link in-stream water quality with watershed land use/cover and hydrologic parameters through a spatial analysis, we only incorporated quality and groundwater data from 2006 through 2010 for building the multiple regression models. Given that growing urbanization can lead to changes in land use/cover and hydrologic parameters, assuming no significant changes in the five-year (2006-10) time-frame is more appropriate than that over the 12-year period (1999-2010). During 2006-10, the water quality data collection dates ranged from $1^{\text {st }}$ of February to $2^{\text {nd }}$ of March (representing Winter), from $26^{\text {th }}$ of April to $22^{\text {nd }}$ of June (Spring), from $2^{\text {nd }}$ of August to $31^{\text {st }}$ of August (Summer), and from $25^{\text {th }}$ of October to $29^{\text {th }}$ of November (Fall). Groundwater level (i.e., water table) data, corresponding to the 19 quality stations, were collected from the Active Groundwater Level Network database of US Geological Survey (USGS) (available online at http://groundwaterwatch.usgs.gov/countymaps/FL_011.html; last accessed July 18 2013). Average water table of the preceding seven days (including the quality sampling day) at the closest groundwater station was assigned as the groundwater level for a subbasin outlet representing a quality station. Five year (2006-10) average data for groundwater and five water quality parameters were considered for each seasonal model. Based on annual rainfall patterns (NOAA, 2012; SFWMD, 2012) we also reanalyzed the data sets by considering only two seasons: wet period (May 1 to October 30) and dry period (November 1 to April 30). The bi-seasonal data sets for groundwater and quality of 19 
stations were prepared by averaging multiple observations first over the seasonal timeframes and then over the 5-year period (2006-10).

\subsubsection{Quality assurance/ quality control}

All the water quality data were processed by the Environmental Monitoring Division of the Broward County Environmental Protection Department. This division has a Florida Department of Health certified laboratory (\#E46053) and follows a comprehensive quality assurance plan (\#870191G). Sampling of freshwater canals was primarily performed from bridge crossings across specific canals (Broward County Environmental Protection Department, 2007). Grab samples were mainly collected via a Kemmerer/Niskin bottle, which was lowered to collect water from a canal. Samples for individual constituents were then placed into clean glass bottles, plastic bottles and/or or whirlpacks depending on the parameter to be analyzed. Samples were placed on ice and brought back to the laboratory within four hours of collection. Specific conductance was measured using whetstone bridge or equivalent technique following USEPA 120.1 method. Dissolved oxygen was measured using Winkler titration technique following USEPA 360.1/360.2 method. Total nitrogen was measured using cadmium reduction (nitrite+nitrate+nitrogen) following USEPA 353.2 method and automated phenate (ammonia-nitrogen) following USEPA 350.1 method (Broward County Environmental Protection Department, 2007). Total phosphorus was measured using acid, block digestion, ascorbic acid following USEPA 365.4 method. Chlorophyll a was measured using membrane filter or $90 \%$ acetone extraction technique following SM $10200 \mathrm{H}$ method (Broward County Environmental Protection Department, 2007). 


\subsubsection{Dataset analysis}

The analysis of stream water quality to investigate the dominant stressors and their relative influence is a complex undertaking, particularly in the highly urbanized, coastal urban settings of our study basins. The dataset was, therefore, analyzed in three steps. First, correlation analyses using 12 years (1999-2010) of four-seasonal time-series of water quality data at 29 stations were conducted to understand interrelations among different in-stream pollutants, as well as to examine auto-correlations (i.e., memory) of each pollutant spatially (linking with the most upstream observations in a canal basin) and temporally (linking quality status with the preceding seasons). Second, principal component analysis (Mahbub et al., 2011), using the 5-year (2006-2010) average spatial datasets (including data from the 19 stations) for different seasons, were conducted involving all parameters (land uses/cover, surface hydrologic, groundwater, seawater, and upstream contributions) to identify the dominant sources and stressors of seasonal stream water quality and the correlations among different predictor and response parameters and variables. Third, the 5-year average spatial datasets of 19 stations were utilized to build seasonal, multiple regression models for determining the relative influence of individual parameters in shaping the in-stream water quality. Findings from the previous two steps were leveraged to develop relatively parsimonious models, which included a reduced parameter set that covers the important contributory aspects.

\subsubsection{Correlation and principal component analysis}

Temporal correlations were first investigated among the stream water quality parameters. Three different temporal correlations were analyzed to get a comprehensive idea of 
stream water quality parameters. At first, the inter-pollutant correlations were analyzed among the five quality parameters in all the 29 sites. The cross pollutant correlations are effective in revealing relationships among different quality parameters in a certain section of stream and explaining stream regimes based upon the correlations.

Second, correlations of quality parameters in all the sites to the most upstream site in the respective canals were investigated to see how correlations change with distance in the downstream direction. The correlations between each site to its most upstream site were plotted against the distance between these two sites to see how correlations change with distance for the same parameter. Correlations of quality parameters at a particular site to the upstream site are also indicators of the influence of stream and flow characteristics.

Third, autocorrelation of the stream water quality time series was analyzed. Autocorrelation refers to the correlation of quality parameter with its own past and future values. Autocorrelation is also sometimes called "lagged correlation" or "serial correlation", which refers to the correlation between members of a series of numbers arranged in time. Positive autocorrelation might be considered a specific form of "persistence", a tendency for a system to remain in the same state from one observation to the next. Autocorrelation between stream water quality from immediate next season up to three seasonal gap were evaluated to see how persistence for quality parameters change with increase in time-lag.

Correlations of each stream water quality parameters to spatial parameters were also analyzed through principal component analysis. The analysis gave useful initial information about correlations of the dependent (response) and independent (predictor) 
variables. The dominant roles of different sources and stressors of water quality were evident through this analysis. Principal component analysis of data sets for four seasons (winter, spring, summer, and fall), as well as for dry and wet periods, were undertaken.

\subsubsection{Multiple regression model development}

The multiple regression model (MRM) can be written as a linear and/or nonlinear function of the contributions of different land use/cover, surface hydrology, groundwater, seawater, and upstream contribution parameters to the overall water quality. The parameters were chosen based on the preliminary correlation and principal component analysis. The idea is that the observed pollutant concentration at the outlet point of a watershed (C) can be reproduced by a linear combination of relevant contributory parameters. We tried three different types of models. At first untransformed parameters were set in to a multiple linear regression model. Then a semi logarithm model was developed where only the concentration terms were log transformed and finally a log transformed model (i.e., power-law regression model) was set where all the parameters were $\log$ transformed. The log transformed model showed better performance in terms of accuracy (lowest root-mean-square errors) and fitting efficiency (highest coefficient of determination values). The power-law MRM can be formulated into a source-receptor model (Henry, 2002; Kang, 2010) and are expressed in natural (e-base) logarithmic form as follows:

$$
\log C=\sum_{i=1}^{i=3} \alpha_{i} \log H_{i}+\sum_{j=1}^{j=6} \beta_{j} \log (U U)_{j}+\gamma \log \left(D_{C}\right)+\eta \log (G W)+\mu \log \left(C_{0}\right)+\delta
$$


Where $\alpha, \beta, \gamma, \eta, \mu, \delta$ are regression coefficients. The three hydrologic parameters $\left(\mathrm{H}_{\mathrm{i}}\right)$ were imperviousness (I), slope (S), and characteristics length (L). The six land uses were single family residential area $\left(A_{R S}\right)$, multifamily residential area $\left(A_{R M}\right)$, commercial area $\left(A_{C}\right)$, industrial area $\left(A_{I}\right)$, parks and open lands $\left(A_{O L}\right)$, and forests $\left(A_{F}\right)$. Groundwater level $(\mathrm{GW})$, distance from the nearby coast $\left(\mathrm{D}_{\mathrm{c}}\right)$, and upstream concentrations $\left(\mathrm{C}_{0}\right)$ were included as representations of groundwater, coastal, and upstream contributions, respectively.

Equation (1) was solved using MS EXCEL. In a backward regression approach, one parameter was taken out in each step until a set of parameters were obtained where all the parameters were significant ( $\mathrm{p}$-value $<0.15$ ). Both four seasonal models, as well as, dry and wet period models, for all the five quality parameters, were developed. The residuals were checked for randomness (by plotting predicted versus residuals) and normality (by plotting histograms of residuals) properties (Appendix).

The fitted the models were evaluated based on four statistical measures. Coefficient of determination $\left(\mathrm{R}^{2}\right)$ explains how much variance about the mean is explained by a model. $\mathrm{R}^{2}$ varies from 0 to 1 and the higher the $\mathrm{R}^{2}$ value the more variance it can explain. However $\mathrm{R}^{2}$ value always increases with the addition of a new predictor irrespective of its correlation with the dependent variable. Therefore, a second parameter adjusted $\mathrm{R}^{2}$ was also considered. Unlike $R^{2}$, the adjusted $R^{2}$ increases when a new explanatory variable is included only if it improves the $R^{2}$ more than that would be expected in the absence of any explanatory value being added by the new explanatory variable. The adjusted $\mathrm{R}^{2}$ value can be negative and never exceeds the value of $\mathrm{R}^{2}$. The root-mean-square error 
(RMSE) is a frequently used measure of the differences between values predicted by a model (or an estimator) and the values actually observed. Although it is commonly accepted that the lower the RMSE the better the model performance is, a satisfactory RMSE is subject to the units of the model predictions. Based on recommendation by Singh et al. (2004), the RMSE-observations' standard deviation ratio (RSR) was, therefore, also considered. A RSR value of zero indicates a perfect model with zero RMSE. A model with a RSR value of 0 to $0.5,0.5$ to $0.6,0.6$ to 0.7 and higher than 0.7 is considered, respectively, very good, good, satisfactory and unsatisfactory (Moriasi, 2007).

\subsection{RESULTS}

\subsubsection{Correlation analysis}

The temporal correlation focuses the relationships among the independent stream water quality parameters. The inter-pollutant correlations identify the significant correlations among the five pollutants. The correlation of water quality at each site with the most upstream site explains how the correlation changes spatially, and the auto correlation explains how these correlations change temporally.

The inter-pollutant correlation analysis showed good correlations of dissolved oxygen (DO) and chlorophyll a to total phosphorus (TP) (Table 4.2). All the sites in C-14, C-13 and NNRC showed significant correlation for these two combinations. The percentages of stations with significant correlations in the rest of the three canals were also high. The strongest correlations between TP and DO were observed in site $3(0.95)$ in Hillsboro 
Canal, in site 109 (0.99) in C-14 Canal, in site 13 (0.99) in C-13 Canal, in site 17 (0.98) in C-12 Canal, in site 22 (0.99) in NNR Canal, and in site 29 (0.99) in C-11 Canal. All these sites are freshwater sites. The strongest correlations between chlorophyll a and TP were observed in site 1(0.83) in Hillsboro Canal, in site 109 (0.99) in C-14, in site 13 (0.99) in C-13 Canal, in site 17 (0.98) in C-12 Canal, in site 22 (0.99) in NNR Canal and in site 28 (0.98) in C-11 Canal. Comparatively, there was weak or no correlations observed for total nitrogen $(\mathrm{TN})$ with DO or chlorophyll a. The strongest correlation observed were in site $110(0.35)$ for TN-DO and site $8(0.56)$ for TN-CHL both in C-14 Canal. Nutrients (total phosphorus and total nitrogen) play an important role for growth of algae and other plants in stream and consequently affect the level of chlorophyll a, which in turn influences the dissolved oxygen concentration in a stream. The strong correlation of TP and relatively no or weak correlation of TN with DO and chlorophyll a shows that TP is the limiting nutrient in this canals. Strong correlations were also observed between specific conductance and TN. Correlations were significant in all the canal stations, except for C-12 and C-11 canals where, respectively, $80 \%$ and $57 \%$ of the stations showed significant correlations. We hypothesize that salinity effects nodulation efficiency (Within legume nodules, nitrogen gas from the atmosphere is converted into ammonia, which is then assimilated into amino acids, the building blocks of proteins), symbiotic nitrogen fixation and other plant physiological processes (Salah et al., 2011) that could also limit TN's role as a nutrient in these canals. 
Table 4.2: Summary of in-stream inter-pollutant correlations in the study area

\begin{tabular}{|c|c|c|c|c|c|c|c|c|c|c|c|}
\hline \multirow[b]{2}{*}{ Descriptions } & \multirow[b]{2}{*}{$\begin{array}{l}\text { Canal } \\
\text { (no of sites) }\end{array}$} & \multicolumn{10}{|c|}{ Correlation between parameters } \\
\hline & & TN-TP & TN-DO & $\begin{array}{l}\text { TN- } \\
\text { CHL }\end{array}$ & TN-CON & TP-DO & TP-CHL & $\begin{array}{l}\text { TP- } \\
\text { CON }\end{array}$ & $\begin{array}{l}\text { DO- } \\
\text { CHL }\end{array}$ & $\begin{array}{l}\text { DO- } \\
\text { CON }\end{array}$ & $\begin{array}{l}\text { CHL- } \\
\text { CON }\end{array}$ \\
\hline \multirow{5}{*}{$\begin{array}{l}\text { Percent } \\
\text { sites with } \\
\text { significant } \\
(p<0.05) \\
\text { correlations }\end{array}$} & $\mathrm{C}-14(7)$ & 57 & 14 & 86 & 100 & 100 & 100 & 14 & 29 & 14 & 29 \\
\hline & C-13 (5) & 0 & 40 & 20 & 100 & 100 & 100 & 0 & 20 & 80 & 20 \\
\hline & C-12 (5) & 0 & 0 & 20 & 80 & 80 & 100 & 20 & 40 & 0 & 40 \\
\hline & NNRC (4) & 0 & 0 & 0 & 100 & 100 & 100 & 25 & 50 & 25 & 25 \\
\hline & C-11 (7) & 29 & 43 & 14 & 57 & 71 & 71 & 14 & 14 & 43 & 14 \\
\hline \multirow{5}{*}{$\begin{array}{l}\text { Range of } \\
\text { correlations }\end{array}$} & Hillsboro & - & - & 0.33 & $0.58-0.82$ & $0.34-0.95$ & $0.61-0.83$ & - & $0.18-0.52$ & 0.32 & $0.22-0.25$ \\
\hline & $\mathrm{C}-14$ & $0.27-0.33$ & 0.35 & 0.56 & $0.53-0.87$ & 0.64-0.99 & $0.2-0.99$ & 0.41 & $0.28-0.54$ & 0.3 & $0.28-0.44$ \\
\hline & C-13 & - & $0.29-0.30$ & 0.26 & $0.23-0.65$ & 0.97-0.99 & 0.98-0.99 & - & 0.2 & $0.38-0.47$ & 0.47 \\
\hline & NNRC & - & - & & $0.41-0.56$ & 0.80-0.99 & 0.70-0.99 & 0.34 & $0.39-0.56$ & 0.29 & 0.29 \\
\hline & $\mathrm{C}-11$ & $0.31-0.51$ & $0.31-0.41$ & 0.25 & $0.35-0.75$ & $0.86-0.99$ & $0.86-0.99$ & 0.21 & 0.71 & 0.39-0.99 & 0.33 \\
\hline
\end{tabular}


The correlations between each site to its most upstream site were plotted against the distance between these two sites to see how correlations change with distance for the same parameter (Figure 4.5). Except for total phosphorus, correlations for all the quality parameters notably varied with distance; correlations became weaker as the distance increases. The change was more evident in TN and specific conductance than DO. For chlorophyll a, power relationship seemed more appropriate (Figure 4.5).

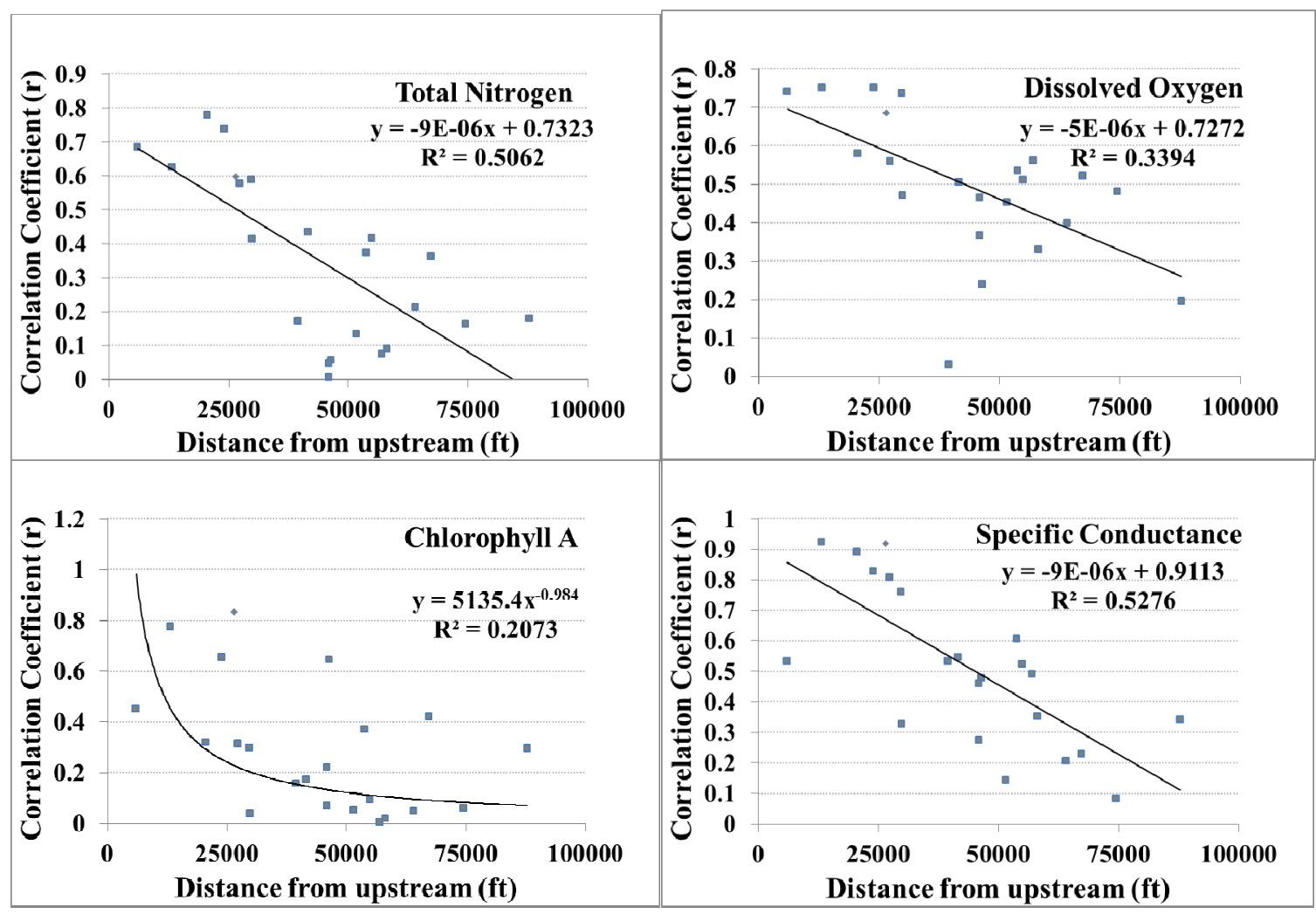

Figure 4.5: Change in correlation coefficient with distance for water quality parameters.

As shown, there is no separate regime evident for any of the pollutants, which may indicate that the stream and flow characteristics were consistent within the study area. The plots are useful in explaining the spatial memory of pollutants. Under similar stream 
and land use conditions, these figures might be useful in generating pollutant profiles for known upstream conditions (or concentrations) with a reasonable accuracy.

From the autocorrelation analysis (Table 4.3), we found that specific conductance had the highest temporal memory. For specific conductance, the correlation, both at 90 days and 180 days, were highest in site 4 ( 0.59 and 0.27 , respectively). All the quality parameters showed moderate correlations at $10-50 \%$ stations at 90 days and only some station showed significant correlations at 180 days for $\mathrm{TN}, \mathrm{DO}$, and specific conductance.

Table 4.3: Summery of autocorrelation analysis of quality parameters

\begin{tabular}{llllll}
$\begin{array}{l}\text { Quality } \\
\text { parameter }\end{array}$ & $\begin{array}{l}\text { No of } \\
\text { sample }\end{array}$ & $\begin{array}{l}\text { Sites with } \\
\text { significant } \\
\text { correlation } \\
(\mathbf{P}<\mathbf{0 . 1}) \text { at 90 } \\
\text { days }\end{array}$ & $\begin{array}{l}\text { Range of } \\
\text { correlation } \\
\text { coefficients at } \\
\mathbf{9 0} \text { days }\end{array}$ & $\begin{array}{l}\text { Sites with } \\
\text { significant } \\
\text { correlation } \\
\mathbf{P}<\mathbf{0 . 1}) \text { at } \\
\mathbf{1 8 0} \text { days }\end{array}$ & $\begin{array}{l}\text { Range of } \\
\text { correlation } \\
\text { coefficients at 180 } \\
\text { days }\end{array}$ \\
\hline Total Nitrogen & 25 & 12 & $0.23-0.46$ & 2 & $0.28-0.37$ \\
Total Phosphorus & 25 & 6 & $0.20-0.47$ & 0 & - \\
Dissolved Oxygen & 25 & 9 & $0.18-0.47$ & 4 & $0.25-0.45$ \\
Chlorophyll a & 25 & 3 & $0.34-0.49$ & 0 & - \\
\hline Sp. Conductance & 25 & 9 & $0.20-0.59$ & 3 & $0.17-0.27$ \\
\hline
\end{tabular}

Autocorrelation or the temporal memory of the quality parameter is expected to decrease with time. For our study, we could hypothesize power relationship for few of the stations based on three data points (Figure 4.6). However, in most of the sites, no such relationships were observed. 


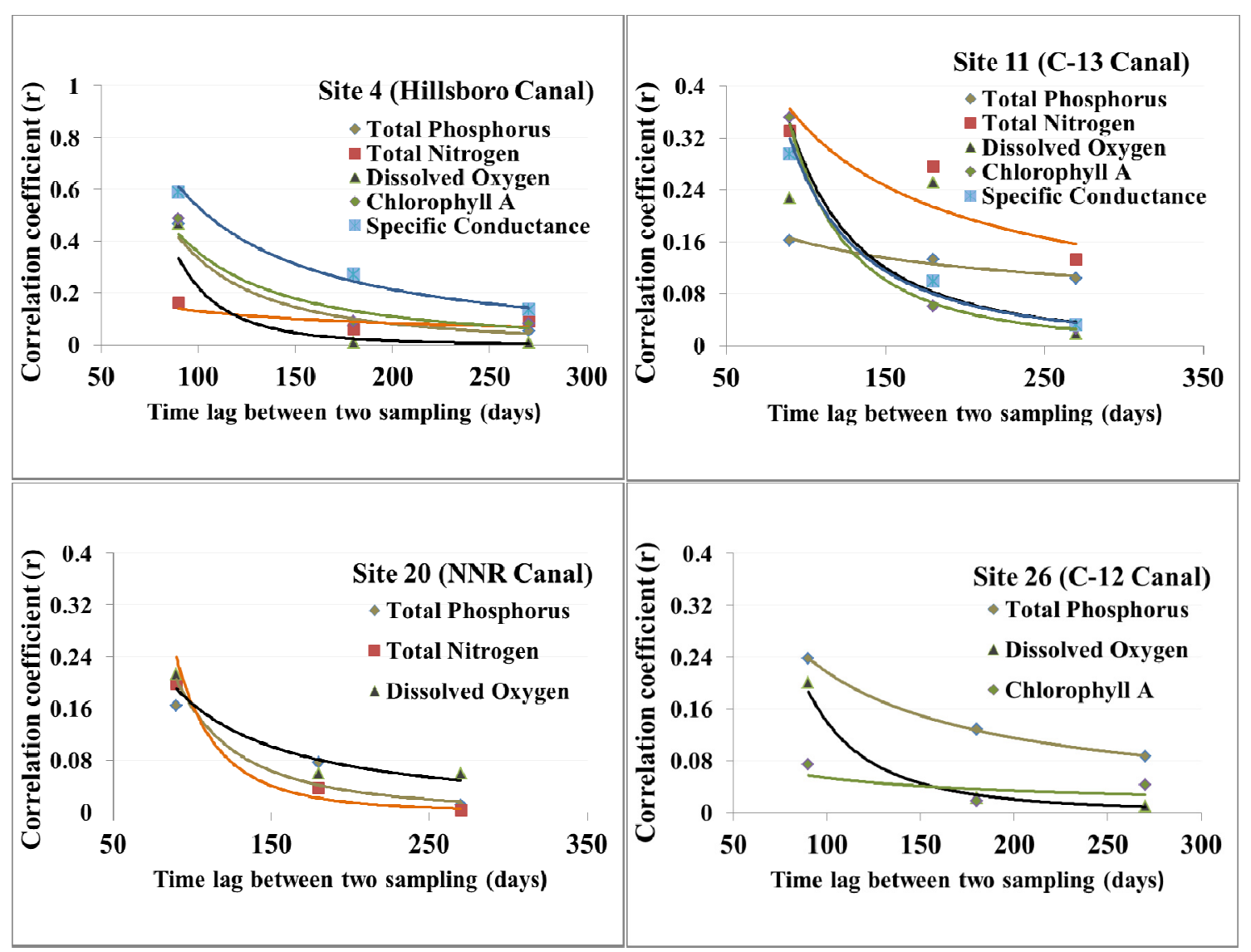

Figure 4.6: Change in correlation over time for the same quality parameters in study area.

\subsubsection{Principal component analysis}

Principal component analysis was undertaken to gain insights into the correlation structure of the data matrix, including all the independent (predictor) and dependent (response) variables (Figure 4.7). The influence of the observations on the variables were also evident in this analysis. The first two principal components explained around $60 \%$ of the total data variance in winter, $61 \%$ in spring, $63 \%$ in summer, and $62 \%$ in fall. It was observed that the land use parameters were correlated and formed a group. Distance from the coast and groundwater were orthogonal to this group, which indicates they were uncorrelated to land use. The hydrologic parameter of slope was almost orthogonal with 
distance from the coast, which indicated they were uncorrelated. Among the independent variables $\mathrm{DO}, \mathrm{Chl}$ a and $\mathrm{TP}$ showed mutual correlations. TN was uncorrelated to this group but correlated to specific conductance.

Winter

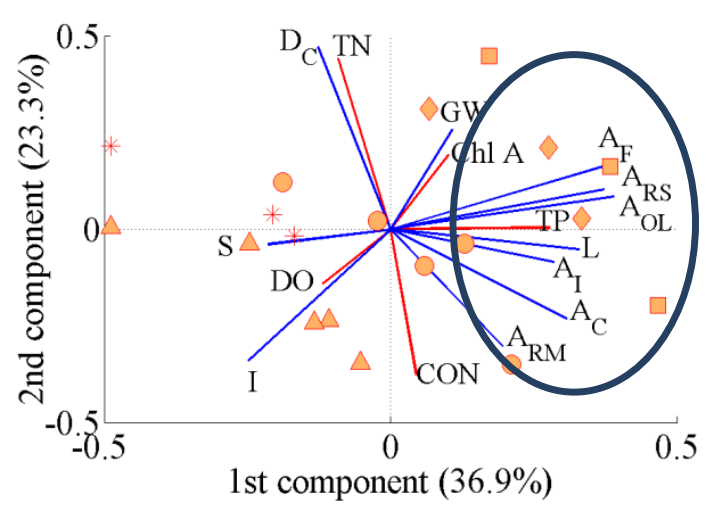

Summer

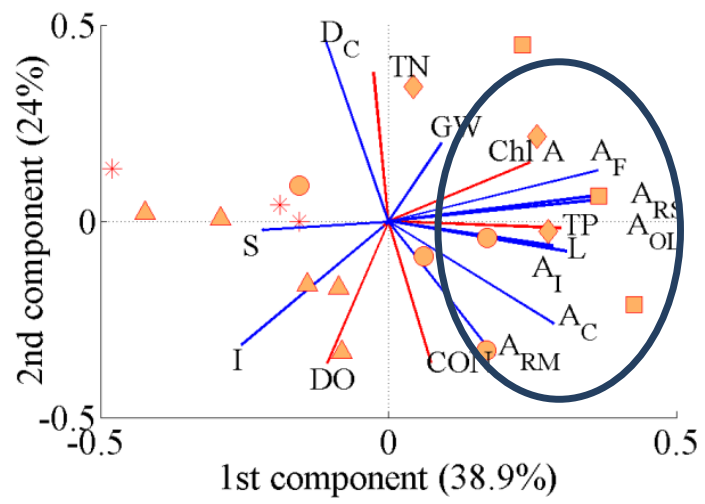

Spring

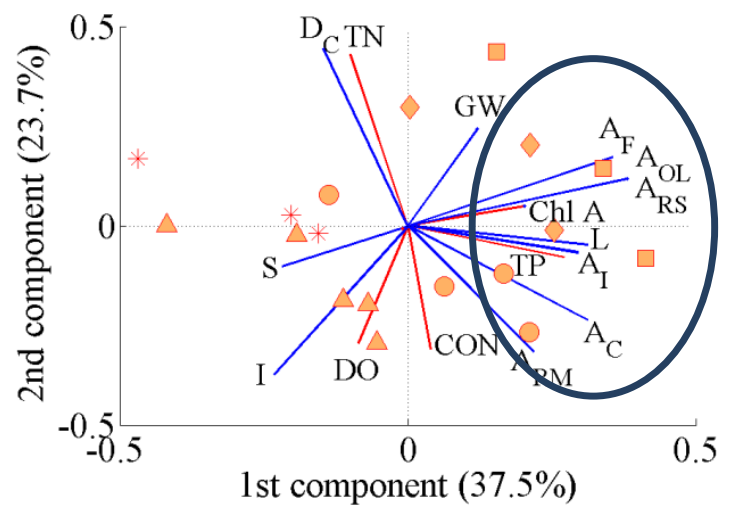

Fall

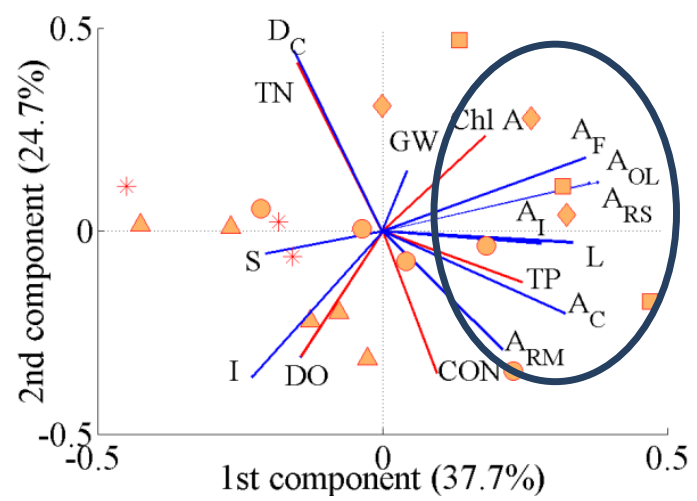

\section{NNR Canal \\ C-11 Canal $\bigcirc$ C-14 Canal \\ Hillsboro Canal $\triangle \mathrm{C}-13$ Canal}

Figure 4.7: Principal component analysis for four seasonal analyses.

The Hillsboro canal and the $\mathrm{C}-11$ canal had higher areas of different land uses but relatively less slope and imperviousness. The C-13 canal and NNR canal were found to have higher hydrologic features (i.e., slope and imperviousness). Groundwater was also 
higher in the Hillsboro canal and the C-11 canal. Since the canals were almost orthogonal to the coast, the distance from the coast was contributed almost equally by all the canals.

From the biplots of the principal component analysis, the first component could be interpreted as the land use/cover and hydrologic component, while the second component could be interpreted as the coastal and groundwater influenced component. TP and DO appeared to be influenced higher by the land use/cover and hydrologic parameters, although groundwater (GW) also showed a strong influence on TP. Chlorophyll a was influenced by both land use and groundwater parameters. Specific conductance and total nitrogen, on the other hand, were less influenced by land use and more influenced by distance from the coast. Seasonal variation was also observed in the dependent variables. DO was more strongly correlated with the second component in summer, which indicate the influence of coast on DO would be stronger in summer. Similar observation was applicable for TN. Chl a and TP, on the other hand, showed higher correlation in summer with first components, which indicate higher influence of land uses on these two variables in summer.

The spatial dataset for the four and the two (dry and wet) seasonal analyses were same. Hence, the biplots for dry and wet period showed similar characteristics as that of four seasons. The DO showed stronger correlation to the second component in wet period. That indicates less dominance of land use on DO in wet period. Chlorophyll a, on the other hand, showed stronger correlation to the first component in wet period, which indicates Chlorophyll was dominated by land use more in wet period than in dry period. 
Although the role of groundwater (GW) did not change much in dry and wet periods, GW was more strongly correlated with the second (coastal) component in the dry period.
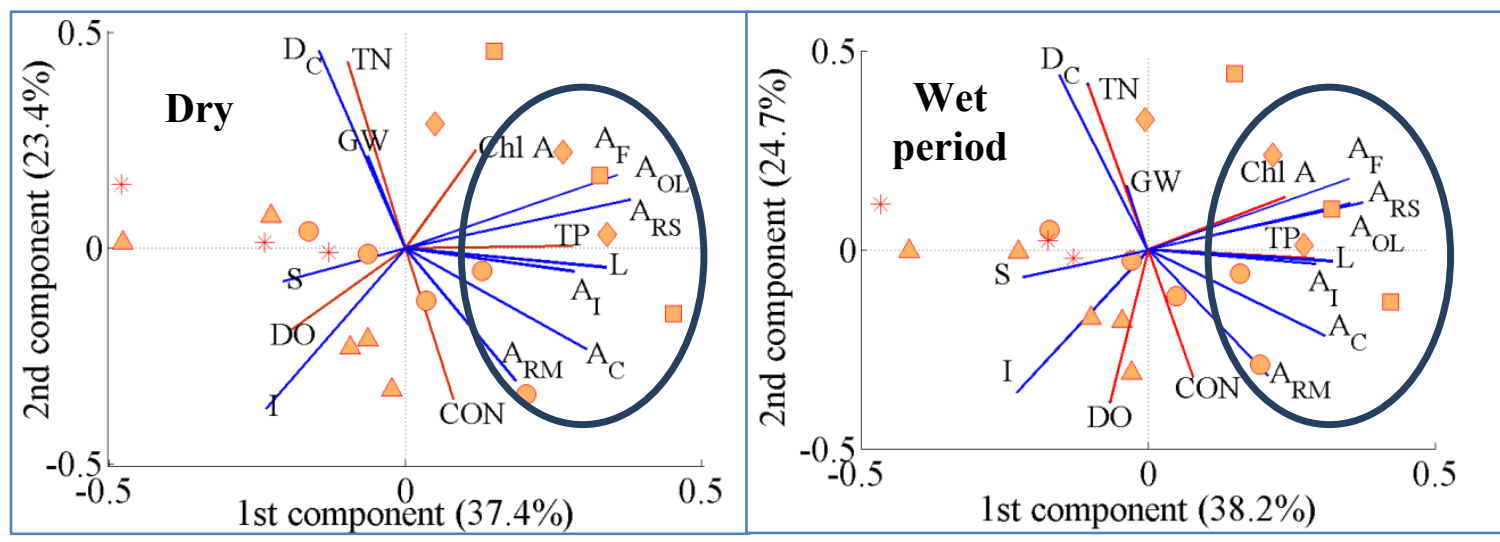

\section{* NNR Canal C-11 Canal C C-14 Canal $\square$ Hillsboro Canal $\triangle$ C-13 Canal}

Figure 4.8: Principal component analyses for dry and wet period.

\subsubsection{Multiple regression models for four seasons}

The multiple linear regression models for all the quality parameters except chlorophyll a were satisfactory (Table 4.3 and Figure 4.9). The seasonal model explained 79\%-92\% of the variance about mean for TN. The seasonal models for TP (51\%-80\%), DO (66\%$90 \%)$ and conductance (74\%-84\%) were satisfactory as well.

Except for few seasonal models (winter and spring model for TP, spring model for DO), the RSR value for all the models are in the "very good" range. For chlorophyll a, none of the seasonal models were satisfactory, which shows that chlorophyll a at a particular section of the stream is more influenced by the in-stream processes and factors than land use and hydrologic stressors of the watershed. 
Table 4.3: Summary of multiple linear regression model performances

\begin{tabular}{llllll}
\hline $\begin{array}{l}\text { Quality } \\
\text { parameter }\end{array}$ & $\begin{array}{l}\text { Temporal } \\
\text { scale }\end{array}$ & R2 & $\begin{array}{l}\text { Adjusted } \\
\text { R2 }\end{array}$ & $\begin{array}{l}\text { Standard } \\
\text { error }\end{array}$ & RSR \\
\hline \multirow{4}{*}{ TN } & Winter & 0.905 & 0.858 & 0.043 & 0.377 \\
& Spring & 0.812 & 0.789 & 0.045 & 0.459 \\
& Summer & 0.869 & 0.818 & 0.038 & 0.428 \\
& Fall & 0.948 & 0.922 & 0.037 & 0.278 \\
\hline \multirow{4}{*}{ TP } & Winter & 0.790 & 0.685 & 0.153 & 0.561 \\
& Spring & 0.592 & 0.510 & 0.175 & 0.700 \\
& Summer & 0.861 & 0.772 & 0.144 & 0.477 \\
& Fall & 0.865 & 0.798 & 0.112 & 0.449 \\
\hline \multirow{4}{*}{ DO } & Winter & 0.897 & 0.857 & 0.023 & 0.378 \\
& Spring & 0.719 & 0.663 & 0.037 & 0.581 \\
& Summer & 0.918 & 0.867 & 0.032 & 0.365 \\
& Fall & 0.936 & 0.895 & 0.023 & 0.325 \\
\hline \multirow{3}{*}{ CON } & Winter & 0.877 & 0.816 & 0.347 & 0.430 \\
& Spring & 0.830 & 0.745 & 0.401 & 0.505 \\
& Summer & 0.900 & 0.836 & 0.282 & 0.406 \\
& Fall & 0.836 & 0.753 & 0.383 & 0.497 \\
\hline \multirow{4}{*}{ Chl A } & Winter & 0.327 & 0.135 & 0.286 & 0.930 \\
& Spring & 0.546 & 0.319 & 0.221 & 0.825 \\
& Summer & 0.560 & 0.435 & 0.248 & 0.752 \\
& Fall & 0.540 & 0.362 & 0.193 & 0.798 \\
\hline & & & & & \\
& & & & \\
& & & &
\end{tabular}




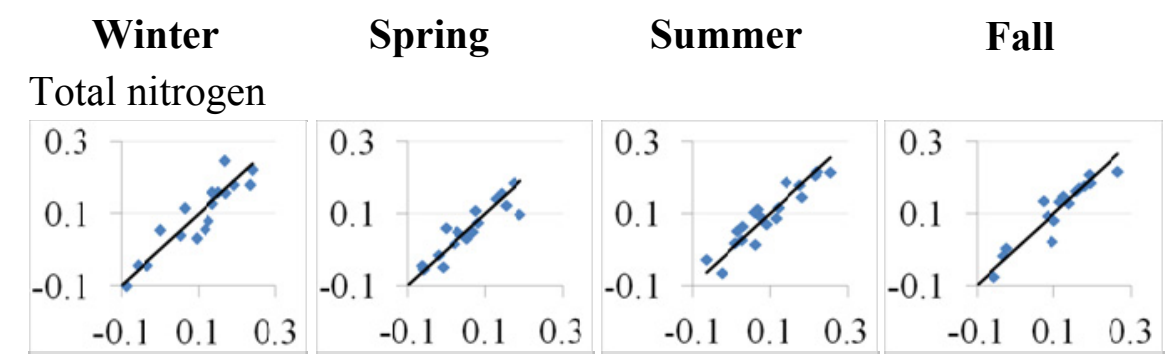

Total phosphorus

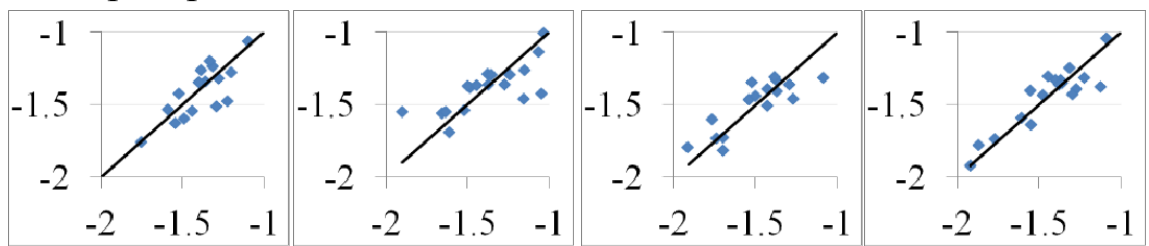

Dissolved oxygen

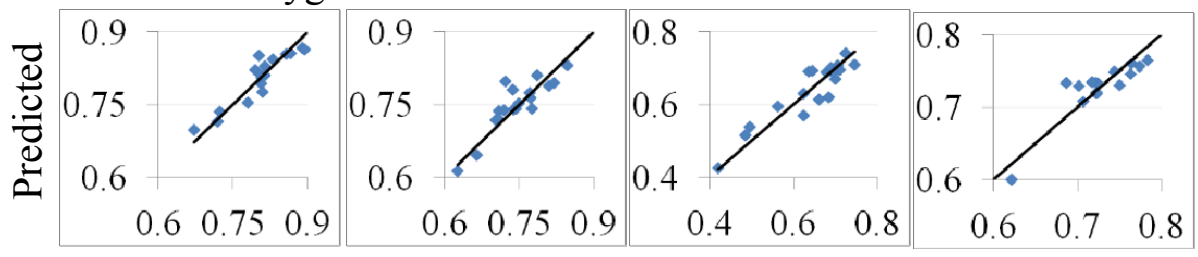

Specific conductivity

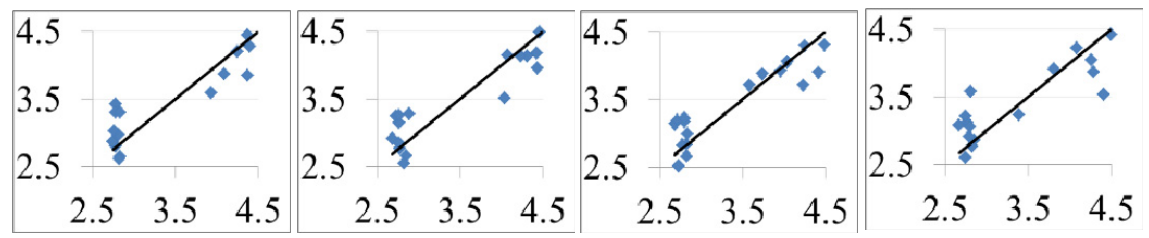

Chlorophyll A

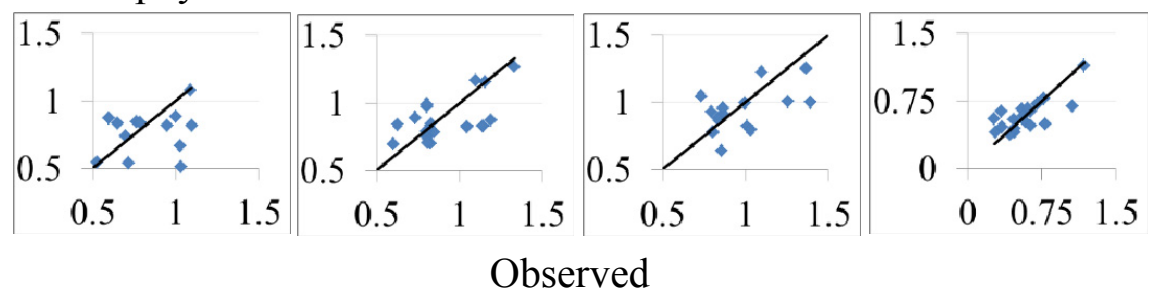

Figure 4.9: Observed vs. predicted values for four seasonal analyses 


\subsubsection{Total nitrogen}

The multiple linear regression models of total nitrogen (TN) explained the variability of corresponding stressors that differ from season to season (Table 4.4). Overall, the distance from the coast and characteristics length are the major dominant hydrologic predictors of TN in this study area. The land use contributions vary in different seasons. In general, upstream contributions play the most significant role for the TN concentrations in a watershed and role of the groundwater is less significant and variable with time.

Table 4.5: Multiple log-linear regression models description of total nitrogen.

\begin{tabular}{|c|c|c|c|c|c|c|c|c|c|c|c|}
\hline Eqn's & & $\begin{array}{l}\text { inter- } \\
\text { cept }\end{array}$ & $\mathbf{D}_{\mathbf{c}}$ & $\mathbf{L}_{\mathbf{C}}$ & I & $\mathbf{A}_{\mathbf{C}}$ & $\mathbf{A}_{I}$ & $\mathbf{A}_{\mathrm{OL}}$ & $\mathbf{A}_{\mathrm{F}}$ & $\mathbf{C}_{\mathrm{US}}$ & GW \\
\hline \multirow{2}{*}{ 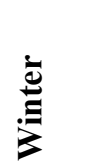 } & 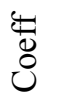 & 0.969 & 0.306 & & -1.176 & 0.218 & & -0.261 & & 1.074 & -0.089 \\
\hline & 崩 & 1.452 & 0.051 & & 0.603 & 0.114 & & 0.128 & & 0.470 & 0.043 \\
\hline \multirow{2}{*}{ 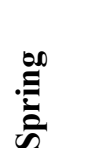 } & $\begin{array}{l}\mathscr{4} \\
0 \\
0\end{array}$ & -0.947 & 0.188 & & & & & & & 1.130 & \\
\hline & 崩 & 0.140 & 0.035 & & & & & & & 0.285 & \\
\hline
\end{tabular}

\begin{tabular}{|c|c|c|c|c|c|c|c|c|c|}
\hline \multirow{2}{*}{$\underset{\Xi}{\grave{\Xi}}$} & ن & -3.930 & 0.317 & \multicolumn{2}{|l|}{0.729} & 0.015 & -0.133 & \multicolumn{2}{|l|}{0.748} \\
\hline & $\sqrt[1]{2}$ & 0.550 & 0.036 & 0.121 & & 0.005 & 0.026 & 0.247 & \\
\hline & $\begin{array}{l}\stackrel{4}{0} \\
\dot{0}\end{array}$ & -3.599 & 0.471 & 0.978 & -0.883 & 0.015 & -0.212 & & 0.169 \\
\hline$\overline{\bar{\pi}}$ & 㭊 & 0.825 & 0.040 & 0.200 & 0.258 & 0.006 & 0.042 & & 0.067 \\
\hline
\end{tabular}

The two important natural processes in which nitrogen $\left(\mathrm{N}_{2}\right)$ is converted into ammonia (nitrogen fixation) and organic nitrogen is produced (assimilation) are adversely affected with an increase in salinity (Silveira et al., 2001; Cordovilla et al., 1994). Greater the distance from the coast, higher TN generation is thus expected. On the other hand, greater the characteristics length, higher the time of concentration is and more accumulation of 
pollutants are allowed. Thus, a positive correlation with characteristics length is also expected.

The forests can either have additive effects on the nutrient concentration in stream as a source of leafs and other organic N-bound components or negative effect, due to nutrient uptakes for their growth based on the plant profiles of the watersheds. In the study area of Broward, TN was seen to have a negative effect which means nutrient uptake dominates in this area and an increase in forests resulted in a decrease in TN. The open land and parks also found to have a negative effect on TN concentration of the stream. This indicates that these areas also work as an uptake of $\mathrm{TN}$ in the watersheds. The industrial areas can produce N-rich effluents and was found to be significantly contributing in summer and fall. However, the contribution is relatively weaker compared to other land use contributions.

The negative coefficients of parks and open lands and forests and the positive coefficients of upstream contribution showed that the $\mathrm{TN}$ concentrations in the watersheds are dominated by their upstream contributions. The surface runoff dilutes the concentration in the watersheds. Groundwater, which may also be an important source of nitrogen, can either have positive or negative effects based on its relative concentration to upstream and surface runoff concentrations. For TN, groundwater had a negative effect in winter when surface runoff is expected to be lower due to less precipitation and upstream contribution was found to have highest coefficient. Groundwater in winter thus brings less $\mathrm{TN}$ and dilutes the overall concentration in winter. In fall, when the upstream 
contribution was not significant, groundwater increased the TN concentration. In general, the annual profile of TN is more dominated by its summer and fall profile.

\subsubsection{Total phosphorus}

The hydrologic parameters that were significant for TP were slope and characteristics length (Table 4.5). It is understandable that, with an increase of slope, runoff is quicker and the accumulation of pollutants is less. Hence, an increase in slope is expected to decrease the surface runoff TP concentration.

Table 4.6: Multiple log-linear regression models description of total phosphorus.

\begin{tabular}{|c|c|c|c|c|c|c|c|c|c|c|c|c|c|}
\hline Eqn & & $\begin{array}{l}\text { inter- } \\
\text { cept }\end{array}$ & $\mathbf{S}$ & $\mathbf{L}_{\mathbf{c}}$ & I & $\mathbf{A}_{\mathrm{RS}}$ & $\mathbf{A}_{\mathbf{R M}}$ & $\mathbf{A}_{\mathbf{C}}$ & $\mathbf{A}_{\mathrm{I}}$ & $\mathbf{A}_{\mathrm{OL}}$ & $\mathbf{A}_{\mathbf{F}}$ & $\mathrm{C}_{\mathrm{us}}$ & GW \\
\hline \multirow{2}{*}{ : } & $\begin{array}{l}4 \\
0 \\
0\end{array}$ & -15.77 & -1.81 & 3.960 & & & -0.49 & & & & -0.289 & -1.378 & 1.182 \\
\hline & 嵓 & 4.161 & 0.483 & 1.075 & & & 0.172 & & & & 0.157 & 0.515 & 0.403 \\
\hline \multirow{2}{*}{$\stackrel{\infty}{E}$} & $\begin{array}{l}4 \\
0 \\
0\end{array}$ & -2.532 & -1.87 & 1.412 & & $\begin{array}{c}- \\
0.498\end{array}$ & & & & & & & \\
\hline & 倣 & 1.419 & 0.454 & 0.583 & & 0.302 & & & & & & & \\
\hline \multirow{2}{*}{ 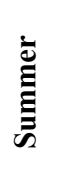 } & ن & 12.506 & -3.12 & 1.424 & -3.53 & -1.45 & & 0.924 & & -1.365 & 0.484 & & \\
\hline & 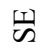 & 5.433 & 0.672 & 0.532 & 1.934 & 0.692 & & 0.404 & & 0.537 & 0.190 & & \\
\hline \multirow{2}{*}{ 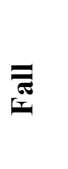 } & 苂 & -5.312 & & 1.952 & & -1.01 & & 0.691 & 0.024 & & & 1.384 & 0.692 \\
\hline & 山 & 1.016 & & 0.562 & & 0.258 & & 0.199 & 0.016 & & & 0.208 & 0.175 \\
\hline
\end{tabular}

( $\mathrm{S}=$ slope, $\mathrm{L}_{\mathrm{c}}=$ characteristics length, $\mathrm{I}=$ imperviousness, $\mathrm{A}_{\mathrm{RS}}=$ single family residential, $\mathrm{A}_{\mathrm{RM}}$ multifamily residential, $A_{C}=$ commercial, $A_{i}=$ industrial, $A_{O L}=$ parks and open lands, $A_{F}=$ forests, $G W=$ groundwater level and $\mathrm{C}_{\mathrm{us}}=$ upstream concentrations)

The role of characteristics length in TP is similar to that of TN and was discussed in the previous section. Comparing with the hydrologic parameters retained in the TN models, 
we can hypothesize that retention time is very important for nutrients as nutrients cannot be readily up taken by runoff as it moves over the surface.

It was observed that residential areas and open land and parks were negatively correlated to TP concentration in the streams. That confirmed that plants in the lawn areas, as well as, in parks and open lands retained TP for their growth and these areas act as a sink for TP concentrations. The upstream inflow that passed through Everglade area was also found to be negatively correlated in winter as plants retained TP in this area, as well, which produced a low concentration upstream in winter. Interestingly, forest areas in the watersheds, followed similar behaviors in winter but acted as a source in summer. In a previous study, it was observed that TP is released from wetland soils during the summer and fall, when relatively low stream flow rates (compared with spring) and warm temperatures (compared with winter) result in stagnant conditions that promote oxygen limitation and the release of soluble $\mathrm{Fe}^{2+}$ and associated P (O'Brien et al., 2013; Carlyle \& Hill, 2001; Roden \& Edmunds, 1997). We hypothesize that forests in this watersheds also act a source in summer under favorable conditions.

Total phosphorus in this zone is much dominated by groundwater, which is apparent in the models. In general, the summer model is dominated by land use and the fall-winter models are dominated by either groundwater or upstream. The spring model for TP has high RSR and low adjusted $\mathrm{R}^{2}$. The relatively higher standard error (compared to coefficient) shows that the spring model is probably influenced by unknown aspects not considered in this study. 


\subsubsection{Dissolved oxygen}

Dissolved oxygen (DO) which is also a measure of water aeration and photosynthetic activity, showed highest dependence on land use ( compared to other quality parameters considered) and relatively low or no dependence on groundwater and upstream (Table 4.6).

Table 4.7: Multiple log-linear regression models description of dissolved oxygen.

\begin{tabular}{|c|c|c|c|c|c|c|c|c|c|c|c|c|}
\hline \multicolumn{2}{|c|}{ Equation } & $\begin{array}{l}\text { inter- } \\
\text { cept }\end{array}$ & $\mathbf{S}$ & $\mathbf{D}_{\mathbf{c}}$ & I & $\mathbf{A}_{\mathrm{RS}}$ & $\mathbf{A}_{\mathbf{R M}}$ & $\mathbf{A}_{\mathbf{C}}$ & $\mathbf{A}_{\mathbf{I}}$ & $\mathbf{A}_{\mathrm{OL}}$ & $\mathbf{A}_{\mathbf{F}}$ & GW \\
\hline \multirow{2}{*}{ 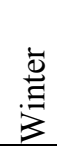 } & $\begin{array}{l}\mathscr{4} \\
0 \\
0\end{array}$ & 1.115 & -0.219 & 0.093 & -0.461 & & 0.273 & & & -0.243 & & \\
\hline & 乩 & 0.742 & 0.091 & 0.029 & 0.285 & & 0.030 & & & 0.041 & & \\
\hline \multirow{2}{*}{$\begin{array}{l}00 \\
\text { की } \\
\text { की }\end{array}$} & $\begin{array}{l}\overrightarrow{4} \\
0 \\
0\end{array}$ & -0.030 & 0.301 & & & & 0.272 & -0.194 & & & & \\
\hline & 㴈 & 0.271 & 0.091 & & & & 0.048 & 0.055 & & & & \\
\hline \multirow{2}{*}{ 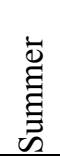 } & $\begin{array}{l}\mathbb{E} \\
8 \\
0\end{array}$ & 0.747 & 0.330 & -0.316 & & 0.598 & 0.380 & -0.79 & -0.009 & & -0.091 & \\
\hline & $\stackrel{\omega}{\mathscr{S}}$ & 0.865 & 0.135 & 0.056 & & 0.134 & 0.063 & 0.139 & 0.004 & & 0.044 & \\
\hline & 离 & -0.863 & & -0.066 & & 0.344 & 0.157 & -0.172 & & & -0.146 & 0.162 \\
\hline 雳 & 笿 & 0.766 & & 0.041 & & 0.154 & 0.058 & 0.086 & & & 0.048 & 0.050 \\
\hline
\end{tabular}

Among the hydrologic parameters, distance from the coast and slope are the major dominant parameters. It was observed that in winter when stream flow is low, DO increased as the distance from the coast increased but in summer and fall DO decreased as the distance from the coast increased. We hypothesize that in winter, due to low flow sea water dominates and intrusion of seawater forces the stream flow. Hence, higher the distance from coast, less the salinity and higher DO is expected. But in summer and fall, when stream flow was high, sea water intrusion was minimum. So, closer to the coast, 
higher the dissolved oxygen was found. The results were in line with the initial observations of spatial distribution of DO, where DO was found higher in downstream direction before reaching the brackish region. These two observations lead to hypothesize that DO in the urban part of the study area increased relative to its forest and agricultural upstream portion. The hypothesis is supported by the coefficients as DO increased with an increase in residential areas and decreased with an increase in agricultural and forest areas. It was observed in a previous study that the concentration of DO was lower in old forests relative to young forests and agricultural areas (Uriarte et al., 2011). In our study, we found negative correlation between forests and DO in the streams. Both forests and agricultural and open lands produce litters and other organic contents that decrease stream DO concentration.

The positive correlation of residential areas can be explained by two observations. Firstly, the conversion of most open lands in this area was used for development of residential areas. Hence higher residential area also signifies higher conversion of open lands which is a major source of litters that lower DO in streams. Also, in the TP model, we found that residential areas retain nutrients which enhance stream DO due to lower possibility of eutrophication. Commercial areas have less nutrient generation and higher runoff due to higher impervious areas. So, eventually commercial areas have low concentration high volume runoff that enhanced DO of the streams, as well. In general, the DO models are urban land use and watershed hydrology dominated. Groundwater was important only in some seasons, when overland flows were low. 


\subsubsection{Specific conductance}

Specific conductance increases with an increase in salinity. Distance of the stream point from the coast is therefore the most important factor for specific conductance of the corresponding stream points. From surface runoff perspective, specific conductance is more triggered by solids for which accumulation time is less likely to be important. Instead a high retention time might cause re-suspension of the dissolved particles. Therefore a quicker runoff might have positive effect on stream specific conductance as seen in the models (Table 4.7).

Table 4.8: Multiple log-linear regression models description of specific conductance.

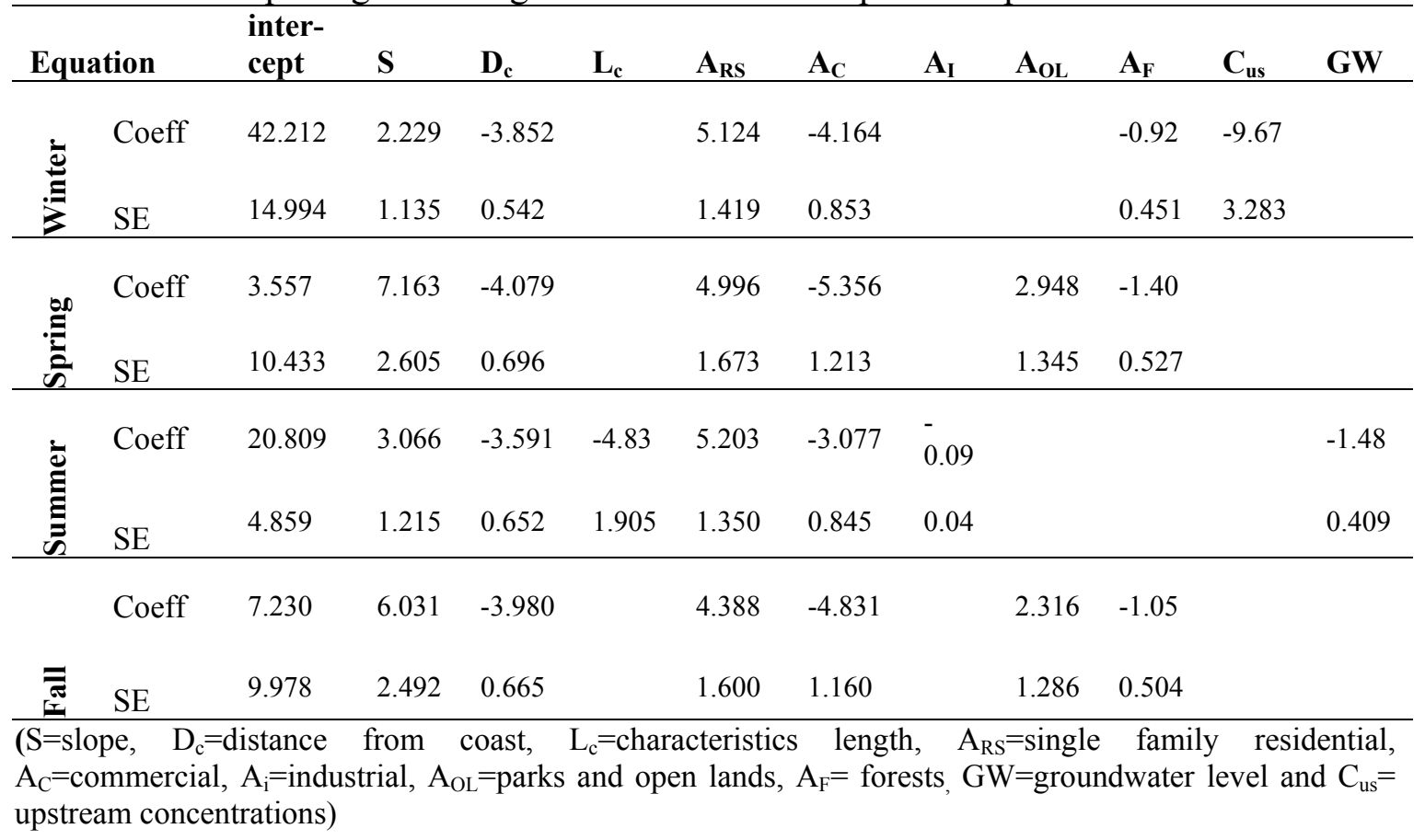

For specific conductance groundwater, is significant only in summer, when precipitation is higher. Upstream contribution was found significant in winter, when there was less 
flow in the streams. The upstream contribution was negative, as it carried freshwater flows.

Among the different types of land uses, residential areas and parks, agricultural areas and open lands were positively correlated with specific conductance, as they are the primary source of solids. Commercial areas are expected to produce less solids (compared to residential) due to lower impervious areas. On the contrary, forests work as retention of solids and decrease the specific conductance in the stream, as well.

\subsubsection{Chlorophyll a}

For chlorophyll a, the models (Table 4.8) did not show a satisfactory goodness of fit. The adjusted $\mathrm{R}^{2}$ value ranged from 0.13 to 0.44 and the RSR was higher than 0.75 . This indicates that chlorophyll a cannot be adequately modeled by considering the hydrologic and land use details of the watershed only. Chlorophyll a is an indication of photosynthetic activities in the stream and depends largely on the algal growth profile and in-stream dynamics. Temperature and lights are two important factors, as well. However, within the scope of the models, chlorophyll a showed some resemblance to TP and TN models. As in case of TN and TP, DO also showed correlated to retention time by retaining slope and characteristics length. 
Table 4.9: Multiple log-linear regression models description of chlorophyll a.

\begin{tabular}{|c|c|c|c|c|c|c|c|c|c|c|c|c|c|}
\hline \multicolumn{2}{|c|}{ Equation } & $\begin{array}{l}\text { inter- } \\
\text { cept }\end{array}$ & S & $\mathrm{D}_{\mathrm{c}}$ & $\mathrm{L}_{\mathrm{c}}$ & I & $A_{R S}$ & $\mathrm{~A}_{\mathrm{C}}$ & $\mathrm{A}_{\mathrm{I}}$ & $\mathrm{A}_{\mathrm{OL}}$ & $\mathrm{A}_{\mathrm{F}}$ & $\mathrm{C}_{\mathrm{us}}$ & GW \\
\hline \multirow{2}{*}{$\stackrel{\overrightarrow{0}}{:}$} & 荧 & -8.582 & -1.999 & 0.629 & 2.135 & & & & & & -0.302 & & \\
\hline & $\sqrt[1]{\Omega}$ & 4.568 & 0.903 & 0.296 & 1.085 & & & & & & 0.185 & & \\
\hline \multirow{2}{*}{ 典 } & $\begin{array}{l}\stackrel{\sharp}{0} \\
8 \\
0\end{array}$ & 0.809 & & -0.746 & 3.079 & & & -1.399 & 0.073 & & & -1.563 & 2.103 \\
\hline & 至 & 3.476 & & 0.303 & 1.420 & & & 0.554 & 0.031 & & & 0.812 & 0.858 \\
\hline \multirow{2}{*}{ 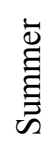 } & 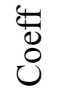 & 7.196 & & & & & -1.273 & & & & 0.579 & 0.571 & \\
\hline & 项 & 5.768 & & & & & 0.904 & & & & 0.310 & 0.382 & \\
\hline \multirow[t]{2}{*}{$\overline{\bar{\sigma}}$} & $\begin{array}{l}\text { 岕 } \\
0 \\
0\end{array}$ & 19.769 & & & & -6.038 & -1.593 & 0.981 & & -0.740 & 0.429 & & \\
\hline & 项 & 7.205 & & & & 2.568 & 0.777 & 0.511 & & 0.533 & 0.250 & & \\
\hline
\end{tabular}

( $\mathrm{S}=$ slope, $\mathrm{D}_{\mathrm{c}}=$ distance from coast, $\mathrm{L}_{\mathrm{c}}=$ characteristics length, $\mathrm{I}=$ imperviousness, $\mathrm{A}_{\mathrm{RS}}=$ single family residential, $A_{C}=$ commercial, $A_{I}=$ industrial, $A_{F}=$ forests, $C_{U S}=$ upstream concentrations, $G W=$ groundwater level)

It is understood from the models that greater the distance from the coast and the higher the concentration of chlorophyll a in the streams. Salinity decreased with an increase in distance from coast. As DO have a negative correlation with salinity, DO increased as the distance from the coast increased. Chlorophyll a is therefore higher in distant sites from the coast. Groundwater, which has higher nutrient and DO concentration was found to be positively correlated with chlorophyll a, also.

\subsubsection{Multiple regression models for dry and wet periods}

The four seasonal analyses revealed similarities in contributory parameters in different seasons for the same water quality parameter. Based on this observation, we developed multiple linear regression models for the water quality parameters by dividing the year in 
two seasons, i.e., dry (November 01 to April 30) and wet (May 1 to October 30) period. The dry and wet period models (Table 4.9 and Figure 4.10 ) explained $93 \%$ and $88 \%$ of the variance about the mean for TN. For DO (91\% and 90\%) and specific conductance $(88 \%$ and $84 \%)$ the model performance was satisfactory as well.

Table 4.10: Multiple linear regression model performances for dry and wet periods.

\begin{tabular}{llllll}
\hline $\begin{array}{l}\text { Quality } \\
\text { parameter }\end{array}$ & $\begin{array}{l}\text { Temporal } \\
\text { scale }\end{array}$ & $\mathbf{R}^{\mathbf{2}}$ & Adjusted $\mathbf{R}^{2}$ & $\begin{array}{l}\text { Standard } \\
\text { error }\end{array}$ & RSR \\
\hline \multirow{2}{*}{ TN } & Dry period & 0.949 & 0.917 & 0.031 & 0.286 \\
& Wet period & 0.876 & 0.841 & 0.037 & 0.399 \\
\hline \multirow{2}{*}{ TP } & Dry period & 0.663 & 0.595 & 0.167 & 0.636 \\
& Wet period & 0.704 & 0.645 & 0.155 & 0.596 \\
\hline \multirow{2}{*}{ DO } & Dry period & 0.911 & 0.885 & 0.019 & 0.339 \\
& Wet period & 0.906 & 0.869 & 0.026 & 0.362 \\
\hline \multirow{2}{*}{ CON } & Dry period & 0.876 & 0.796 & 0.354 & 0.451 \\
& Wet period & 0.836 & 0.754 & 0.375 & 0.496 \\
\hline \multirow{2}{*}{ Chl a } & Dry period & 0.293 & 0.091 & 0.248 & 0.953 \\
& Wet period & 0.452 & 0.343 & 0.230 & 0.811 \\
\hline
\end{tabular}

For TP (60\% and 65\%) and chlorophyll a (9\% and 34\%) the model was not successful in explaining variance. For specific conductance, similar to four seasonal analyses, two distinct regimes were visible for freshwater and seawater, which indicates that two separate models would be more appropriate for specific conductance. 


\section{TN}

TP

DO

CON

Chl A

Dry period

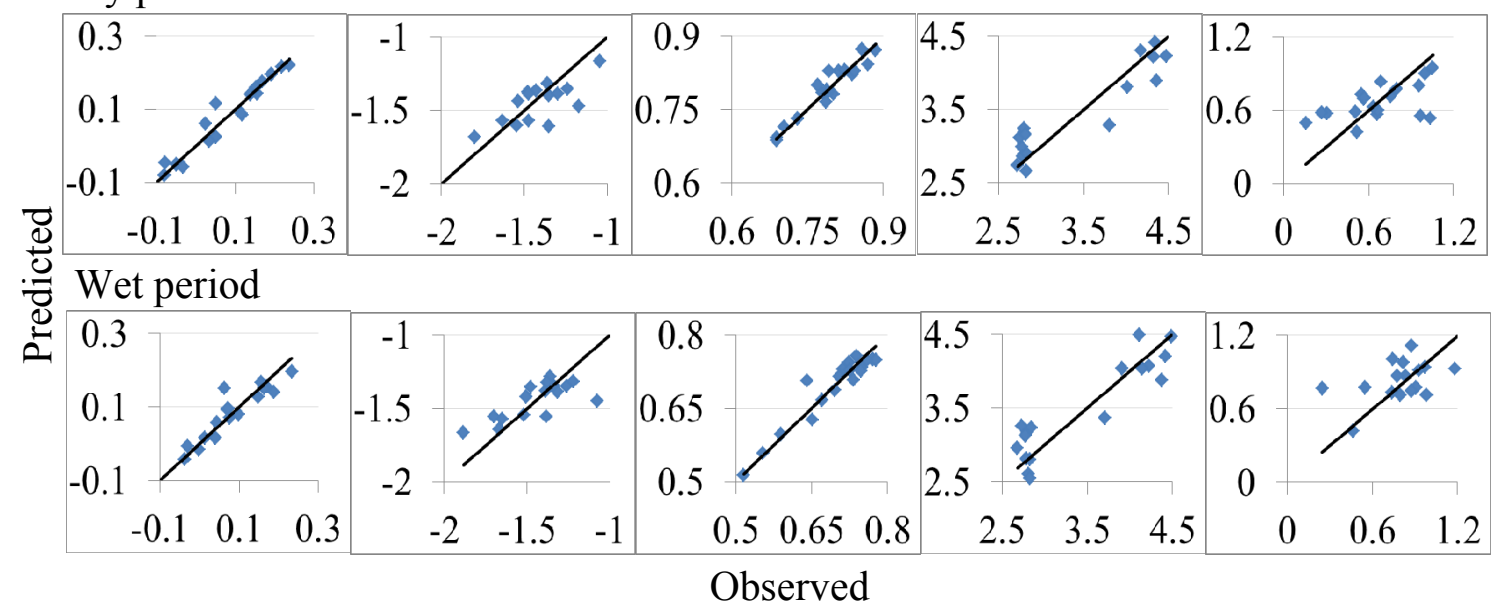

Figure 4.10: Observed vs. predicted values for dry and wet period

\subsubsection{Total nitrogen}

The dry and wet period model for TN was consistent with the seasonal models previously described (Table 4.10). Distance from the coast and the characteristics length appeared to be significant hydrologic parameters for TN in this case as well. Among the land use parameters, commercial and industrial areas were found to be positively and open lands and forests were found to be negatively correlated.

Table 4.11: Multiple log-linear regression models description of Total nitrogen.

\begin{tabular}{|c|c|c|c|c|c|c|c|c|c|c|}
\hline Equation & $\begin{array}{l}\text { inter- } \\
\text { cept }\end{array}$ & $\mathbf{D}_{\mathbf{c}}$ & $\mathbf{L}$ & I & $\mathbf{A}_{\mathrm{RM}}$ & $\mathbf{A}_{\mathbf{C}}$ & $\mathbf{A}_{\mathbf{I}}$ & $\mathbf{A}_{\mathrm{OL}}$ & $\mathbf{A}_{\mathbf{F}}$ & $\mathrm{C}_{\mathrm{US}}$ \\
\hline$\tau^{\text {Coeff }}$ & 0.630 & 0.307 & & -1.154 & 0.096 & 0.224 & 0.010 & -0.346 & & 1.494 \\
\hline 党 $\mathrm{SE}$ & 1.082 & 0.035 & & 0.413 & 0.052 & 0.078 & 0.005 & 0.089 & & 0.315 \\
\hline \multirow{2}{*}{$\begin{array}{ll} & \text { Coeff } \\
\text { SE } & \end{array}$} & -1.609 & 0.275 & 0.495 & -0.655 & & & & & -0.09 & \\
\hline & 0.682 & 0.034 & 0.117 & 0.239 & & & & & 0.023 & \\
\hline
\end{tabular}

( $D_{c}=$ distance from coast, $L_{c}=$ characteristics length, $I=$ imperviousness, $A_{c}=$ commercial area $A_{l}=$ industrial area, $\mathrm{A}_{\mathrm{OL}}=$ open lands and parks, $\mathrm{A}_{\mathrm{F}}=$ forests, $\mathrm{C}_{\mathrm{us}}=$ upstream concentrations) 
The only major difference with the seasonal models was the role of groundwater. Unlike four seasonal analyses, groundwater didn't retain in any of the models as a significant contributor for TN. In general, upstream contribution was dominant for TN in dry periods and the relative role of land use and upstream could not be revealed due to dominance of hydrologic parameters in wet periods.

\subsubsection{Total phosphorus}

For total phosphorus, the dry and wet period models (Table 4.11) were dominated by two hydrologic parameters as well. The models were, however, consistent as slope was negatively and characteristics length was positively correlated to TP in four seasons, as well. Similar to the wet period model of TN, in both dry and wet period models for TP, none of the land use, groundwater and coastal parameter retained due to dominance of the two hydrologic parameters. We hypothesize that, for nutrients, the seasonal classification solely based on rainfall increases the explanatory power of hydrologic parameters. The high RSR values ( 0.64 for dry and 0.6 for wet period) for TP model need careful consideration for application of the models.

Table 4.12: Multiple log-linear regression models description of total phosphorus.

\begin{tabular}{|c|c|c|c|c|c|}
\hline Equation & & intercept & $\mathbf{S}$ & $\mathbf{L}_{\mathbf{c}}$ & $\mathbf{A}_{\mathrm{OL}}$ \\
\hline $\begin{array}{l}\overrightarrow{0} \\
\frac{0}{0} \\
2\end{array}$ & 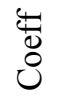 & -3.218 & -2.432 & 1.394 & -0.404 \\
\hline$\vec{b}$ & 㥈 & 1.426 & 0.623 & 0.464 & 0.251 \\
\hline $\begin{array}{l}\overrightarrow{0} \\
\overrightarrow{0} \\
2\end{array}$ & 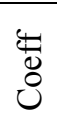 & -2.618 & -2.586 & 1.310 & -0.414 \\
\hline 3 & 뎅 & 1.319 & 0.576 & 0.429 & 0.232 \\
\hline
\end{tabular}




\subsubsection{Dissolved oxygen}

The dry and wet period models (Table 4.12) for dissolved oxygen were consistent with the four seasonal models, as well. Distance from the coast was positively correlated in the dry period and was negatively correlated in the wet period. Residential areas were found to be positively correlated and commercial areas and open lands and parks were negatively correlated, as previous. The dry and wet period model supports our assumption that urban DO increased in the residential area dominated urban part relative to its agricultural and forest upstream parts in wet seasons. The dry period was dominated by seawater intrusion, as previous, too.

Table 4.13: Multiple log-linear regression models description of dissolved oxygen.

\begin{tabular}{|c|c|c|c|c|c|c|c|c|}
\hline & Equation & intercept & $\mathbf{S}$ & $\mathbf{D}_{\mathbf{c}}$ & $\mathbf{A}_{\mathrm{RS}}$ & $\mathbf{A}_{\mathrm{RM}}$ & $\mathbf{A}_{\mathrm{C}}$ & $\mathrm{A}_{\mathrm{OL}}$ \\
\hline 宽 & 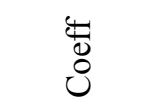 & 0.187 & -0.245 & 0.109 & & 0.225 & & -0.189 \\
\hline$\vec{E}$ & 蚖 & 0.225 & 0.060 & 0.020 & & 0.022 & & 0.020 \\
\hline $\begin{array}{l}\overrightarrow{0} \\
\frac{0}{0} \\
2\end{array}$ & $\begin{array}{l}\stackrel{4}{\mathscr{D}} \\
0 \\
0\end{array}$ & 1.186 & 0.393 & -0.181 & 0.181 & 0.383 & -0.564 & \\
\hline$\sum^{0}$ & 崩 & 0.323 & 0.097 & 0.041 & 0.069 & 0.049 & 0.109 & \\
\hline
\end{tabular}

$\left(\mathrm{S}=\right.$ slope, $\mathrm{L}_{\mathrm{c}}=$ characteristics length, $\mathrm{I}=$ imperviousness, $\mathrm{A}_{\mathrm{RS}}=$ single family residential, $\mathrm{A}_{\mathrm{RM}}$ multifamily residential, $A_{C}=$ commercial, $A_{i}=$ industrial, $A_{O L}=$ parks and open lands, $A_{F}=$ forests, $G W=$ groundwater level and $\mathrm{C}_{\mathrm{us}}=$ upstream concentrations)

\subsubsection{Specific conductance}

For the specific conductance model (Table 4.13) for dry period, upstream contribution was a significant contributor. The observation was consistent with the four seasonal model where upstream contribution was significant in winter model only. The major difference with the four seasonal model was the absence of GW as a significant predictor in wet period, unlike in summer model. Relative roles of different land uses were 
consistent with the four seasonal models, as well. For specific conductance, similar to four seasonal analyses, two distinct regimes were visible for freshwater and seawater, which indicates that two separate models would be more appropriate for specific conductance.

Table 4.14: Multiple log-linear regression models description of specific conductance.

\begin{tabular}{|c|c|c|c|c|c|c|c|c|c|c|}
\hline \multicolumn{2}{|c|}{ Equation } & intercept & $S$ & $\mathbf{D}_{\mathrm{c}}$ & $\mathbf{A}_{\mathrm{RS}}$ & $\mathbf{A}_{\mathrm{C}}$ & $\mathbf{A}_{I}$ & $A_{\mathrm{OL}}$ & $A_{F}$ & $\mathrm{C}_{\mathrm{us}}$ \\
\hline \multirow{2}{*}{ 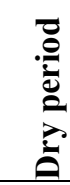 } & ن̈ & 82.594 & 3.245 & -4.605 & 8.287 & -6.423 & -0.128 & & -1.095 & -25.481 \\
\hline & 番 & 28.364 & 1.225 & 0.707 & 1.777 & 1.317 & 0.068 & & 0.464 & 9.065 \\
\hline \multirow{2}{*}{ 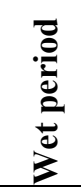 } & ن⿺辶 & 5.108 & 6.271 & -3.891 & 4.561 & -4.884 & & 2.510 & -1.185 & \\
\hline & 番 & 9.762 & 2.438 & 0.651 & 1.565 & 1.135 & & 1.259 & 0.493 & \\
\hline
\end{tabular}

( $\mathrm{S}=$ slope, $\mathrm{L}_{\mathrm{c}}=$ characteristics length, $\mathrm{I}=$ imperviousness, $\mathrm{A}_{\mathrm{RS}}=$ single family residential, $\mathrm{A}_{\mathrm{RM}}$ multifamily residential, $A_{C}=$ commercial, $A_{i}=$ industrial, $A_{O L}=$ parks and open lands, $A_{F}=$ forests,$G W=$ groundwater level and $\mathrm{C}_{\mathrm{us}}=$ upstream concentrations)

\subsubsection{Chlorophyll a}

For chlorophyll a, the dry and wet season models (Table 4.14) did not show a satisfactory goodness of fit, as well. The adjusted $\mathrm{R}^{2}$ value in this cases were 0.09 (dry) and 0.34 (wet). The RSR values were 0.95 and 0.81 accordingly. This lead to conclude that chlorophyll a cannot be adequately modeled by considering the hydrologic and land use details of the watershed only. The algal growth profile and in-stream dynamics should be carefully considered, too. 
Table 4.15: Multiple log-linear regression models description of chlorophyll a.

\begin{tabular}{|c|c|c|c|c|c|c|c|c|}
\hline Equation & & intercept & $\mathbf{S}$ & $\mathbf{D}_{\mathbf{c}}$ & $\mathbf{L}_{\mathbf{c}}$ & $\mathbf{A}_{\mathrm{RS}}$ & $\mathbf{A}_{\mathrm{OL}}$ & $\mathbf{A}_{\mathbf{F}}$ \\
\hline \multirow{2}{*}{ 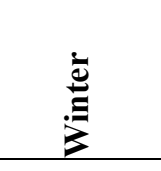 } & נֶّ & -1.428 & -2.146 & 0.388 & 1.340 & & -0.565 & \\
\hline & s & 2.397 & 1.057 & 0.220 & 0.817 & & 0.420 & \\
\hline \multirow{2}{*}{$\stackrel{60}{E}$} & ن & 8.897 & & & & -1.460 & & 0.630 \\
\hline & 秃 & 4.935 & & & & 0.783 & & 0.263 \\
\hline
\end{tabular}

\subsection{DISCUSSION}

Linking land use to stream water quality using spatial data has been an area of active research. Kang et al. (2010) developed regression models linking land use types for urban watershed and predicted bacterial and metal concentrations with reasonable goodness of fit (Adjusted $\mathrm{R}^{2}$ from 0.5 to 0.83 for dry weather and $0.67-0.95$ for wet weather). In our study, we also found a statistically significant linkage between watershed land use and corresponding stream water quality. The inclusion of upstream, coastal and groundwater contribution added more explanatory power to the models with reasonable goodness of fit.

For total nitrogen $(\mathrm{TN})$, in our study we found stronger contribution of upstream than that of watershed land uses. It was observed in a previous study (Swaney et al., 2012) that $75 \%$ or so of net anthropogenic nitrogen inputs of watershed is not exported in rivers which explains the reason for weaker correlations with the watershed land use (compared to upstream). The study (Swaney et al., 2012) also suggested that forests act 
as retention sites for nutrients, which is supported in our findings. Mayer et al. (2010) showed optimal conditions for nitrogen removal in urban streams probably occur when groundwater residence time is long. In our study, we also found negative correlation between groundwater and TN concentration of stream in winter, when stream flow is low and groundwater residence time is possibly high.

According to the literature (Drolc \& Koncan, 2002; Mainstone \& Parr, 2002), the major anthropogenic sources for total phosphorus (TP) include wastewater treatment plants, animal excreta, point sources and agriculture. In our study, we could not establish any such relationships. However, according to Mainstone and Parr (2002), sub-surface drainage and leaching may be important pathways for phosphorus under certain conditions, particularly if the soil is overloaded with phosphorus. Sandy soils and underlying sandstone geology are particularly vulnerable since they have a very low adsorption capacity for phosphorus. Geological formation of Broward County suggests most of the study area has well or excessively drained sandy soil. We hypothesize that, subsurface flow is the major source for total phosphorus in Broward, which is evident in the models due to its geological formation. For TP, distance from the coast was not significant which indicates less influence of seawater in comparison to surface runoff, groundwater and upstream contribution. The initial findings of correlation analysis that suggested that total phosphorus is the limiting nutrient in this zone is strengthened as TP is less affected by salinity in this coastal watersheds.

Dissolved oxygen has been suggested to be used as a natural tracer (Sklash et al., 1976) of watershed pollution (Sanchez et al., 2007). We also found stronger influence of land 
use components (compared to nutrients) on dissolved oxygen (DO) concentration in a complex urban watershed compared to upstream, coastal and groundwater. It was interesting to observe that residential areas were not significant in total nitrogen models as they were in DO models. We hypothesize that the relative dominance of upstream contribution limited the significance in case of total nitrogen. In a watershed, receiving little or no TN from upstream, the significance of residential areas will be higher.

Specific conductance in the streams were influenced both by their distance from the coast and corresponding land uses. This was expected as the majority of the sites were freshwater sites for which watershed disturbance is a major source of solids. The term "watershed disturbance" refers to alteration of natural lands for urban development and should be differentiated from "watershed pollution" as the first term refers mostly to generation of solids. According to literature (Dow \& Zampella, 2000; Zampella et al., 2007), specific conductance can be used as an indicator of watershed disturbance. We also found good correlations between land use and stream specific conductance.

Chlorophyll a in a stream largely depends on DO and nutrients, which in turn are affected by watershed land use and hydrology. A correlation of watershed response to stream chlorophyll a is thus expected. However, to develop a predictive model for chlorophyll a, in-stream details of zooplankton abundance, hydrologic flushing rate (Hoyer \& zones, 2011), biomass, substratum are to be considered. In our study however, we found reasonable correlations of watershed land use and hydrology parameters. But the model lacks predictive power and goodness of fit, as the stream and flow characteristics are not considered. 
The empirical predictive models we have developed can significantly explain the relative role of watershed land use and hydrology to groundwater, coastal and upstream contribution. The consistency of variables in four seasonal models to dry and wet period models showed that the technique can be useful in understanding dominating stressors for in-stream water quality parameters. However, the models are climate implicit, which means they can interpret the effect of changing climate in terms of the parameters considered but climatic details are not incorporated in the model. The limited spatial dataset might also affect the results and the models need to be validated with a larger dataset. A climate implicit model may be useful in predicting stream water quality, however the parameterization of the model should carefully consider the risk of multicolinearity.

\subsection{CONCLUSIONS}

The research broadens the perspective of traditional empirical modeling of urban water quality by comparing internal (i.e., land use and hydrology) and external components (i.e., seawater, groundwater, upstream input) of a watershed simultaneously. It can provide insight into the stream water quality by considering the concurrent dataset of spatially variable stressors and correlating each water quality parameter with the dominant ones.

From the analysis and results, it is evident that internal components were more dominant for dissolved oxygen and specific conductance (in non-coastal areas) and external components were more dominant for total nitrogen (upstream contribution) and total phosphorus (Subsurface flow) in the watershed of Broward County. For chlorophyll a, in- 
stream variables and flow characteristics should be considered for more insightful and explanatory model development. The dry and wet period analysis showed that hydrologic parameters gain higher explanatory powers in purely rainfall based seasonal divisions. The dry and wet period analysis was consistent with the four seasonal analysis, which shows potential of multiple regression analysis in robust explanatory stream water quality model developments.

The results recommend a holistic watershed approach for appropriate empirical modeling and predictions of stream water quality in complex urban watersheds. The temporal validity of these models would require careful consideration of the changing pattern of land use and climate. Appropriate scaling technique, for incorporating temporal variability, might be useful for developing a robust model for stream water quality with respect to spatio-temporal variables. 


\section{CHAPTER 5}

\section{CONCLUSIONS AND RECOMMENDATIONS}

\subsection{CONCLUSIONS}

The research broadens the perspective of traditional stormwater modeling by resolving stormwater runoff as a component of the total watershed water budget, incorporating all the important processes (i.e., groundwater, sea level, in addition to climatic drivers and land use features) using both the mechanistic and empirical approaches. The results recommend a holistic watershed approach for appropriate modeling and predictions of stream water quality in complex urban watersheds.

The sensitivity analysis using rainfall-runoff model showed that stormwater runoff and quality has the greatest sensitivity to rainfall between the climate parameters and imperviousness among the hydrologic parameters. Higher increase in runoff and pollutants was also found for conversion of open lands and agricultural areas. The study quantified seasonal as well as annual sensitivity coefficients for runoff and six major quality parameters (TSS, TN, TP, BOD, $\mathrm{Cu}$ and $\mathrm{Zn}$ ). The quantified climate and land use sensitivity would be useful for appropriate management of stormwater quantity and quality in complex urban watersheds under a changing climate, sea level, hydrology, and land use/cover.

The empirical models quantitatively explained stream water quality by considering the concurrent dataset of spatially variable stressors. In-stream dissolved oxygen and total 
phosphorus in the coastal urban watersheds were dictated by internal stressors, while external stressors were dominant for total nitrogen and specific conductance. Statistically significant spatio-temporal empirical models were developed for the five quality parameters (TN, TP, DO, chlorophyll a and specific conductance) that can be used to predict seasonal stream water quality profiles under similar hydro-climatic and land use conditions.

\subsection{LIMITATIONS OF THE STUDY}

Due to the limitations in the parameterization of Storm Water Management Model (EPA SWMM 5), the variation of important climate parameters (i.e., radiation, temperature) could not be included in this study. The lack of climate data at appropriate temporal and spatial scale for stormwater modeling also affected the analysis results. Although the model was developed on historical event mean concentrations of quality parameters, a site specific water quality measurement would be more appropriate for the analysis.

The regression models are climate implicit which means they can interpret the effect of changing climate in terms of the parameters considered, but climatic details are not incorporated in the model. The limited spatial dataset might also affect the results and the models need to be validated with a larger dataset.

\subsection{RECOMMENDATIONS}

For the sensitivity analysis using rainfall-runoff model, a comparison with similar watershed scale models, developed in different hydro-climatological regimes, will be helpful for comparing the robustness of the model prediction. It will be interesting to see 
the model response in connection with some of the regional climate models (RCM) for assessing future stormwater runoff and quality under changing climate and land use scenarios (Rehfeldt et al., 2012; Terando et al., 2012). A comprehensive uncertainty analysis of the parameters will provide more insights on sensitivities in changing hydroclimatic and land use conditions.

For the spatio-temporal regression model, a climate-explicit scheme may be useful in predicting stream water quality. However, the parameterization of the model should be carefully considered to avoid the risk of multicolinearity. Appropriate scaling techniques for incorporating spatio-temporal variability can be useful for developing a robust model for stream water quality analysis and predictions. 


\section{REFERENCES}

Abdul-Aziz (2008). Ecohydrology of Unit River Ecosystems: Scaling and Critical Responses of Stream Health Indicators to the Environmental Drivers. Ph.D. thesis, Department of Civil Engineering, University of Minnesota, Minneapolis.

Abdul-Aziz, O.I., Wilson, B.N. and Gulliver, J. S. (2010). Two-zone model for stream and river ecosystems. Hydrobiologia, 638 (1): 85-107, doi: 10.1007/s10750-009$0011-7$.

Akbal, F., Gürel, L., Bahadır, T., Güler, İ., Bakan, G., \& Büyükgüngör, H. (2011). Multivariate Statistical Techniques for the Assessment of Surface Water Quality at the Mid-Black Sea Coast of Turkey. Water, Air, \& Soil Pollution, 216(1), 21-37.

Al-Amin, S. and Abdul-Aziz, O.I. (2013). "Challenges in mechanistic and empirical modeling of stormwater: Review and perspectives." Irrigation and Drainage, Wiley, in press.

Alves, M. R., Dias, H. C. T., Lani, J. L., Paiva, H. D., Gleriani, J. M., \& Pinheiro, J. A. C. (2009). Water quality in the function of the catchment pluviometria of the stream Zerede, Timoteo, Minas Gerais. Floresta e Ambiente, 16(1), 30-38.

Astel, A., Tsakovski, S., Barbieri, P., \& Simeonov, V. (2007). Comparison of selforganizing maps classification approach with cluster and principal components analysis for large environmental data sets. Water Research, 41(19), 4566-4578.

Bach, P. M., McCarthy, D. T., \& Deletic, A. (2010). Redefining the stormwater first flush phenomenon. Water research, 44(8), 2487-2498.

Bäckström M, Nilsson U, Håkansson K, Allard B, Karlsson S. 2003. Speciation of heavy metals in road runoff and roadside total deposition. Water, Air, \& Soil Pollution, 147(1), 343-366.

Barrocu, G., Dahab, K., Taniguchi, M., \& Holman, I. P. (2010). Changing climate and saltwater intrusion in the Nile Delta, Egypt. Groundwater response to changing climate, 11-25.

Bhaduri, B., Harbor, J., Engel, B., \& Grove, M. (2000). Assessing watershed-scale, longterm hydrologic impacts of land-use change using a GIS-NPS model. Environmental Management, 26(6), 643-658.

Bhattacharya, B., Deibel, I. K., Karstens, S. A. M., \& Solomatine, D. P. (2007). Neural networks in sedimentation modeling approach channel of the port area of Rotterdam. Proceedings in Marine Science, 8, 477-492. 
Bhattacharya, B., Lobbrecht, A. H., \& Solomatine, D. P. (2003). Neural networks and reinforcement learning in control of water systems. Journal of water resources planning and management, 129(6), 458-465.

Brezonik, P. L., \& Stadelmann, T. H. (2002). Analysis and predictive models of stormwater runoff volumes, loads, and pollutant concentrations from watersheds in the Twin Cities metropolitan area, Minnesota, USA. Water Research, 36(7), 17431757.

Broward County Environmental Protection Department. (2007). Broward County, florida water quality atlas: freshwater canals $1998-2003$.

http://www.broward.org/EnvironmentAndGrowth/EnvironmentalProgramsResourc es/Publications/Documents/water_atlas_19982003.pdf (accessed on July 19, 2013)

Burian, S. J., Streit, G. E., McPherson, T. N., Brown, M. J., \& Turin, H. J. (2001). Modeling the atmospheric deposition and stormwater washoff of nitrogen compounds. Environmental Modeling \& Software, 16(5), 467-479.

Burns, M. J., Fletcher, T. D., Walsh, C. J., Ladson, A. R., \& Hatt, B. E. (2012). Hydrologic shortcomings of conventional urban stormwater management and opportunities for reform. Landscape and Urban Planning.

Butler, J. R., Wong, G. Y., Metcalfe, D. J., Honzák, M., Pert, P. L., Rao, N., \& Brodie, J. E. (2011). An analysis of trade-offs between multiple ecosystem services and stakeholders linked to land use and water quality management in the Great Barrier Reef, Australia. Agriculture, Ecosystems \& Environment.

Cardenas, M. B. (2008). Surface water-groundwater interface geomorphology leads to scaling of residence times. Geophysical Research Letters, 35(8), L08402.

Chang, H. (2008). Spatial analysis of water quality trends in the Han River basin, South Korea. Water Research, 42(13), 3285-3304.

Chang, H. (2007). Comparative streamflow characteristics in urbanizing basins in the Portland Metropolitan Area, Oregon, USA. Hydrological Processes, 21(2), 211 222.

Chang, H., \& Kwon, W. T. (2007). Spatial variations of summer precipitation trends in South Korea, 1973-2005. Environmental Research Letters, 2(4), 045012.

Chang, H. (2005). Spatial and temporal variations of water quality in the Han River and its tributaries, Seoul, Korea, 1993-2002. Water, Air, and Soil Pollution, 161(1-4), 267-284.

Chang, H., \& Carlson, T. N. (2005). Water quality during winter storm events in Spring Creek, Pennsylvania USA. Hydrobiologia, 544(1), 321-332. 
Chiew, F. H. S., Whetton, P. H., McMahon, T. A., \& Pittock, A. B. (1995). Simulation of the impacts of climate change on runoff and soil moisture in Australian catchments. Journal of Hydrology, 167(1), 121-147.

Chelsea Nagy, R., Graeme Lockaby, B., Kalin, L., \& Anderson, C. (2012). Effects of urbanization on stream hydrology and water quality: the Florida Gulf Coast. Hydrological Processes, 26(13), 2019-2030.

Claessens, L., Hopkinson, C., Rastetter, E., \& Vallino, J. (2006). Effect of historical changes in land use and climate on the water budget of an urbanizing watershed. Water Resources Research, 42(3), W03426.

Cooper, R. M., \& Lane, J. (1987). An atlas of eastern Broward County Surface water management basins. Water Resources Division, Resource Planning Department, South Florida Water Management District.

Cordovilla, M. P., Ligero, F., \& Lluch, C. (1994). The effect of salinity on N fixation and assimilation in Vicia faba. Journal of experimental botany, 45(10), 1483-1488.

Crosa, G., Froebrich, J., Nikolayenko, V., Stefani, F., Galli, P., \& Calamari, D. (2006). Spatial and seasonal variations in the water quality of the Amu Darya River (Central Asia). Water research, 40(11), 2237-2245.

Dean, C. M., Sansalone, J. J., Cartledge, F. K., \& Pardue, J. H. (2005). Influence of hydrology on rainfall-runoff metal element speciation. Journal of Environmental Engineering, 131(4), 632-642.

Dibike, Y. B., \& Solomatine, D. P. (2001). River flow forecasting using artificial neural networks. Physics and Chemistry of the Earth, Part B: Hydrology, Oceans and Atmosphere, 26(1), 1-7.

Dow, C. L., \& Zampella, R. A. (2000). Specific conductance and pH as indicators of watershed disturbance in streams of the New Jersey Pinelands, USA. Environmental Management, 26(4), 437-445.

Drolc, A., \& Zagorc Koncan, J. (2002). Estimation of sources of total phosphorus in a river basin and assessment of alternatives for river pollution reduction. Environment international, 28(5), 393-400.

Ferguson, B. K. (1990). Role of the long-term water balance in management of stormwater infiltration. Journal of Environmental Management, 30(3), 221-233.

Foulquier, A., Malard, F., Mermillod-Blondin, F., Datry, T., Simon, L., Montuelle, B., \& Gibert, J. (2010). Vertical change in dissolved organic carbon and oxygen at the water table region of an aquifer recharged with stormwater: biological uptake or mixing?. Biogeochemistry, 99(1-3), 31-47. 
Giorgi, F., Shields Brodeur, C., \& Bates, G. T. (1994). Regional climate change scenarios over the United States produced with a nested regional climate model. Journal of Climate, 7(3), 375-399.

Gilbert, J. K., \& Clausen, J. C. (2006). Stormwater runoff quality and quantity from asphalt, paver, and crushed stone driveways in Connecticut. Water research, 40(4), $826-832$.

Gironás, J., Roesner, L. A., Crossman, L. A., \& Davis, J. (2010). A new applications manual for the Storm Water Management Model (SWMM). Environmental Modeling \& Software, 25(6), 813-814.

Goonetilleke, A., Thomas, E., Ginn, S., \& Gilbert, D. (2005). Understanding the role of land use in urban stormwater quality management. Journal of Environmental Management, 74(1), 31-42.

Govindaraju RS. 2000. Artificial neural network in hydrology. Journal of Hydrologic Engineering, 5(2), 115-137.

Hanrahan, G., Gledhill, M., House, W. A., \& Worsfold, P. J. (2003). Evaluation of phosphorus concentrations in relation to annual and seasonal physico-chemical water quality parameters in a UK chalk stream. Water research, 37(15), 35793589.

Hatt, B. E., Fletcher, T. D., Walsh, C. J., \& Taylor, S. L. (2004). The influence of urban density and drainage infrastructure on the concentrations and loads of pollutants in small streams. Environmental Management, 34(1), 112-124.

Ha, S. J., \& Stenstrom, M. K. (2008). Predictive modeling of storm-water runoff quantity and quality for a large urban watershed. Journal of Environmental Engineering, 134(9), 703-711.

Hamid, R., Tsihrintzis, V. A., \& Fuentes, H. R. (1995). Model validation for runoff pollution from urban watersheds. In The 22 nd Annual Conference on Integrated Water Resources Planning for the 21 st Century, Cambridge, MA, USA, 05/0711/95 (pp. 141-144).

Han, W. S., \& Burian, S. J. (2009). Determining effective impervious area for urban hydrologic modeling. Journal of Hydrologic Engineering, 14(2), 111-120.

Hatt, B. E., Fletcher, T. D., Walsh, C. J., \& Taylor, S. L. (2004). The influence of urban density and drainage infrastructure on the concentrations and loads of pollutants in small streams. Environmental Management, 34(1), 112-124. 
Helsel, D. R., Kim, J. I., Grizzard, T. J., Randall, C. W., \& Hoehn, R. C. (1979). Land use influences on metals in storm drainage. Journal (Water Pollution Control Federation), 709-717.

Hood, M. J., Clausen, J. C., \& Warner, G. S. (2007). Comparison of Stormwater Lag Times for Low Impact and Traditional Residential Development1. JAWRA Journal of the American Water Resources Association, 43(4), 1036-1046.

Hoyer, M. V., \& Jones, J. R. (1983). Factors affecting the relation between phosphorus and chlorophyll a in midwestern reservoirs. Canadian journal of fisheries and aquatic sciences, 40(2), 192-199.

Hsu, K. L., Gupta, H. V., \& Sorooshian, S. (1995). Artificial neural network modeling of the rainfall-runoff process. Water resources research, 31(10), 2517-2530.

Huber, W. C., Dickinson, R. E., Barnwell Jr, T. O., \& Branch, A. (1988). Storm Water Management Model, version 4. Environmental Protection Agency, 600, 3-88.

Jain, S. K. (2001). Development of integrated sediment rating curves using ANNs. Journal of hydraulic engineering, 127(1), 30-37.

Jankowsky, S., Branger, F., Braud, I., Rodriguez, F., Debionne, S., \& Viallet, P. (2011, September). Influence of urban expansion on the hydrology of small catchments: development of the suburban PUMMA model by coupling of urban and rural hydrological models. In Proceedings of the 12th International Conference on Urban Drainage.

Jewell, T. K., \& Adrian, D. D. (1978). SWMM stormwater pollutant washoff functions. Journal of the Environmental Engineering Division, 104(5), 1036-1040.

Jones, K. B., Neale, A. C., Nash, M. S., Van Remortel, R. D., Wickham, J. D., Riitters, K. H., \& O'Neill, R. V. (2001). Predicting nutrient and sediment loadings to streams from landscape metrics: a multiple watershed study from the United States Mid-Atlantic Region. Landscape Ecology, 16(4), 301-312.

Kang, J. H., Lee, S. W., Cho, K. H., Ki, S. J., Cha, S. M., \& Kim, J. H. (2010). Linking land-use type and stream water quality using spatial data of fecal indicator bacteria and heavy metals in the Yeongsan river basin. Water research, 44(14), 4143-4157.

Kannel, P. R., Lee, S., Kanel, S. R., Khan, S. P., \& Lee, Y. S. (2007). Spatial-temporal variation and comparative assessment of water qualities of urban river system: A case study of the river Bagmati (Nepal). Environmental Monitoring and Assessment, 129(1-3), 433-459. 
Kauffman, G. J., Corrozi, M. B., \& Vonck, K. J. (2006). Imperviousness: a performance measure of a delaware water resource protection area ordinance1. JAWRA Journal of the American Water Resources Association, 42(3), 603-615.

Lau, S. L., Han, Y., Kang, J. H., Kayhanian, M., \& Stenstrom, M. K. (2009). Characteristics of highway stormwater runoff in Los Angeles: metals and polycyclic aromatic hydrocarbons. Water Environment Research, 81(3), 308-318.

Lee, J. G., \& Heaney, J. P. (2003). Estimation of urban imperviousness and its impacts on storm water systems. Journal of Water Resources Planning and Management, $129(5), 419-426$.

Lee, J. H., Huang, Y., Dickman, M., \& Jayawardena, A. W. (2003). Neural network modelling of coastal algal blooms. Ecological Modelling, 159(2), 179-201.

Maestre, A., \& Pitt, R. (2006). Identification of Significant Factors Affecting Stormwater Quality Using the NSQD. Stormwater and Urban Water Systems Modeling Proceedings, Monograph, 14, 287-326.

Mahbub, P., Goonetilleke, A., Egodawatta, P. K., Yigitcanlar, T., \& Ayoko, G. A. (2011). Analysis of build-up of heavy metals and volatile organics on urban roads in Gold Coast, Australia. Water Science and Technology, 63(9), 2077-2085.

Mahbub, P., Ayoko, G. A., Egodawatta, P., Yigitcanlar, T., \& Goonetilleke, A. (2011). Traffic and climate change impacts on water quality: measuring build-up and wash-off of heavy metals and petroleum hydrocarbons. Green Technologies: Concepts, Methodologies, Tools and Applications, 1, 1804-1823.

Mahbub, P., Goonetilleke, A., \& Ayoko, G. A. (2012). Prediction of the wash-off of traffic related semi-and non-volatile organic compounds from urban roads under climate change influenced rainfall characteristics. Journal of hazardous materials, 213, 83-92.

Ma, J. S., Kang, J. H., Kayhanian, M., \& Stenstrom, M. K. (2009). Sampling issues in urban runoff monitoring programs: Composite versus grab. Journal of Environmental Engineering, 135(3), 118-127.

May, D. B., \& Sivakumar, M. (2009). Prediction of urban stormwater quality using artificial neural networks. Environmental Modelling \& Software, 24(2), 296-302.

Mayer, P. M., Groffman, P. M., Striz, E. A., \& Kaushal, S. S. (2010). Nitrogen dynamics at the groundwater-surface water interface of a degraded urban stream. Journal of environmental quality, 39(3), 810-823. 
Migliaccio, K., \& Castro, B. (2009). Storm Event Sampling in Biscayne Bay Watershed: Final Project Report.

Moriasi, D. N., Arnold, J. G., Van Liew, M. W., Bingner, R. L., Harmel, R. D., \& Veith, T. L. (2007). Model evaluation guidelines for systematic quantification of accuracy in watershed simulations. Transactions of the ASABE, 50(3), 885-900.

Moussa, R., \& Bocquillon, C. (1996). Criteria for the choice of flood-routing methods in natural channels. Journal of Hydrology, 186(1), 1-30.

Muttil, N., \& Lee, J. H. (2005). Genetic programming for analysis and real-time prediction of coastal algal blooms. Ecological modelling, 189(3), 363-376.

Nearing, M. A., Jetten, V., Baffaut, C., Cerdan, O., Couturier, A., Hernandez, M., ... \& Van Oost, K. (2005). Modeling response of soil erosion and runoff to changes in precipitation and cover. Catena, 61(2), 131-154.

Nelson, E. J., \& Booth, D. B. (2002). Sediment sources in an urbanizing, mixed land-use watershed. Journal of Hydrology, 264(1), 51-68.

National Oceanic and Atmospheric Administration. (2012). South Florida dry season outlook 2012-2013.

http://www.srh.noaa.gov/images/mfl/news/DrySeasonOutlook1213.pdf (accessed July 18 2013)

Novotny, V. (1991). Urban diffuse pollution: sources and abatement. Water Environment \& Technology WAETEJ, 3(12).

Novotny, V., \& Olem, H. (2003). Water Quality: Prevention, Identification, and Management of Diffuse Pollution. Wiley.

O'Brien, H. D., Eimers, M. C., Watmough, S. A., \& Casson, N. J. (2013). Spatial and temporal patterns in total phosphorus in south-central Ontario streams: the role of wetlands and past disturbance. Canadian Journal of Fisheries and Aquatic Sciences, 70(5), 766-774.

Oke, T. R. (1992). Boundary layer climates. Psychology Press.

Olsson, J., Amaguchi, H., Alsterhag, E., Dåverhög, M., Adrian, P. E., \& Kawamura, A. (2013). Adaptation to climate change impacts on urban storm water: a case study in Arvika, Sweden. Climatic Change, 116(2), 231-247.

Opher, T., Ostfeld, A., \& Friedler, E. (2009). Modeling highway runoff pollutant levels using a data driven model. Water Science and Technology, 60(1), 19. 
Park, M. H., Swamikannu, X., \& Stenstrom, M. K. (2009). Accuracy and precision of the volume-concentration method for urban stormwater modeling. Water research, 43(11), 2773-2786.

Pitt, R. (1996). Groundwater contamination from stormwater infiltration. CRC PressI Llc.

Ragosta, G., Evensen, C., Atwill, E. R., Walker, M., Ticktin, T., Asquith, A., \& Tate, K. W. (2010). Causal connections between water quality and land use in a rural tropical island watershed. EcoHealth, 7(1), 105-113.

Rauch, W., Henze, M., Koncsos, L., Reichert, P., Shanahan, P., Somlyódy, L., \& Vanrolleghem, P. (1998). River water quality modeling: I. State of the art. Water Science \& Technology, 38(11), 237-244.

Reay, W. G., Gallagher, D. L., \& Simmons, G. M. (1992). Groundwater discharge and its impact on surface water quality in a chesapeake bay inlet. JAWRA Journal of the American Water Resources Association, 28(6), 1121-1134.

Rehfeldt, G. E., Crookston, N. L., Sáenz-Romero, C., \& Campbell, E. M. (2012). North American vegetation model for land-use planning in a changing climate: a solution to large classification problems. Ecological Applications, 22(1), 119-141.

Ramirez, J. A. (2000). Prediction and modeling of flood hydrology and hydraulics. Inland flood hazards: Human, riparian and aquatic communities, 293-333.

Rosenberg, E. A., Keys, P. W., Booth, D. B., Hartley, D., Burkey, J., Steinemann, A. C., \& Lettenmaier, D. P. (2010). Precipitation extremes and the impacts of climate change on stormwater infrastructure in Washington State. Climatic Change, 102(1), 319-349.

Rossman, L. A. (2010). Storm water management model user's manual, version 5.0. National Risk Management Research Laboratory, Office of Research and Development, US Environmental Protection Agency, Cincinnati, OH.

Rozemeijer, J., Van der Velde, Y., Van Geer, F., \& Broers, H. (2011). Direct measurements of the tile drain and groundwater contributions to surface water contamination: from field-scale concentration patterns in groundwater to catchment-scale surface water quality. In AGU Fall Meeting Abstracts (Vol. 1, p. $02)$.

Salah, I. B., Slatni, T., Gruber, M., Messedi, D., Gandour, M., Benzarti, M., ... \& Abdelly, C. (2011). Relationship between symbiotic nitrogen fixation, sucrose synthesis and anti-oxidant activities in source leaves of two Medicago ciliaris lines 
cultivated under salt stress. Environmental and Experimental Botany, 70(2), 166173.

Sánchez, E., Colmenarejo, M. F., Vicente, J., Rubio, A., García, M. G., Travieso, L., \& Borja, R. (2007). Use of the water quality index and dissolved oxygen deficit as simple indicators of watersheds pollution. Ecological Indicators, 7(2), 315-328.

Shamsi, U. M. (1996). Storm-water management implementation through modeling and GIS. Journal of Water Resources Planning and Management, 122(2), 114-127.

Shaw, H., Reisinger, A., Larsen, H., \& Stumbles, C. (2005, May). Incorporating climate change into stormwater design - why and how. In South Pacific Conference on Stormwater and Aquatic Resource Protection, Ministry for the Environment, Auckland, New Zealand.

Silveira, J. A. G., Melo, A. R. B., Viégas, R. A., \& Oliveira, J. T. A. (2001). Salinityinduced effects on nitrogen assimilation related to growth in cowpea plants. Environmental and Experimental Botany, 46(2), 171-179.

Singh, A., Jakubowski, A. R., Chidister, I., \& Townsend, P. A. (2013). A MODIS approach to predicting stream water quality in Wisconsin. Remote Sensing of Environment, 128, 74-86.

Singh, K. P., Malik, A., Mohan, D., \& Sinha, S. (2004). Multivariate statistical techniques for the evaluation of spatial and temporal variations in water quality of Gomti River (India): A case study. Water Research, 38(18), 3980-3992.

Simillen, J. T., \& Shaltcross, A. L. (1999). Updating the US nationwide urban runoff quality database. Water Science \& Technology, 39(12), 9-16.

Sklash, M. G., Farvolden, R. N., \& Fritz, P. (1976). A conceptual model of watershed response to rainfall, developed through the use of oxygen-18 as a natural tracer. Canadian Journal of Earth Sciences, 13(2), 271-283.

South Florida Water Management District (SFWMD). (2012). News Release. http://www.sfwmd.gov/portal/page/portal/xrepository/sfwmd_repository_pdf/ nr_2012_1019_nws_dryseason.pdf (accessed July 18 2013)

Stedmon, C. A., Seredyńska-Sobecka, B., Boe-Hansen, R., Le Tallec, N., Waul, C. K., \& Arvin, E. (2011). A potential approach for monitoring drinking water quality from groundwater systems using organic matter fluorescence as an early warning for contamination events. Water research, 45(18), 6030-6038.

St John, M. S., \& Horner, R. R. (1997). Effect of road shoulder treatments on highway runoff quality and quantity (No. WA-RD 429.1). 
Stubblefield, A. P., Reuter, J. E., Dahlgren, R. A., \& Goldman, C. R. (2007). Use of turbidometry to characterize suspended sediment and phosphorus fluxes in the Lake Tahoe basin, California, USA. Hydrological Processes, 21(3), 281-291.

Subramanya, K. (1994). Engineering hydrology. Tata McGraw-Hill Education.

Sutherland RC. 2010. Stormwater Quality Modeling Improvements Needed For SWMM. Pacific Water Resources, Inc. http://www.pacificwr.com/Publications/stormwater\%20quality\%20modeling\%20 improvements\%20needed\%20for\%20SWMM.pdf. (accessed January 28 2013).

Swaney, D. P., Hong, B., Ti, C., Howarth, R. W., \& Humborg, C. (2012). Net anthropogenic nitrogen inputs to watersheds and riverine $\mathrm{N}$ export to coastal waters: a brief overview. Current Opinion in Environmental Sustainability, 4(2), 203-211.

Terando, A. J., Easterling, W. E., Keller, K., \& Easterling, D. R. (2012). Observed and modeled 20 th century spatial and temporal patterns of selected agro-climate indices in North America. Journal of Climate, 25, 473-490.

Tran, C. P., Bode, R. W., Smith, A. J., \& Kleppel, G. S. (2010). Land-use proximity as a basis for assessing stream water quality in New York State (USA). Ecological Indicators, 10(3), 727-733.

Tsihrintzis, V. A., \& Hamid, R. (1998). Runoff quality prediction from small urban catchments using SWMM. Hydrological Processes, 12(2), 311-329.

Tyler, D. (2006). Fecal and Total Coliform TMDL for Wagner Creek (WBID 3288A).

Uriarte, M., Yackulic, C. B., Lim, Y., \& Arce-Nazario, J. A. (2011). Influence of land use on water quality in a tropical landscape: a multi-scale analysis. Landscape ecology, 26(8), 1151-1164.

Urban Drainage and Flood Control District. (2001). Drainage Criteria Manual. Colorado. Denver.

US Environmental Protection Agency (USEPA). (1990). National water quality inventory - 1988 report to Congress, Office of the Water Program Operations, Water Planning Division, Washington, DC.

US Department of Agriculture. (2012). National Engineering Handbook 3, Hydrology (Draft). Natural Resources Conservation Service. Washington, DC.

Varol, M., \& Şen, B. (2009). Assessment of surface water quality using multivariate statistical techniques: a case study of Behrimaz Stream, Turkey. Environmental monitoring and assessment, 159(1), 543-553. 
Vaze, J., \& Chiew, F. H. (2002). Experimental study of pollutant accumulation on an urban road surface. Urban Water, 4(4), 379-389.

Viezzoli, A., Tosi, L., Teatini, P., \& Silvestri, S. (2010). Surface water-groundwater exchange in transitional coastal environments by airborne electromagnetics: The Venice Lagoon example. Geophysical Research Letters, 37(1).

Viklander, M., \& Marsalek, j. (2010). Controlling contaminants in urban stormwater: linking environmental science and policy. On the water front, 100-107.

Wheeler, G. L., \& Rolfe, G. L. (1979). The relationship between daily traffic volume and the distribution of lead in roadside soil and vegetation. Environmental Pollution (1970), 18(4), 265-274.

Winz, I., Brierley, G., \& Trowsdale, S. (2011). Dominant perspectives and the shape of urban stormwater futures. Urban Water Journal, 8(6), 337-349.

Woolhiser, D. A., \& Liggett, J. A. (1967). Unsteady, one-dimensional flow over a plane-The rising hydrograph. Water Resources Research, 3(3), 753-771.

Zampella, R. A., Procopio, N. A., Lathrop, R. G., \& Dow, C. L. (2007). Relationship of Land-Use/Land-Cover Patterns and Surface-Water Quality in The Mullica River Basin1. JAWRA Journal of the American Water Resources Association, 43(3), 594-604. 


\section{APPENDIX}

Table 1: Principal components table (upto component 4) for winter season

\begin{tabular}{|c|c|c|c|c|}
\hline Variable & PC1 & PC2 & PC3 & PC4 \\
\hline $\mathrm{TN}$ & -0.091 & -0.442 & 0.063 & 0.216 \\
\hline $\mathrm{TP}$ & 0.279 & -0.004 & -0.317 & -0.283 \\
\hline $\mathrm{DO}$ & -0.119 & 0.141 & 0.458 & -0.329 \\
\hline $\mathrm{CON}$ & 0.045 & 0.377 & -0.398 & 0.083 \\
\hline $\mathrm{Chl} \mathrm{a}$ & 0.102 & -0.192 & -0.296 & -0.235 \\
\hline $\mathrm{S}$ & -0.214 & 0.039 & 0.135 & 0.576 \\
\hline $\mathrm{D}_{\mathrm{C}}$ & -0.126 & -0.472 & 0.047 & 0.106 \\
\hline $\mathrm{L}$ & 0.33 & 0.053 & -0.067 & 0.377 \\
\hline $\mathrm{I}$ & -0.249 & 0.339 & 0.113 & 0.162 \\
\hline $\mathrm{A}_{\mathrm{RS}}$ & 0.373 & -0.102 & 0.094 & 0.229 \\
\hline $\mathrm{A}_{\mathrm{RM}}$ & 0.196 & 0.303 & 0.387 & -0.132 \\
\hline $\mathrm{A}_{\mathrm{C}}$ & 0.307 & 0.233 & 0.241 & 0.198 \\
\hline $\mathrm{A}_{\mathrm{I}}$ & 0.285 & 0.086 & -0.001 & -0.021 \\
\hline $\mathrm{A}_{\mathrm{OL}}$ & 0.39 & -0.085 & 0.046 & -0.047 \\
\hline $\mathrm{A}_{\mathrm{F}}$ & 0.371 & -0.162 & 0.09 & 0.163 \\
\hline $\mathrm{GW}$ & 0.108 & -0.257 & 0.418 & -0.23 \\
\hline
\end{tabular}


Table 2: Principal components table (upto component 4) for spring season

\begin{tabular}{|c|c|c|c|c|}
\hline Variable & PC1 & PC2 & PC3 & PC4 \\
\hline TN & -0.025 & -0.379 & -0.224 & -0.354 \\
\hline $\mathrm{TP}$ & 0.3 & 0.017 & 0.344 & -0.223 \\
\hline $\mathrm{DO}$ & -0.107 & 0.361 & 0.232 & -0.067 \\
\hline $\mathrm{CON}$ & 0.074 & 0.359 & -0.075 & -0.429 \\
\hline $\mathrm{Ch} 1 \mathrm{a}$ & 0.246 & -0.149 & 0.284 & -0.203 \\
\hline $\mathrm{S}$ & -0.217 & 0.021 & -0.542 & 0.092 \\
\hline $\mathrm{D}_{\mathrm{C}}$ & -0.11 & -0.466 & -0.103 & 0.113 \\
\hline $\mathrm{L}$ & 0.31 & 0.076 & -0.372 & -0.166 \\
\hline $\mathrm{I}$ & -0.256 & 0.314 & -0.16 & 0.102 \\
\hline $\mathrm{A}_{\mathrm{RS}}$ & 0.36 & -0.065 & -0.263 & 0.065 \\
\hline $\mathrm{A}_{\mathrm{RM}}$ & 0.184 & 0.342 & 0.029 & 0.381 \\
\hline $\mathrm{A}_{\mathrm{C}}$ & 0.287 & 0.259 & -0.26 & 0.214 \\
\hline $\mathrm{A}_{\mathrm{I}}$ & 0.286 & 0.062 & 0.012 & -0.068 \\
\hline $\mathrm{A}_{\mathrm{OL}}$ & 0.378 & -0.057 & 0 & 0.059 \\
\hline $\mathrm{A}_{\mathrm{F}}$ & 0.365 & -0.13 & -0.176 & 0.088 \\
\hline
\end{tabular}


Table 3: Principal components table (upto component 4) for spring season

\begin{tabular}{|c|c|c|c|c|}
\hline Variable & PC1 & PC2 & PC3 & PC4 \\
\hline $\mathrm{TN}$ & -0.099 & -0.43 & 0.02 & -0.17 \\
\hline $\mathrm{TP}$ & 0.271 & 0.079 & 0.39 & 0.23 \\
\hline $\mathrm{DO}$ & -0.086 & 0.294 & -0.417 & 0.243 \\
\hline $\mathrm{CON}$ & 0.04 & 0.309 & 0.405 & -0.296 \\
\hline $\mathrm{Chl} \mathrm{a}$ & 0.203 & -0.049 & 0.284 & 0.351 \\
\hline $\mathrm{S}$ & -0.218 & 0.102 & -0.286 & -0.361 \\
\hline $\mathrm{D}_{\mathrm{C}}$ & -0.146 & -0.445 & -0.152 & -0.05 \\
\hline $\mathrm{L}$ & 0.313 & 0.048 & -0.063 & -0.429 \\
\hline $\mathrm{I}$ & -0.232 & 0.372 & -0.102 & -0.021 \\
\hline $\mathrm{A}_{\mathrm{RS}}$ & 0.357 & -0.112 & -0.181 & -0.239 \\
\hline $\mathrm{A}_{\mathrm{RM}}$ & 0.219 & 0.316 & -0.274 & 0.214 \\
\hline $\mathrm{A}_{\mathrm{C}}$ & 0.312 & 0.237 & -0.245 & -0.123 \\
\hline $\mathrm{A}_{\mathrm{I}}$ & 0.295 & 0.067 & 0.046 & 0.031 \\
\hline $\mathrm{A}_{\mathrm{OL}}$ & 0.38 & -0.117 & -0.044 & -0.022 \\
\hline $\mathrm{A}_{\mathrm{F}}$ & 0.356 & -0.172 & -0.164 & -0.143 \\
\hline $\mathrm{GW}$ & 0.12 & -0.242 & -0.332 & 0.438 \\
\hline
\end{tabular}


Table 4: Principal components table (upto component 4) for fall season

\begin{tabular}{|c|c|c|c|c|}
\hline Variable & PC1 & PC2 & PC3 & PC4 \\
\hline TN & -0.15 & -0.414 & 0.067 & 0.154 \\
\hline $\mathrm{TP}$ & 0.245 & 0.127 & 0.192 & -0.39 \\
\hline $\mathrm{DO}$ & -0.143 & 0.308 & -0.436 & -0.047 \\
\hline $\mathrm{CON}$ & 0.095 & 0.35 & 0.402 & -0.106 \\
\hline $\mathrm{Chl}$ a & 0.181 & -0.234 & -0.043 & -0.33 \\
\hline $\mathrm{S}$ & -0.205 & 0.055 & 0.09 & 0.582 \\
\hline $\mathrm{D}_{\mathrm{C}}$ & -0.155 & -0.444 & -0.039 & 0.149 \\
\hline $\mathrm{L}$ & 0.334 & 0.028 & 0.232 & 0.298 \\
\hline $\mathrm{I}$ & -0.229 & 0.358 & -0.041 & 0.219 \\
\hline $\mathrm{A}_{\mathrm{RS}}$ & 0.362 & -0.119 & -0.009 & 0.264 \\
\hline $\mathrm{A}_{\mathrm{RM}}$ & 0.21 & 0.292 & -0.371 & 0.092 \\
\hline $\mathrm{A}_{\mathrm{C}}$ & 0.319 & 0.203 & -0.126 & 0.291 \\
\hline $\mathrm{A}_{\mathrm{I}}$ & 0.278 & 0.03 & -0.053 & 0.034 \\
\hline $\mathrm{A}_{\mathrm{OL}}$ & 0.378 & -0.121 & -0.059 & -0.013 \\
\hline $\mathrm{A}_{\mathrm{F}}$ & 0.357 & -0.181 & -0.051 & 0.184 \\
\hline $\mathrm{GW}$ & 0.044 & -0.148 & -0.615 & -0.079 \\
\hline
\end{tabular}


Table 5: Principal components table (upto component 4) for dry period

\begin{tabular}{|c|c|c|c|c|}
\hline Variable & PC1 & PC2 & PC3 & PC4 \\
\hline $\mathrm{TN}$ & -0.097 & -0.431 & -0.041 & 0.264 \\
\hline $\mathrm{TP}$ & 0.282 & -0.005 & -0.235 & -0.366 \\
\hline $\mathrm{DO}$ & -0.192 & 0.188 & 0.455 & -0.11 \\
\hline $\mathrm{CON}$ & 0.081 & 0.35 & -0.41 & -0.056 \\
\hline $\mathrm{Chl} \mathrm{a}$ & 0.12 & -0.226 & -0.201 & -0.316 \\
\hline $\mathrm{S}$ & -0.207 & 0.077 & -0.034 & 0.557 \\
\hline $\mathrm{D}_{\mathrm{C}}$ & -0.146 & -0.458 & 0.054 & 0.155 \\
\hline $\mathrm{L}$ & 0.34 & 0.045 & -0.126 & 0.337 \\
\hline $\mathrm{I}$ & -0.236 & 0.371 & 0.004 & 0.149 \\
\hline $\mathrm{A}_{\mathrm{RS}}$ & 0.364 & -0.109 & 0.095 & 0.25 \\
\hline $\mathrm{A}_{\mathrm{RM}}$ & 0.187 & 0.307 & 0.404 & -0.034 \\
\hline $\mathrm{A}_{\mathrm{C}}$ & 0.306 & 0.234 & 0.21 & 0.221 \\
\hline $\mathrm{A}_{\mathrm{I}}$ & 0.285 & 0.054 & 0.07 & -0.044 \\
\hline $\mathrm{A}_{\mathrm{OL}}$ & 0.379 & -0.112 & 0.134 & -0.031 \\
\hline $\mathrm{A}_{\mathrm{F}}$ & 0.358 & -0.169 & 0.108 & 0.18 \\
\hline $\mathrm{GW}$ & -0.063 & -0.214 & 0.507 & -0.252 \\
\hline
\end{tabular}


Table 6: Principal components table (upto component 4) for wet period

\begin{tabular}{|c|c|c|c|c|}
\hline Variable & PC1 & PC2 & PC3 & PC4 \\
\hline $\mathrm{TN}$ & -0.105 & 0.417 & 0.19 & -0.072 \\
\hline $\mathrm{TP}$ & 0.29 & -0.022 & -0.262 & -0.369 \\
\hline $\mathrm{DO}$ & -0.066 & -0.382 & -0.221 & 0.17 \\
\hline $\mathrm{CON}$ & 0.078 & -0.319 & 0.18 & -0.443 \\
\hline $\mathrm{Chl} \mathrm{a}$ & 0.24 & 0.133 & -0.252 & -0.281 \\
\hline $\mathrm{S}$ & -0.216 & -0.069 & 0.463 & 0.225 \\
\hline $\mathrm{D}_{\mathrm{C}}$ & -0.155 & 0.439 & 0.063 & 0.159 \\
\hline $\mathrm{L}$ & 0.321 & -0.028 & 0.397 & -0.01 \\
\hline $\mathrm{I}$ & -0.229 & -0.358 & 0.126 & 0.079 \\
\hline $\mathrm{A}_{\mathrm{RS}}$ & 0.353 & 0.117 & 0.226 & 0.18 \\
\hline $\mathrm{A}_{\mathrm{RM}}$ & 0.208 & -0.316 & -0.149 & 0.366 \\
\hline $\mathrm{A}_{\mathrm{C}}$ & 0.308 & -0.217 & 0.168 & 0.281 \\
\hline $\mathrm{A}_{\mathrm{I}}$ & 0.292 & -0.036 & -0.055 & -0.001 \\
\hline $\mathrm{A}_{\mathrm{OL}}$ & 0.374 & 0.119 & -0.033 & 0.103 \\
\hline $\mathrm{A}_{\mathrm{F}}$ & 0.35 & 0.178 & 0.14 & 0.166 \\
\hline $\mathrm{GW}$ & -0.037 & 0.162 & -0.484 & 0.435 \\
\hline
\end{tabular}




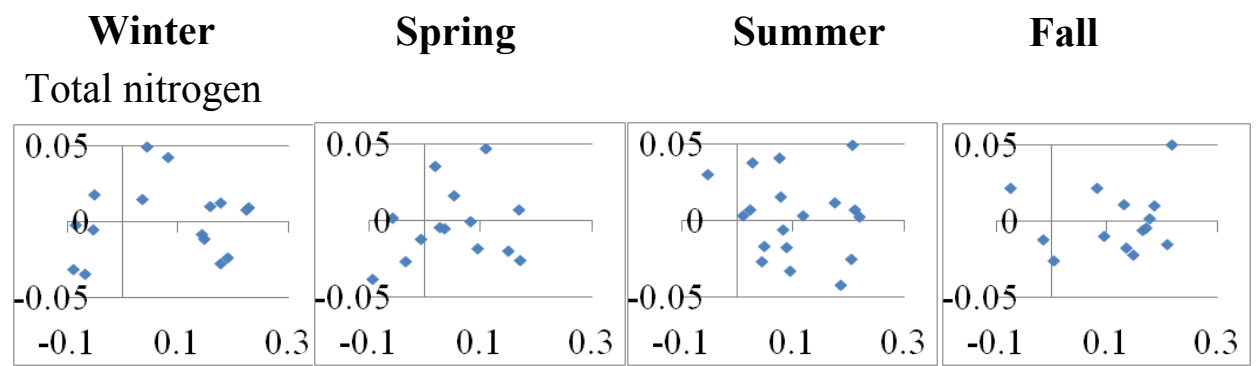

Total phosphorus

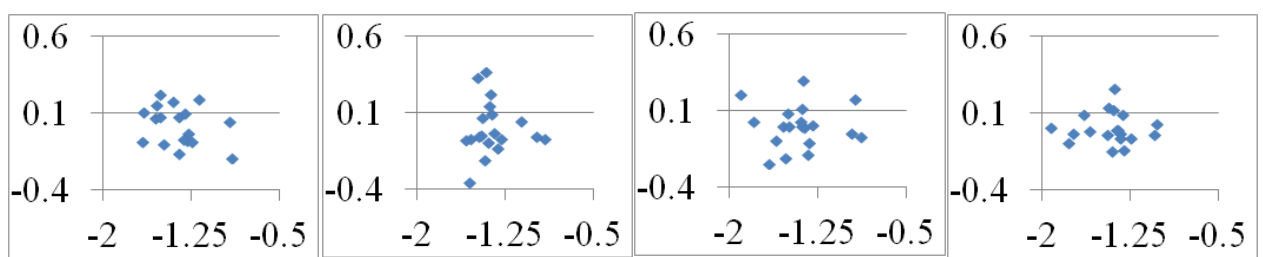

Dissolved oxygen

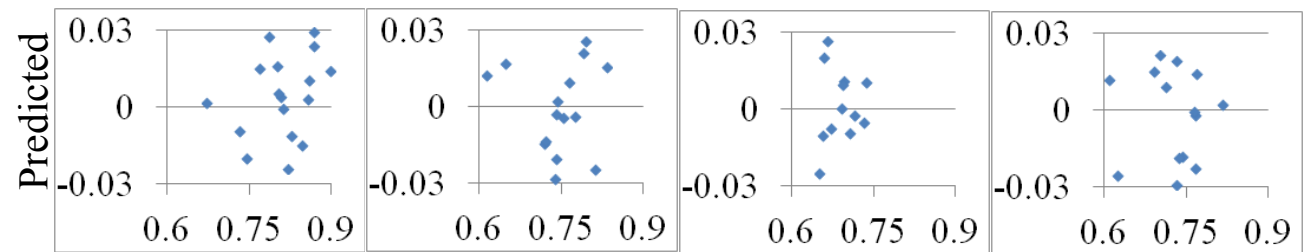

Specific conductivity

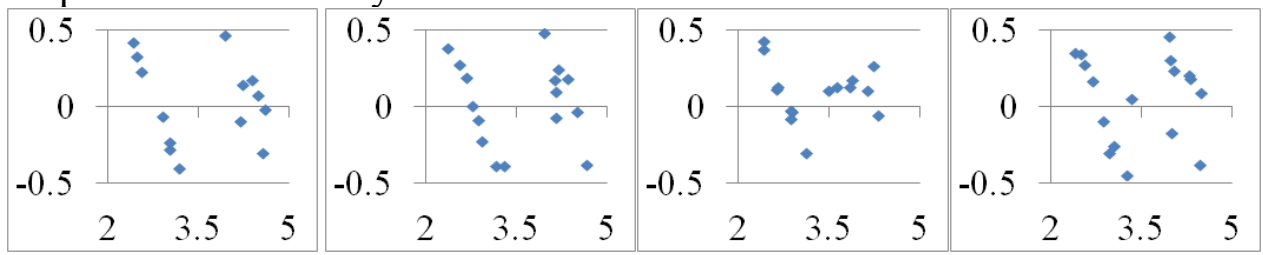

Chlorophyll A

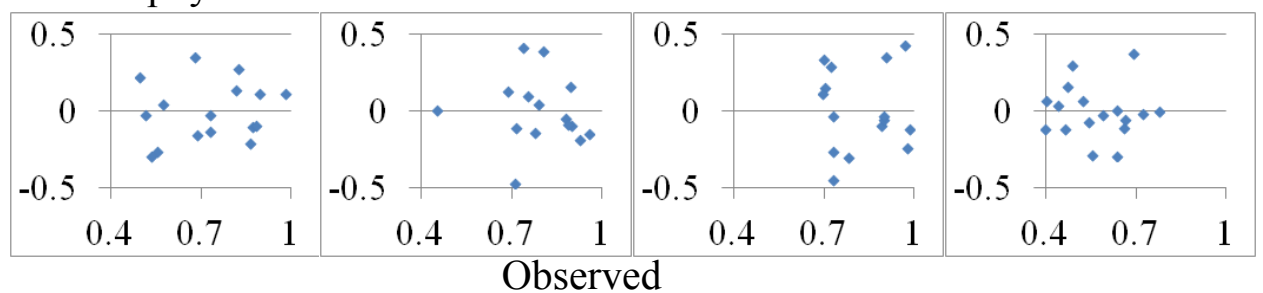

Figure 1: Residual plots for four seasonal analyses. 


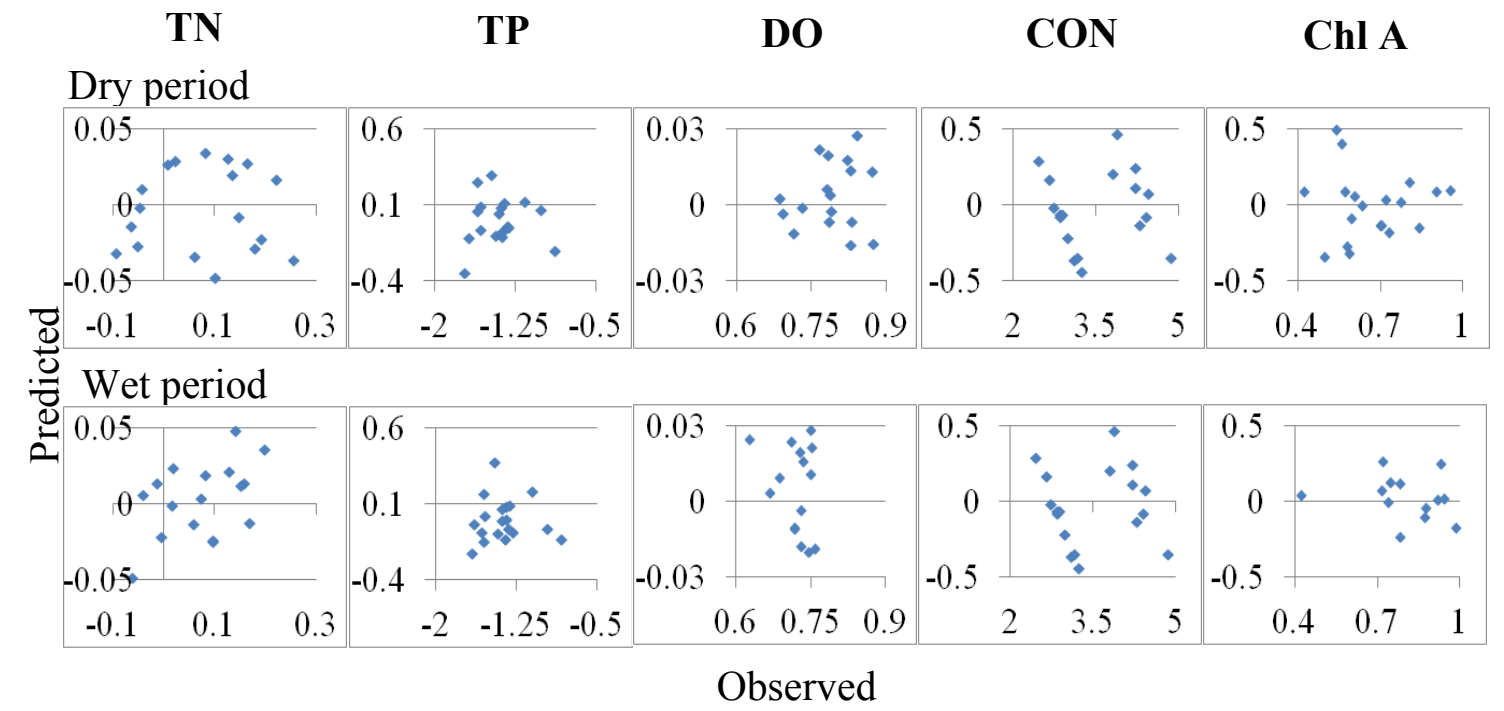

Figure 2: Residual plots for dry and wet period analyses. 